\title{
Receiver Side Control for Efficient Inductive Power Transfer for Vehicle Recharging
}

\section{Mohammadhossein Afshin}

\author{
A Thesis \\ In the Department \\ of \\ Electrical and Computer Engineering \\ Presented in Partial Fulfillment of the Requirements \\ For the Degree of Master of \\ Applied Science (Electrical \& Computer Engineering) at \\ Concordia University \\ Montreal, Quebec, Canada.
}

February 2018

(C) Mohammadhossein Afshin, 2018 


\section{CONCORDIA UNIVERSITY \\ SCHOOL OF GRADUATE STUDIES}

This is to certify that the thesis prepared

By: Mohammadhossein Afshin

Entitled:

Receiver Side Control for Efficient Inductive Power Transfer for Vehicle Recharging

and submitted in partial fulfillment of the requirements for the degree of

\section{Master of Applied Science}

Complies with the regulations of this University and meets the accepted standards with respect to originality and quality.

Signed by the final examining committee:

Chair

Dr. D. Qiu

Examiner, External

Dr. C. Alecsandru To the Program

Examiner

Dr. M.Z. Kabir

Supervisor

Dr. A.Rathore

Approved by:

Dr. W. E. Lynch, Chair

Department of Electrical and Computer Engineering

20

Dr. Amir Asif, Dean

Faculty of Engineering and Computer

Science 


\section{ABSTRACT}

This thesis presents a new wireless inductive power transfer topology using half bridge current fed converter and a full bridge active single phase rectifier. Generally, the efficiency of inductive power transfer system is lower than the wired system due to higher power loss in inductive power transfer coils. The proposed converter reduces these limitations and shows more than $4 \%$ overall efficiency improvement comparing with such system in battery charging of low-voltage light-load electrical vehicles such as passenger cars, golf carts etc. This is realized by synchronous rectification technique of the vehicle side converter. Simulation results obtained from Matlab Simulink are included to validate the analysis and performance of the proposed converter. A scale-down $250 \mathrm{~W}$ lab prototype is developed and experimental results are presented to verify the comparative study results. 
I Dedicated to My Grandparents and Their Children. 


\section{AKNOWLEDGEMENT}

I would like to sincerely thank my supervisor Prof. Akshay Kumar Rathore for his support and guidance in completion of my MASc. studies. The expertise and knowledge that he shared, helped me immensely in my research goals.

Also I would like to express my sincere gratitude to Suvendu Samanta as he shared a lot of his knowledge with me during my Masters study.

Last but not least, I would like to express my graduate to my amazing office mates, Karin, Luccas, Deepak and Mohammad who made the past year, as one of the best years of my life with their company. I was lucky to be a part of S3.306 research lab and make life time friends with these amazing people.

Also I would like to take this opportunity to thank my family, who supported me and trusted me in any step of my life. I would never forget, how much they believed in me and trusted me with decisions I made. I could never ask for a better family to grow up in. 


\section{Table of Contents}

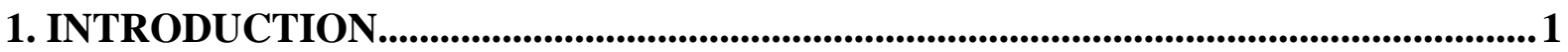

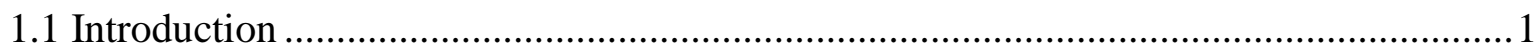

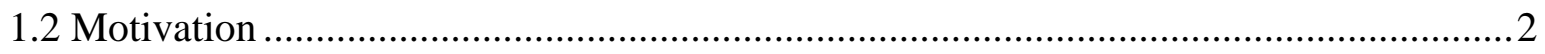

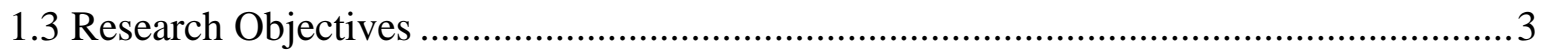

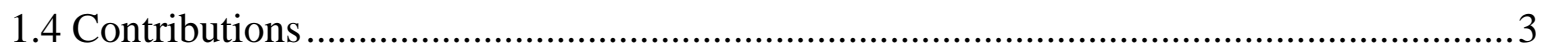

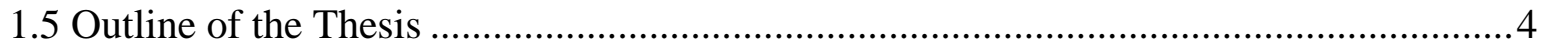

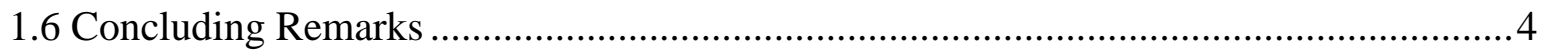

2. LITERATURE REVIEW ..................................................................................................................5

2.1 Wireless Charging Technology …………………………….....................................5

2.2 Stationary Wireless Charging .....................................................................................5

2.2.1 Inductive Power Transfer...........................................................................

2.2.2 Magnetic Resonance Coupling Transfer.............................................................

2.2.3 Permanent Magnet Coupling ………………………...................................

2.3 Dynamic/In Motion Wireless Charging ………………........................................

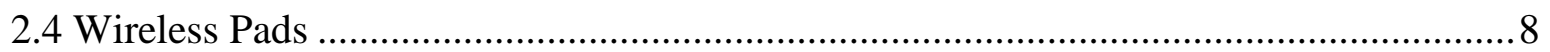

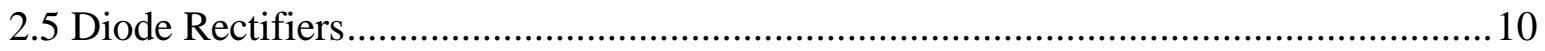

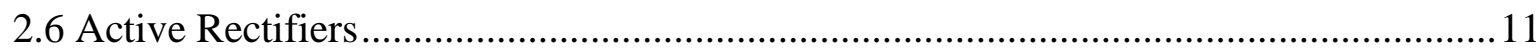

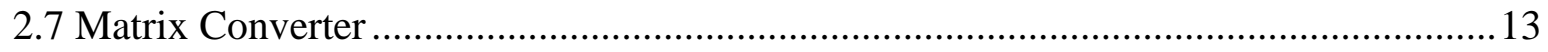

2.8 Safety

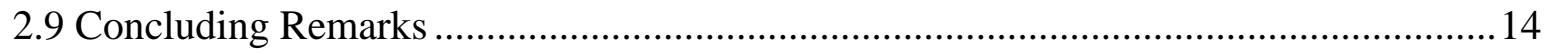

3. WIRELESS POWER TRANSFER WITH DIODE RECTIFICATION.........................15

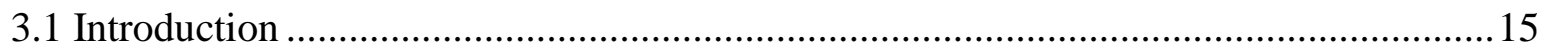

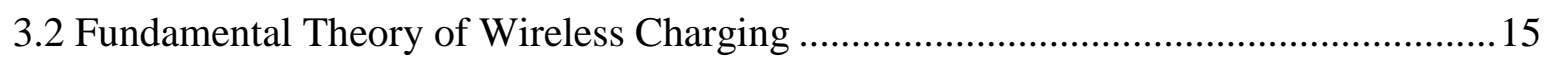

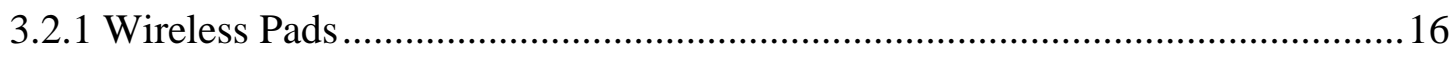

3.2.2 Compensation Network …………………………………………………...21

3.2.3 Analysis and study approach ......................................................................2 
3.3 Wireless Power Transfer with Diode Rectification.....................................................2

3.3.1 Analysis of Wireless Power Transfer Using a Diode Rectifier .........................24

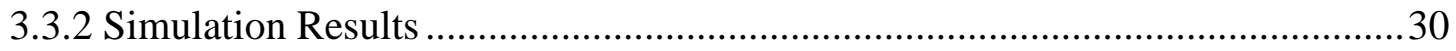

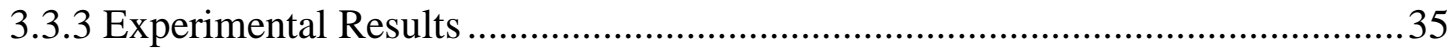

3.3.3.1 Wireless Pads Implementation................................................................... 36

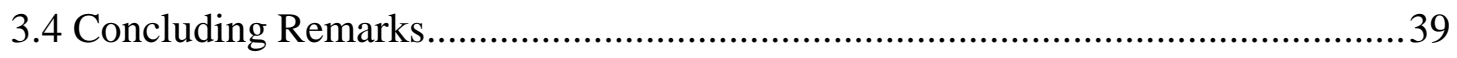

\section{WIRELESS POWER TRANSFER USING AN ACTIVE SINGLE PHASE}

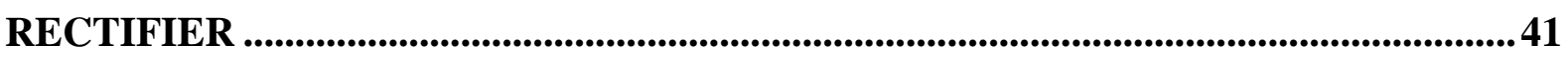

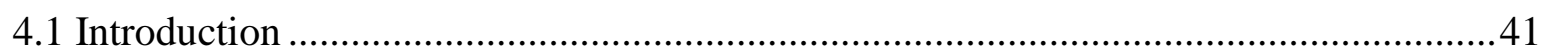

4.2 Proposed Wireless IPT Topology with an Active Single Phase Rectifier .....................41

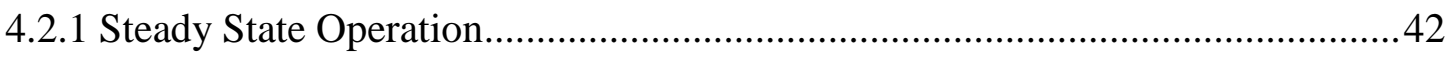

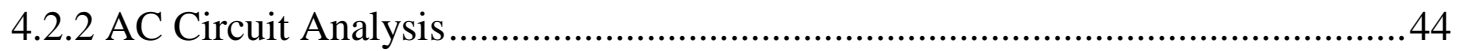

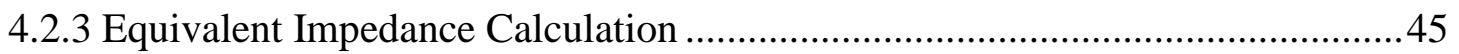

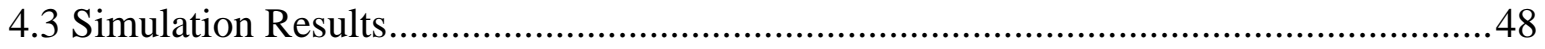

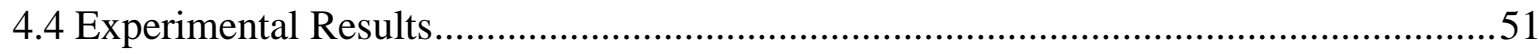

4.5 Efficiency Analysis and Comparison with Diode Rectifier ........................................54

4.5.1 Conduction Losses of A Power MOSFET .....................................................55

4.5.2 Switching Losses of a Power MOSFET …….................................................5

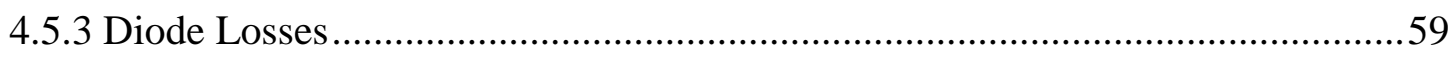

4.5.4 Comparison of Diode and MOSFET Conduction Losses.................................60

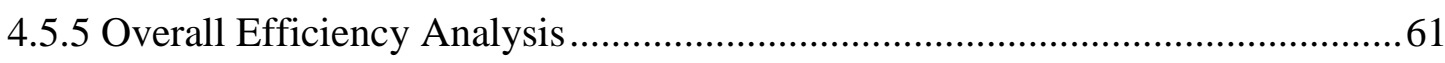

4.5.6 Other Common Power Losses of an IPT System ............................................ 62

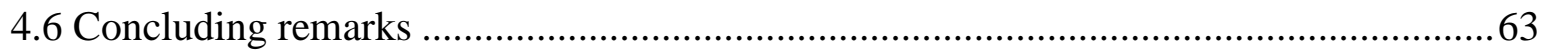

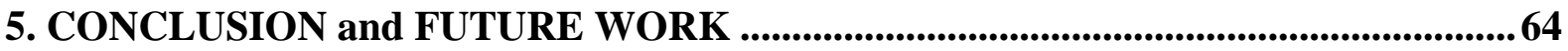

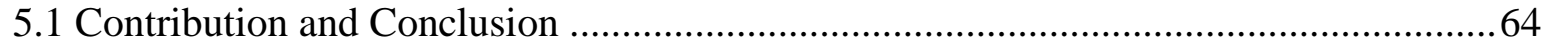

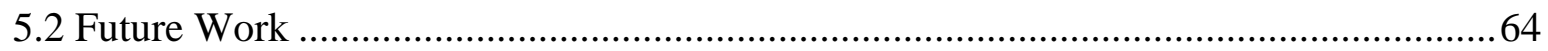


BIBILIOGRAPHY

.66 


\section{List of Figures}

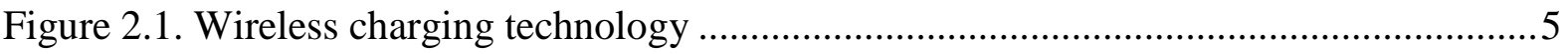

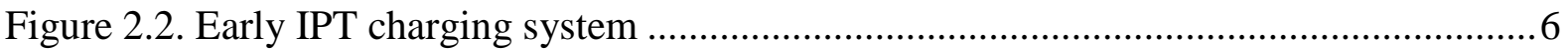

Figure 2.3. IPT charging system with compensation network.........................................6

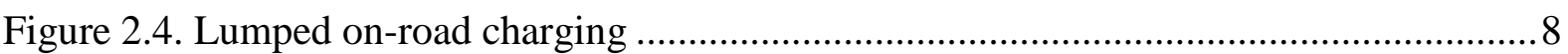

Figure 2.5. Typical single-coil circular rectangular pad .................................................

Figure 2.6. Typical single-coil circular non-polarized pad...............................................

Figure 2.7. A multiple-coil homogeneous pad................................................................ 10

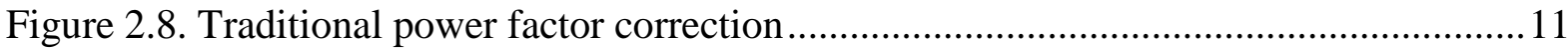

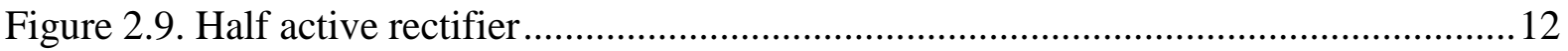

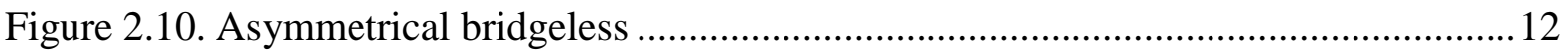

Figure 2.11. Full-bridge full-controlled rectifier ............................................................... 13

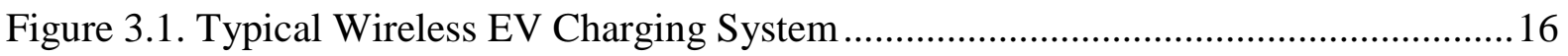

Figure 3.2. Two Coils Wireless Power Transfer System ...................................................... 16

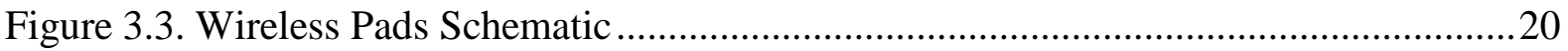

Figure 3.4. Basic Compensation Network Topologies, (a) SS, (b)SP, (c) PS, (d) PP ............22

Figure 3.5. Wireless Power Transfer Topology using diode Rectifier ...................................24

Figure 3.6. Steady State Voltage and Current Waveforms of Different Components.............26

Figure 3.7. Equivalent Circuits for Different Intervals of WPT Converter with Diode

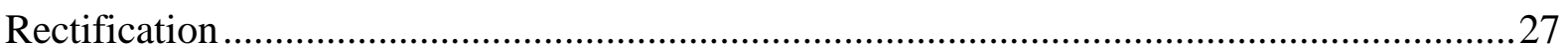

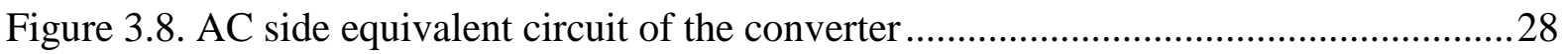

Figure 3.9. T equivalent circuit of the transformer referred to primary side .........................28

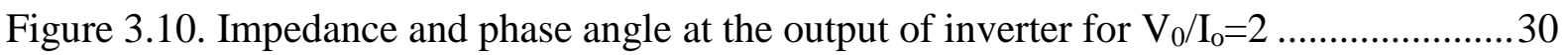

Figure 3.11. Simulation results of gating signals for inverter switches $S_{1}$ and $S_{2} \ldots \ldots \ldots \ldots \ldots . . . . .31$

Figure 3.12. Simulation results of the voltage across the first leg of inverter $S_{1}$ and $D_{1} \ldots \ldots . . .32$

Figure 3.13. Simulation results of the voltage across the second leg of inverter $S_{2}$ and $D_{2} \ldots .32$

Figure 3.14. Simulation results of inverter output current and voltage at rated load ..............32

Figure 3.15. Simulation results of voltages across the transmitter coil and receiver coil........33

Figure 3.16. Simulation results of rectifier input current and voltage ....................................33

Figure 3.17. Simulation results of voltage across the first leg (D3, D4) and the second leg

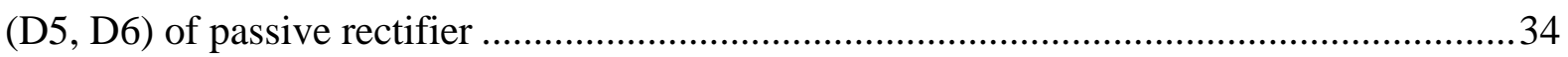

Figure 3.18. Simulation results of steady state waveforms of load current and voltage ..........34 


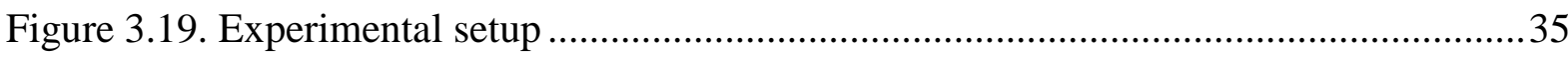

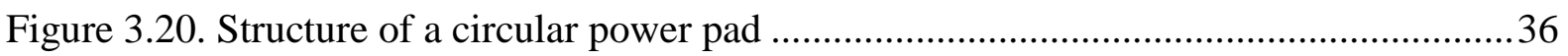

Figure 3.21. Experimental results: gating signals for inverter switches $\mathrm{S} 1$ and $\mathrm{S} 2$.................37

Figure 3.22. Experimental results: inverter output current and voltage at $\mathrm{R}_{0}=2.33 \ldots \ldots \ldots \ldots . . . .38$

Figure 3.23. Experimental results: voltages across the transmitter coil and receiver coil ........38

Figure 3.24. Experimental results: rectifier input current and voltage ..................................39

Figure 3.25. Experimental results: steady state waveforms of load current and voltage.........39

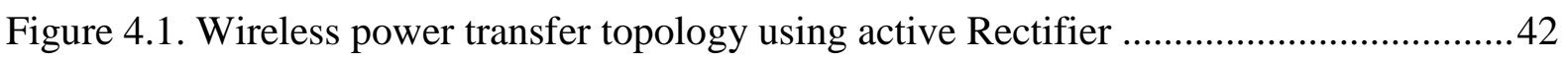

Figure 4.2. Steady state voltage and current waveforms of different components ................. 43

Figure 4.3. Equivalent circuit of ASPR during subintervals of a switching cycle .................44

Figure 4.4. Operating waveforms of receiver current and the input voltage of ASPR. (a)

Resistive mode (b) Inductive mode (c) Capacitive mode.....................................................45

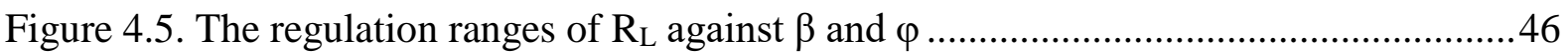

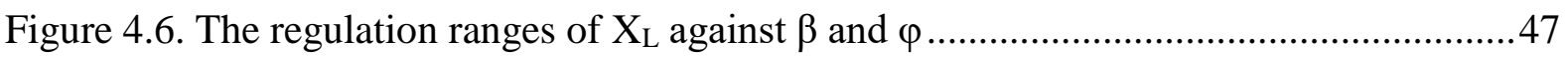

Figure 4.7. Simulation results of inverter output current and voltage at rated load ............... 49

Figure 4.8. Simulation results of voltages across the transmitter coil and receiver coil.........49

Figure 4.9. Simulation results of rectifier input current and voltage ....................................50

Figure 4.10. Simulation results of gating signal for rectifier switches ................................50

Figure 4.11. Simulation results of steady state waveforms of load current and voltage .........50

Figure 4.12. Experimental board of a full-bridge active rectifier ..........................................51

Figure 4.13. Experimental board of a full-bridge passive rectifier ......................................51

Figure 4.14. Experimental results: inverter output current and voltage at $\mathrm{R}_{0}=2.33 \ldots \ldots \ldots \ldots . .52$

Figure 4.15. Experimental results: voltages across the transmitter coil and receiver coil .......52

Figure 4.16. Experimental results: rectifier input current and voltage .................................53

Figure 4.17. Experimental results: gating signals for active rectifier switches $S_{3}$ and $S_{5} \ldots . . .53$

Figure 4.18. Experimental results of steady state waveforms of load current and voltage .....54

Figure 4.19. Switch-on and switch-off transients of a power MOSFET …...........................56

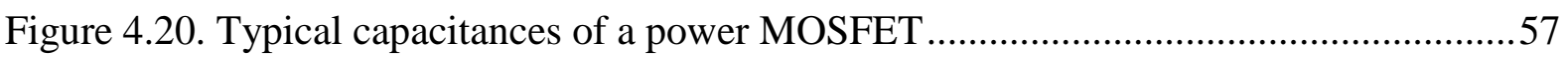

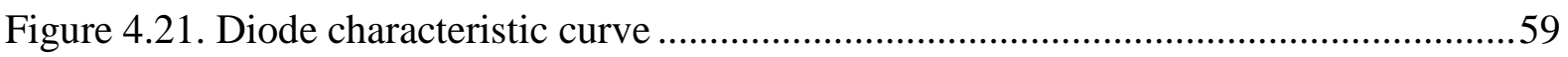




\section{List of Tables}

Table 3.1. Selected values of different components for simulation...................................... 31

Table 3.2. Selected circuit parameter for experimental setup............................................. 35

Table 4.1. Comparison of Diode and MOSFET conducting losses ....................................... 60

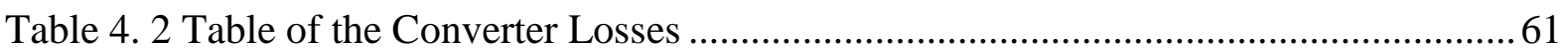




\section{List of Abbreviations}

$\begin{array}{ll}\text { EV } & \text { Electric Vehicle } \\ \text { IPT } & \text { Inductive Power Transfer } \\ \text { ASPR } & \text { Active Single Phase Rectifier } \\ \text { WPT } & \text { Wireless Power Transfer } \\ \text { MRCT } & \text { Magnetic Resonance Coupling Transfer } \\ \text { DDP } & \text { Double-D Polarized Pad } \\ \text { DDQP } & \text { Double-D Quadrature Polarized Pad } \\ \text { BBP } & \text { Bipolar Polarized Pad } \\ \text { PFC } & \text { Power Factor Correction } \\ \text { HAR } & \text { Half Active Rectifier } \\ \text { VSI } & \text { Voltage Source Inverter } \\ \text { TC } & \text { Transmitter Coil } \\ \text { RC } & \text { Receiver Coil } \\ \text { FOM } & \text { Figure Of Merit } \\ \text { FEA } & \text { Finite Element Analysis } \\ \text { ZVS } & \text { Zero Voltage Switching }\end{array}$




\section{Chapter 1}

\section{INTRODUCTION}

\subsection{Introduction}

Based on the report of Statista in 2015, near 1.3 billion vehicles are currently operational in the world [1]. Majority of the vehicles use petroleum-powered internal combustion engine that is costly and causes environmental pollution. Electrical Vehicles (EVs) are increasingly becoming popular due to less air pollution, cheaper to run, maintain and come along with several other benefits. This trend is apparent from more than six-fold increase of annual EV sales from 2011 to 2015 [2].

Saving energy, environment, and other reasons promoted transportation electrification in recent years. For instance the wireless power transfer (WPT) technologies for railway systems have already been well developed. It should be noticed that since a train operates on a fixed track, it is not challenging to transfer power through a conductive rail. On the other hand, since electric vehicles have high flexibility of speed, acceleration and motion, it is not easy to get electric power in a similar way [3].

Onboard chargers are a profitable part of EVs as they eliminate the need for quick dc charging stations. Presently, chargers for EVs are supplied as an independent units when they are set on board. Comparing with a vehicle without a locally available charger, these units adversely affect the cost, weight and extra space in the vehicle. Nonetheless, control electronic parts that frame a normal installed charger do not vary from the components that as of now exist on board and that are required for impetus [4].

Plug-in chargers are considered as a conventional method of charging EVs which comes with challenges such as heavy battery packs and high battery cost. From the energy consumption standpoint, heavy battery packs make critical negative influences. In contrast, the wireless charging of electrical vehicles due wireless power transfer technology, may overcome the challenges of plug-in chargers.

Frequent charging of electrical vehicles can be achieved by wireless charging methods, which leads to battery downsizing and vehicle mass reduction. Furthermore, the fuel economy which is defined as the ratio of electricity consumption in batteries, is improved, comparing to 
plug-in charging as an advantage of vehicle light-weighting. Equation (1.1) describes the relationship between the total amounts of energy charged in a battery, due to a frequent charging process [5].

$$
E=\sum_{i=1}^{N} e_{i}=\eta P T
$$

Where $E$ is the total amount of electricity charged during the vehicle operation time, $e_{i}$ is the amount of electricity charged at each stop, $\mathrm{N}$ is the total number of stop, $\eta$ is the average charging efficiency, $P$ is the charging power and finally $T$ shows the total amount of charging time at charging stops. According to the research done in [5], 10\% vehicle mass reduction for a conventional bus in the Autonomy model provides about 5\% reduction in energy consumption.

Nikola Tesla proposed the first Inductive Power Transfer (IPT) without a magnetic core about a century ago. During the past century a tremendous development has been achieved on low power, closely coupled wireless charging methods, while the wireless chargers are available for portable and wearable devices [6].

A number of wireless inductive power transfer (IPT) were proposed in [2], [7]-[9]. These topologies have different combinations of transmitter and receiver coil resonances. Another new inductive wireless power transfer topology is proposed in [10], which is based upon a current-fed half bridge CLC transmitter and LC receiver. A diode rectifier is used to get the DC output voltage. Owing to uncontrolled rectification, the conduction losses of rectifier diodes are significantly high for low voltage battery charging applications. This thesis proposes a new IPT topology with full-bridge active rectifier at receiver side to enable synchronous rectification. This considerably improves overall efficiency, thereby making it more suitable for practical use.

\subsection{Motivation}

The main advantage of wireless inductive charging is the absence of the need of the vehicle to be plugged in and hence, the charging process can occur in a wide range of places such as in a garage overnight, at bus stops, dynamic charging on the go, commercial lots, at workplace, etc. [11]. Although, this technology has several advantages but it has lower efficiency than the wired charging system due to higher copper loss in IPT coils. This research presents a new wireless inductive power transfer topology using half bridge current fed converter and a full 
bridge Active Single Phase Rectifier (ASPR). Generally, the efficiency of inductive power transfer system is lower than the wired system. The proposed converter achieves an overall efficiency of more than $4 \%$ compared to the existing systems used in battery charging of lowvoltage light-load electric vehicles such as passenger cars, golf carts etc. This has been achieved by using synchronous rectification in vehicle side converter, which is the secondary side of IPT coils. A scale down lab prototype of $250 \mathrm{~W}$ was built and tested to verify the results in the comparative study.

\subsection{Research Objectives}

The objectives of this research are listed below:

- To analyze and design a new topology for wireless power using a current-fed highfrequency converter at source or transmitter circuit and active rectifier at vehicle or receiver circuit for battery recharging applications of low-voltage light-load electric vehicles such as golf carts, passenger cars, campus vehicles, etc..

- To develop a proof-of-concept hardware prototype in laboratory and experimentally demonstrate the performance.

- Conduct a comparative study from efficiency standpoint with wireless power transfer system with diode based rectifier on receiver circuit.

\subsection{Contributions}

In this thesis, a new power electronic circuit topology using an active rectifier is proposed for wireless recharging of light-load low-voltage electric vehicles battery. The proposed circuit topology shows $4 \%$ improvement in overall efficiency compared to diode rectifier based existing systems. Proposed active rectifier at receiver side adopts synchronous rectification technique for power flow control. The mentioned converter was designed and simulated to confirm the designed parameters. Further, a scale down lab prototype of $250 \mathrm{~W}$ is implemented to verify the analysis and simulation results, and to compare the proposed topology from efficiency perspective with a similar converter using diode rectification. 


\subsection{Outline of the Thesis}

The thesis is outlined as follows:

- Chapter 2: In this chapter, the key topologies of different parts of a Wireless Power Transfer (WPT) systems are classified and presented as a literature review. Further, some novel contributions relating to wireless pads design, diode rectifiers and active rectifiers are also mentioned as well.

- Chapter 3: The basic theories of energy transformation, wireless pads and compensation networks are presented in this chapter. Moreover, a WPT topology using a full-bridge passive rectifier has been analyzed with diligence and simulated in Matlab Simulink. Finally, a scale down lab prototype was built to validate the analysis and simulation results are presented in chapter 3.

- Chapter 4: A new wireless power transfer topology using an active single phase rectifier has been proposed, analyzed and simulated in this chapter. The experimental results of such topology and efficiency analysis is presented and compared to the converter with passive rectifier.

- Chapter 5: Summary of this work and its results are presented in chapter 5 to conclude the thesis.

\subsection{Concluding Remarks}

This chapter reported the motivation behind the proposed work on wireless power transfer for EV recharging applications and discussed the outline of the thesis in various chapters. Next chapter deals with the literature review on wireless power transfer. Major focus is on the power electronics part. 


\section{Chapter 2}

\section{LITERATURE REVIEW}

\subsection{Wireless Charging Technology}

Wireless charging for electrical vehicle (EV) technology are categorized into two main sections; Stationary wireless charging and Dynamic (in-motion) charging. An EV can be charged by the stationary wireless charging device only in parked position, since the charging process takes time. Figure 2.1 illustrates a catalogue for wireless charging technology.

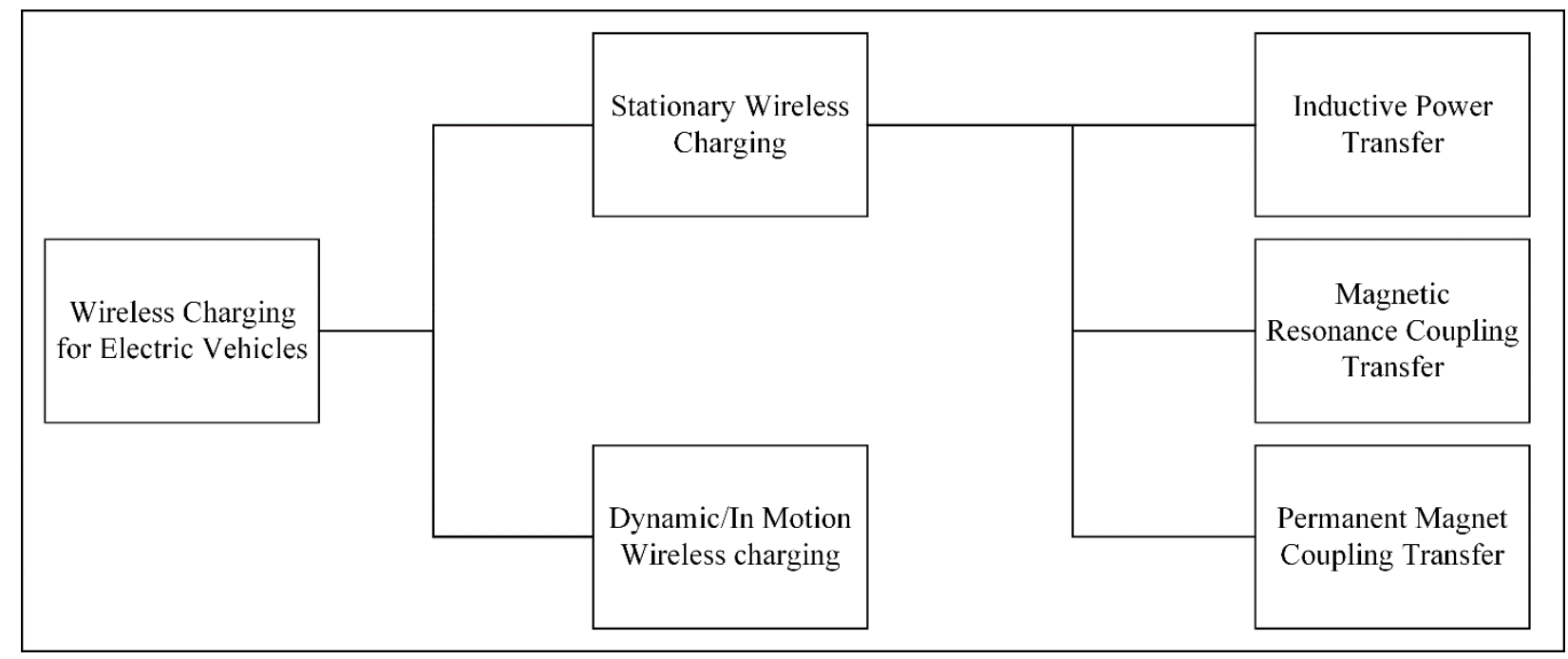

Figure 2.1. Wireless charging technology

Stationary wireless charging process starts when the vehicle is within a relatively small airgap with the transmitter coil, since the couplers should be correctly aligned. The coupling mechanism usually happens via inductive power transfer, magnetic resonance coupling transfer or permanent magnet coupling transfer. On the other hand, dynamic/in motion wireless charging takes place when the vehicle is in operation on the road or highway. In this case, charging units must be charged quickly and it is very difficult to establish a small air-gap with the road.

\subsection{Stationary Wireless Charging}

Stationary wireless charging achieves whenever an electric vehicle is parked and being charged such as overnight in garage or at residence. Also, charging process can happen in 
stationary position in short pauses at intersections or fast charging stations. Charging over a short period could only be considered if the energy storage units as batteries or ultra-capacitors, are designed to accommodate fast power transfer. Moreover, for stationary wireless charging, the transmitter side should be installed and fixed under the ground or surface while the receiver side mounts underneath of the vehicle to reduce the electromagnetic leakage and interference with other objects and vehicles [12].

\subsubsection{Inductive Power Transfer}

Power transfer through contactless converters happens by using a loosely coupled transformers (wireless coils/pads/couplers). The couplers have to transfer the power via the air gap since no core exist to link the transmitter and receiver coils. The first generation of stationary IPT systems and systems using impedance matching for EVs are represented in Figure 2.2 and Figure 2.3, respectively.

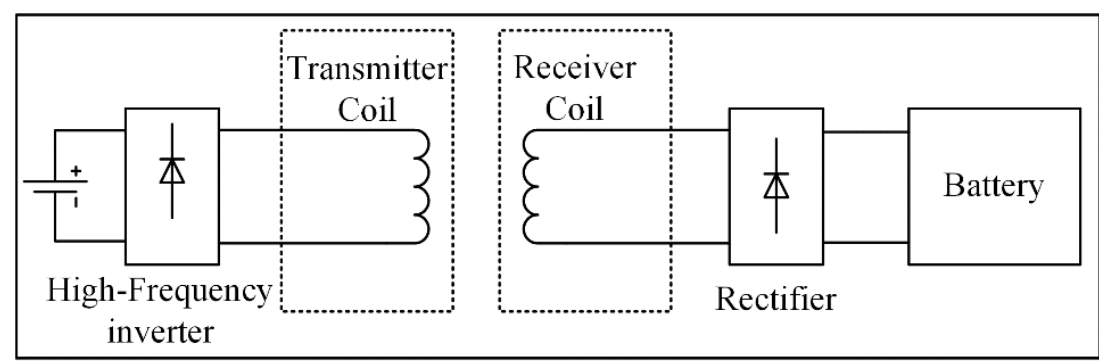

Figure 2.2. Early IPT charging system

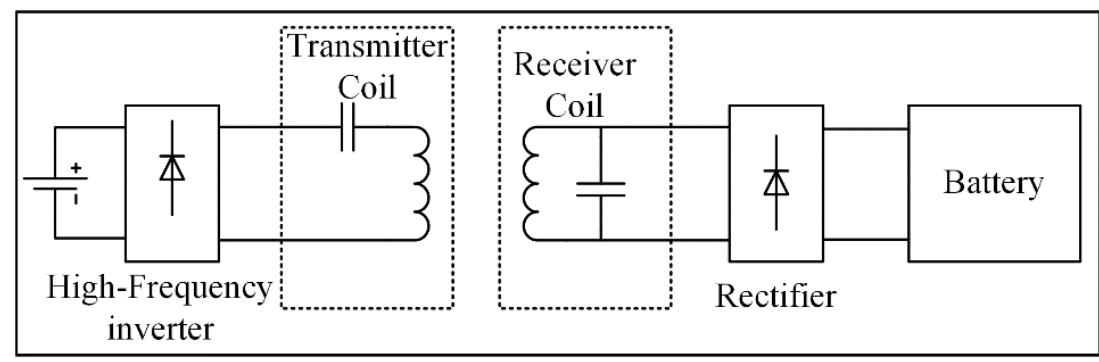

Figure 2.3. IPT charging system with compensation network

The main difference between an "early IPT system" and "IPT charging system" is using a compensation network which is the tuning capacitors. Based on the capacitors connection in series or parallel with the wireless pads, there are four major compensation network topologies which are presented in section 3.2.2, chapter 3. 
One of the main concerns for IPT systems is the clearance and the air gap between wireless pads. The fact that impedance matching is more efficient by adding the capacitors in series or parallel with both primary and secondary sides, has been researched in [13].

\subsubsection{Magnetic Resonance Coupling Transfer}

Magnetic Resonance Coupling Transfer (MRCT) is proposed in [14] that is based on the coupled mode theory and, by using this technology, transferring power is achieved in a higher range of air gap comparing with IPT technologies. The efficiency of WPT system proposed in [14] is calculated as $90 \%$ with a meter air-gap. The theory for resonance coupling is very similar to IPT systems with resonant winding but it should be noted that the self-inductance of antennas, the integrated capacitance from the resonance and the operating frequencies are in the range of $\mathrm{MHz}$. the details on different methods to improve above technology are covered in [15] and [16]. Since the application of MRCT is to transmit medium to high power, the limitation of this technology is related to the cutting-edge technology of semiconductor devices as they have poor efficiency in $\mathrm{MHz}$ range.

\subsubsection{Permanent Magnet Coupling}

Permanent magnet coupling technology was proposed by the University of British Columbia and the power transmission is through "magnetic gear effect". In this technique a magnetic gear is used as a coupler [17] [18]. The rotor on primary side is magnetized permanently by rotation and makes the secondary side rotor to rotate with the synchronous speed. A lab prototype was developed in [19] validates the power is transferred by $81 \%$ efficiency across $150 \mathrm{~mm}$ distance with relatively low frequency of $150 \mathrm{~Hz}$. Utilizing a number of mechanical components in this technology might be a disadvantage, due to its alignment and maintenance concerns.

\subsection{Dynamic/In Motion Wireless Charging}

Dynamic wireless charging was used for decades to supply trolley buses and in some cities they are functional. Vehicle needs continuous power for traction drive and a high amount of power for acceleration. In order to provide and deliver this power a limited battery resource may not be enough. For wireless supply, the couplers use a lumped pad structure [18] and distributed lines [20], as the primary side. 
Figure 2.4 depicts a lumped on-road charging topology presented in [19]. Lumped on-road charging contains a series of wireless pads on the road to make the power track along road lanes.

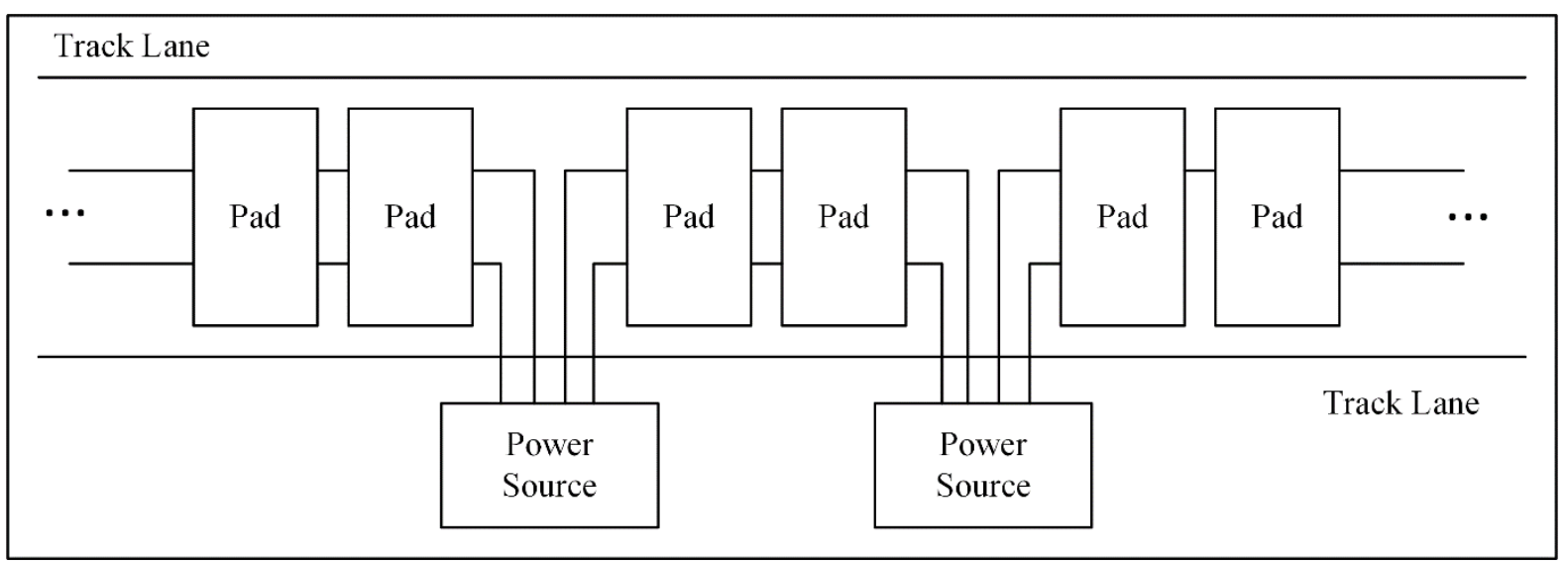

Figure 2.4. Lumped on-road charging

According to Figure 2.4, as the vehicle drives on the road, wireless pads provide a continuous magnetic field that the secondary pickups, couple with. Hence, a motion detection technique is needed to turn on and off the power flow through the transmitter coils to reduce power losses, since when there is no vehicle passing by, the primary pads being excited but not coupled [12].

Based on the research in [21] and [22] circular pads are not the ideal option for wireless charging due to a null in their profile when horizontally offset by $38 \%$ of the pad diameter. A variety of high performance pads are presented in [23] to [25]. Furthermore, a dual type and a mono type of power transfer couplers are designed in [26] that concludes when a dual type has two opposite power lines, a large amount of power can be transferred with a better coupling coefficient compared to mono type. However, the mono type has a better misalignment tolerance.

\subsection{Wireless Pads}

There are a wide range of designs for wireless pads regarding their applications and power ratings. Figure 2.5 shows a circular rectangular pad, which was proposed and used in early development of WPT. Although this topology improves the flux area and the decline in flux leakage on the edges, the large total flux leakage and low efficiency are considerable [27]. 


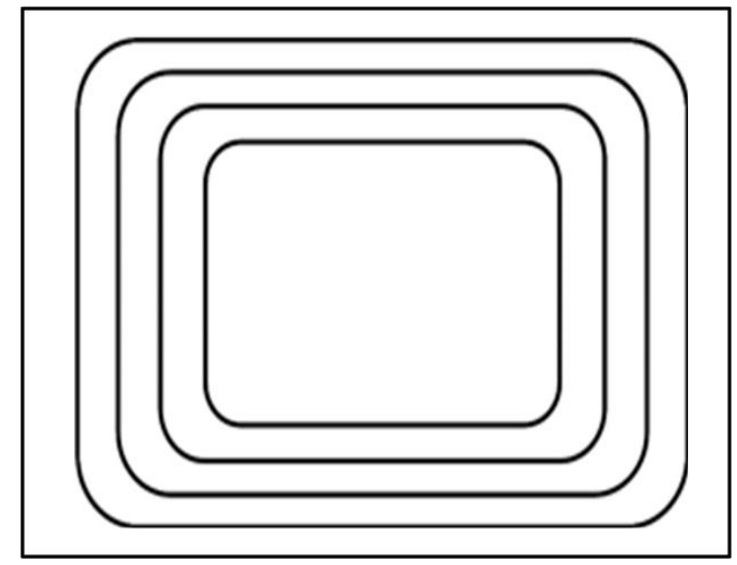

Figure 2.5. Typical single-coil circular rectangular pad

Figure 2.6 illustrates the schematic of a typical single-coil circular wireless pads where ferrite bars are added to the back of coil pad, to reduce the flux leakage and to facilitate a low reluctant path. Further, an aluminum shield is also placed at the back of the whole coil to hold up the flux distribution [28]. This topology is easy to assemble but it should be mentioned that the transfer distance is limited by the diameter of the pad. The process for designing a circular pads is discussed in detail in section 3.2.1.1.

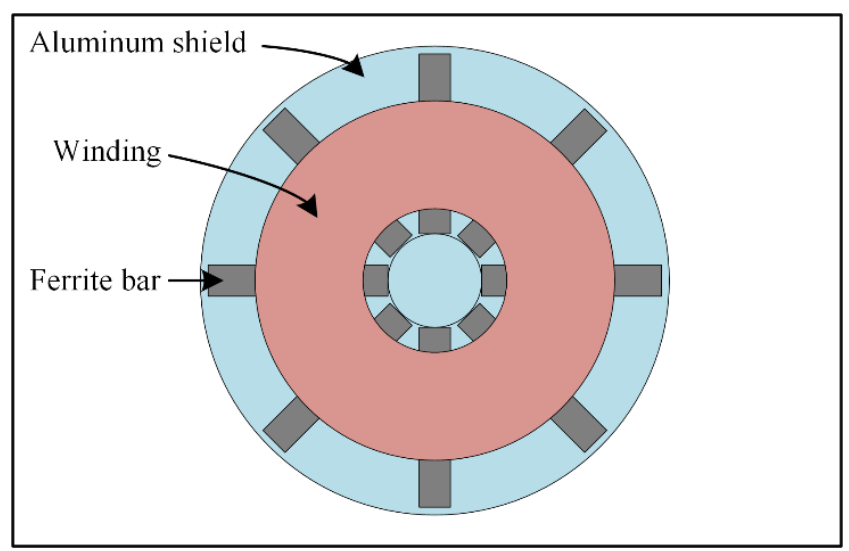

Figure 2.6. Typical single-coil circular non-polarized pad

A new structure of transmitting side wireless pad called, multiple-coil homogeneous pad, is proposed in [29] and the schematic is shown in Figure 2.7. The main application of this topology is for EVs used in a specific and limited area. As an advantage of this topology, the average magnetic flux density is increased and the corresponding field distribution variance is improved. However, low power rating, the drawbacks of high conduct losses and difficulties in fabrication are the disadvantages and limits of this topology for its potential applications. 


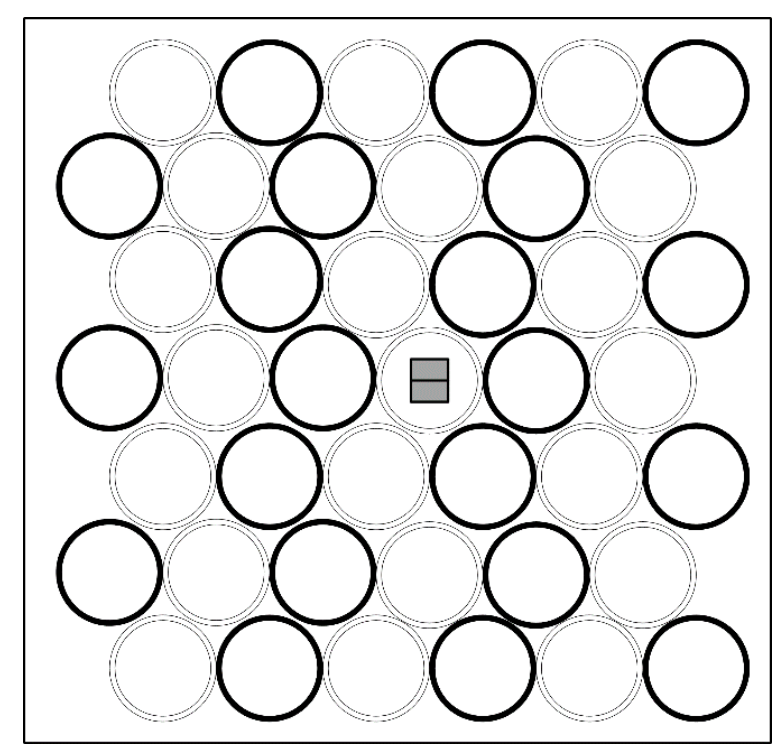

Figure 2.7. A multiple-coil homogeneous pad

In previous decades, researchers have proposed a verity of wireless coils for different applications. Double-D polarized pad or DDP pads are proposed in [30] where, the transmission distance is extended with high frequency through using ferrite bars to create flux path narrower and taller. Furthermore, there are some other remarkable topologies that should be mentioned as multiple-coil Double-D Quadrature Polarized Pad (DDQP) and multiple-coil Bipolar Polarized Pad (BPP) that are covered [31] and [32], respectively.

\subsection{Diode Rectifiers}

In recent years, a considerable amount of research was performed on construction of static converters with high efficiency and high gain. Although the voltage-fed DC-DC converters are popular but has usage of electrolytic capacitors, and high transformer turn ratio [33]. As DCDC current fed converters do not have these issues, they are more preferred for wireless charging application of electrical vehicles. The first two-inductor current-fed isolated DC-DC converter was proposed via duality principle from half bridge voltage fed converter [34].

An important part of a DC-DC converter for wireless charging of EVs is the rectification process on the receiver side to provide DC voltage and current for battery charging application. A full-bridge diode rectifier and a voltage doubler topology and a lab prototype was built to validate the analysis and simulation results [35]. Further, a comparison of diode full-bridge rectifier and voltage-doubling diode rectifier is presented in [33] along with experimental results. 


\subsection{Active Rectifiers}

An experimental comparison of single phase active rectifiers is presented in [36]. In this paper, four major topologies of active rectifiers are listed:

- Traditional Power-Factor Correction (PFC).

- Symmetrical bridgeless, Half Active Rectifiers (HAR).

- Asymmetrical bridgeless.

- Full-bridge full controlled.

Figure 2.8 demonstrates the traditional power factor correction topology where a full-bridge diode rectifier is followed by a boost DC-DC converter. This design contains 5 diodes which is a disadvantage due to high conduction losses compared with MOSFETs.

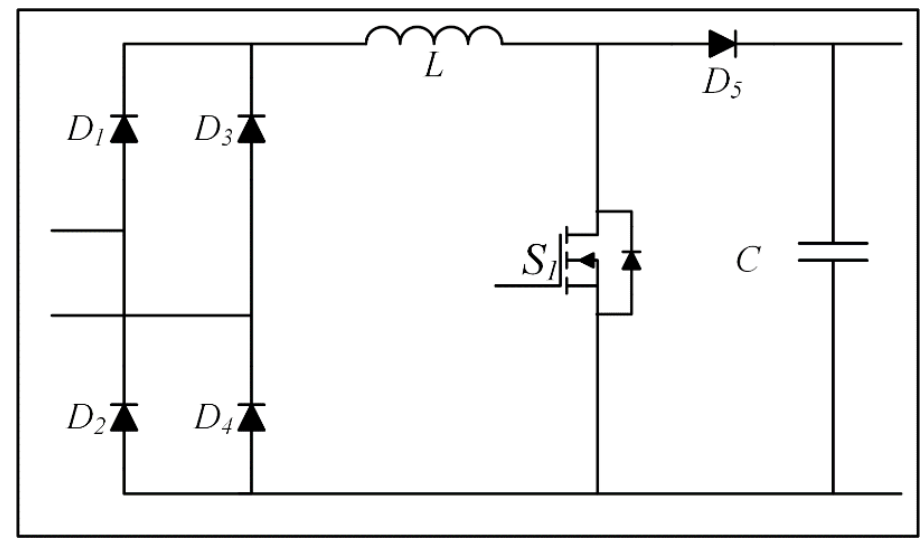

Figure 2.8. Traditional power factor correction

The symmetrical bridgeless active rectifier or the half active rectifier is presented in Figure 2.9. This design is formed by a diode and a fully controlled switch in each leg. A phase shift control of a half active rectifier is investigated with diligence to apply this topology for wireless charging applications in [8] and [37]. 


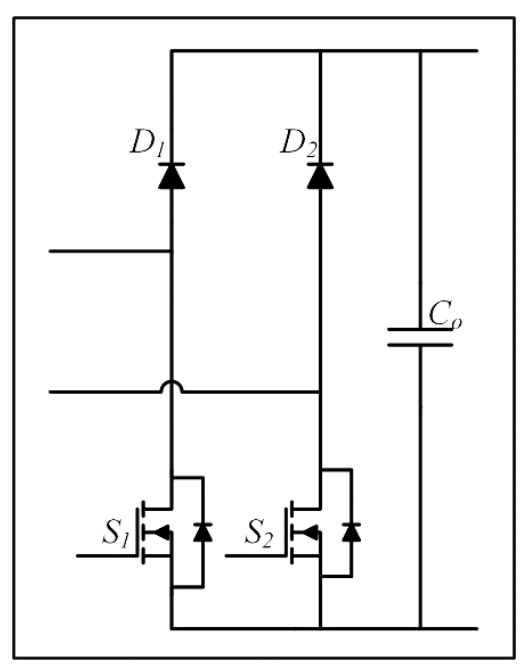

Figure 2.9. Half active rectifier

Similar to half active rectifier, asymmetrical bridgeless active rectifier is formed by a leg of two diodes and a leg of two MOSFETs, as it is shown in Figure 2.10.

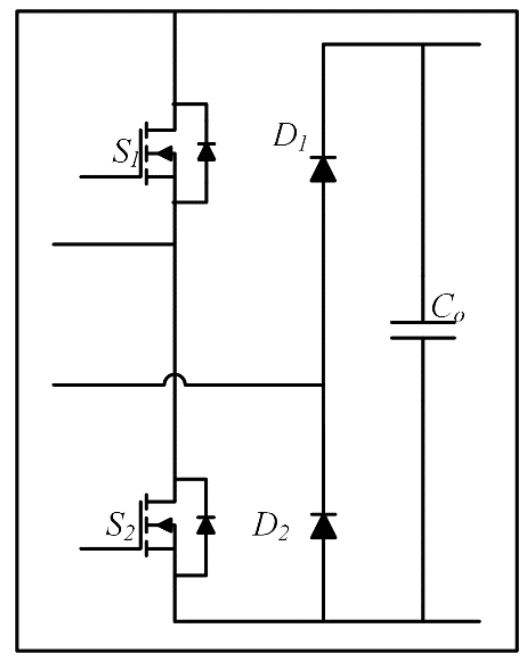

Figure 2.10. Asymmetrical bridgeless

Figure 2.11 shows the topology of a full-bridge full-controlled rectifier. Since the efficiency of WPT system is highly dependent on the output load and detuning conditions, an active single phase full-bridge rectifier is adopted in [7] to track the maximum efficiency during load variation and a corresponding control method is also proposed for such purposes. Furthermore, a variety of control strategies and efficiency analysis of active single-phase full-bridge converters are presented in [38] to [44]. 


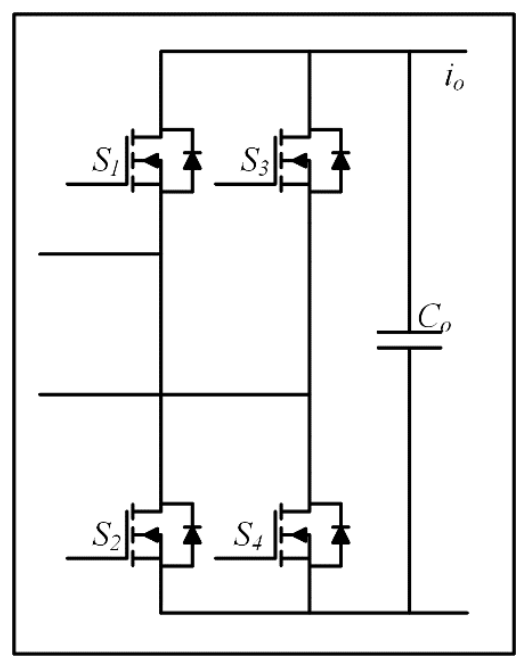

Figure 2.11. Full-bridge full-controlled rectifier

Another benefit of replacing rectifier diodes by active switches, is bidirectional WPT function which allows the WPT systems to inject power into grid. It is recognized that by optimizing EV charging procedure, loads could be balanced by valley filling and peak shaving [3].

\subsection{Matrix Converter}

In general, for plug-in EV battery recharging application, AC-DC-AC converter topologies are used where the AC-DC rectifier and DC-AC inverter are interconnected by a dc link. However, the AC-DC-AC converters can be replaced by AC-AC converter topologies such as the classic matrix converters. Matrix converters are able to converter the AC input to high frequency AC output with advantages of eliminating energy storage devices, reliability and reaching high power density [45]. Specifically, for bidirectional wireless power transfer systems for EV charging applications, the three-phase to single-phase, and single-phase to single phase matrix converters have been studied in [46] and [47].

\subsection{Safety}

Since the power level and the transmission distance of wireless EV charging goes up to $20 \mathrm{~kW}$ and $250 \mathrm{~mm}$, respectively, a major concern for practical applications is the electromagnetic field hazards from human perspective. For instance, the magnetic field 
strength distribution outside the EV for a practical wireless charger, has been researched in [48].

\subsection{Concluding Remarks}

In this chapter, two methods of WPT systems are briefly reviewed as stationary wireless charging and dynamic wireless charging. Future a literature review is performed on different parts of a WPT system as wireless pads, diode rectifiers and active rectifiers.

In following chapter, the basics of WPT systems theory are given. Moreover, a WPT topology using diode rectification is introduced and analyzed in section 3.3. In order to confirm the mathematical analysis and simulation results, a scale down lab prototype is built and the experimental results are discussed in section 3.3.3. 


\section{Chapter 3}

\section{WIRELESS POWER TRANSFER WITH DIODE RECTIFICATION}

\subsection{Introduction}

In this chapter the basics of wireless charging theory such as energy transformation through wireless pads and compensation networks are presented. Moreover a topology of WPT using a full-bridge diode rectifier is analyzed with diligence in two main parts, steady state operation and $\mathrm{AC}$ equivalent circuit analysis. In order to validate the mathematical analysis, the WPT topology presented in section 3.3 is simulated using MATLAB Simulink software. The simulation results and designed components values are provided in 3.3.2. Finally a scale down lab prototype is constructed to verify both mathematical analysis and simulation results. Section 3.3.3 represents the selected values of components and the experimental results of the WPT setup using diode rectification.

\subsection{Fundamental Theory of Wireless Charging}

Figure 3.1 depicts a typical process of wireless charging of EVs, which contains four mandatory and one optional subsystems:

- The utility ac power is converted to a dc power source using an AC to DC converter with power factor correction.

- The DC power is converted to high frequency AC using a variety of inverter topologies to drive the transmitting coils via a compensation network.

- According to the probability of insulation failure of the transmitting coils, a highfrequency isolating transformer might be inserted between the DC-AC inverter and transmitter coil for additional safety and protection purposes (optional).

- An alternating magnetic field would be generated by the high-frequency current through the transmitting coils. As a result, an AC voltage is influenced on the receiving coils.

- The AC power is rectified and filtered for battery charging applications. The rectification process can be done using different methods such as passive rectification and active rectification. 


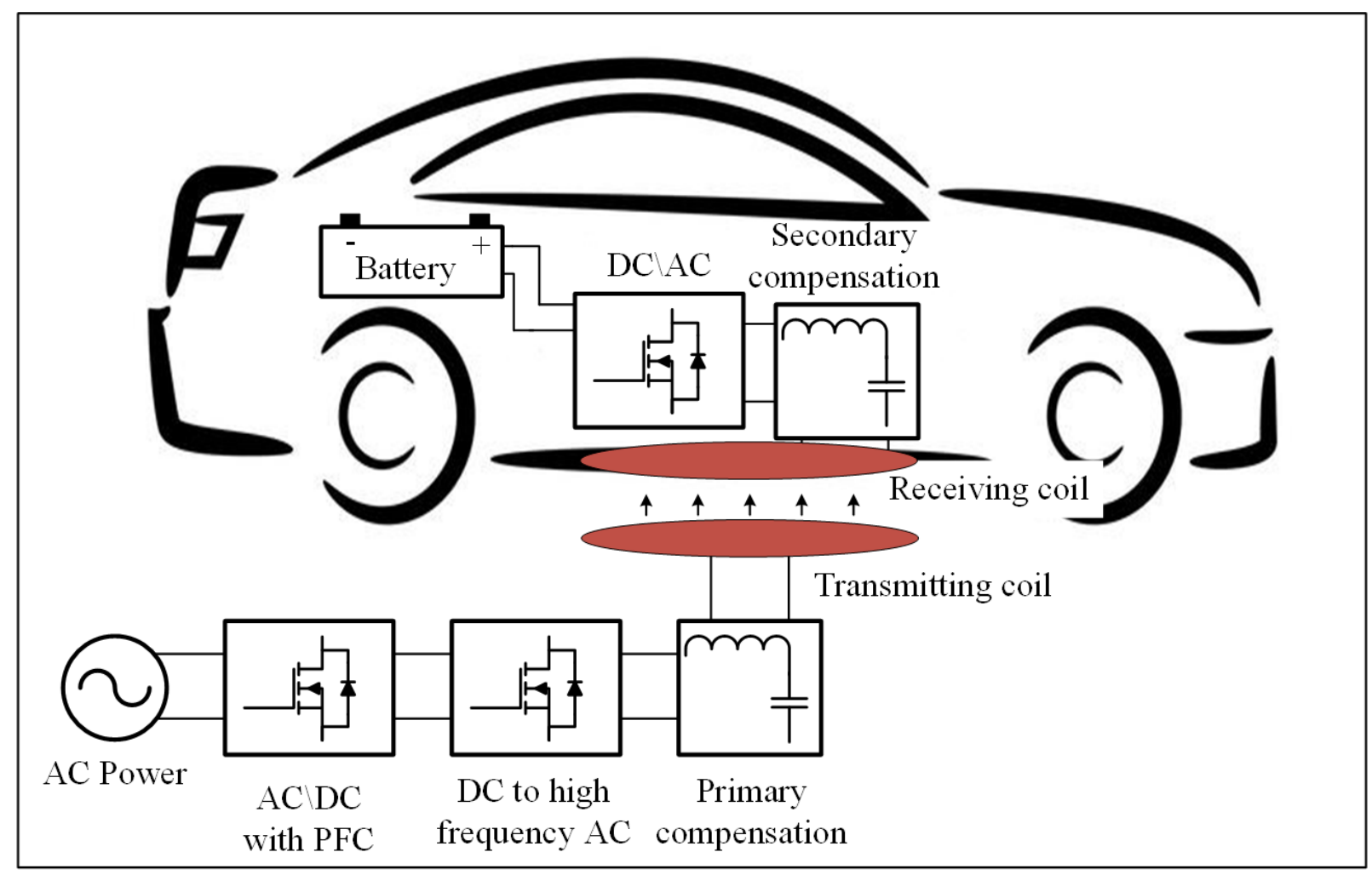

Figure 3.1. Typical Wireless EV Charging System

\subsubsection{Wireless Pads}

The main difference between wired chargers and wireless chargers is that transformer is replaced by a set of loosely coupled coils.

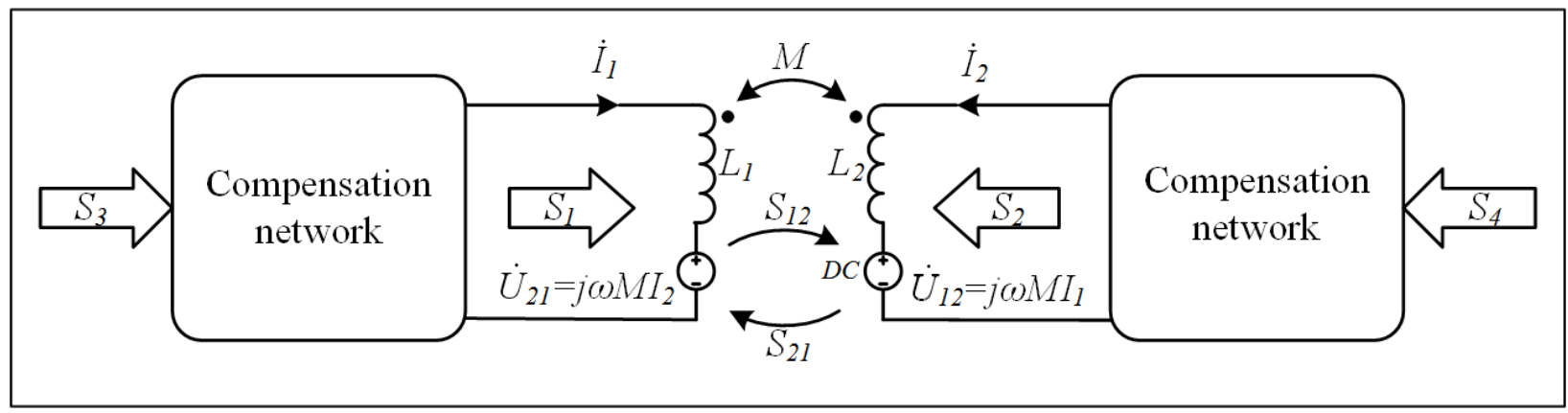

Figure 3.2. Two Coils Wireless Power Transfer System

Figure 3.2 illustrates the connection between both primary and secondary side compensation networks and coils where:

- $\dot{U}_{21}$ : The voltage in the transmitting coil induced by the current in receiver coil due to coupling or mutual inductance between the primary and secondary side coils.

- $\dot{U}_{12}$ : represents the voltage in secondary side induced by the current in transmitting side.

- $I_{1}$ and $I_{2}$ : Currents going through primary and secondary coils, respectively. 
- $L_{1}$ and $L_{2}$ : The self-inductance of transmitting and receiving coils.

- $M$ : The mutual inductance of wireless coils.

- $S_{1}$ and $S_{2}$ : apparent power passing by $L_{1}$ and $L_{2}$, respectively

- $S_{3}$ : The apparent power generated by inverter and goes into compensation network.

- $S_{4}$ : Apparent power by the rectifier side and goes into compensation network at the secondary side.

- $S_{12}$ and $S_{21}$ : The apparent power exchange between two coils.

Neglecting the coil resistance and magnetic losses, the exchanged of complex power from $L_{1}$ and $L_{2}$ derived as:

$$
\begin{aligned}
& S_{12}=-\dot{U}_{12} \dot{I}_{2}^{*}=-j \omega M \dot{I}_{1} \dot{I}_{2}^{*}=\omega M I_{1} I_{2} \sin \varphi_{12}-j \omega M I_{1} I_{2} \cos \varphi_{12} \\
& S_{21}=-\dot{U}_{12} \dot{I}_{1}^{*}=-j \omega M \dot{I}_{2} \dot{I}_{1}^{*}=\omega M I_{1} I_{2} \sin \varphi_{12}-j \omega M I_{1} I_{2} \cos \varphi_{12}
\end{aligned}
$$

Where $I_{1}$ and $I_{2}$ are the RMS value of current going into the coils and $\varphi_{12}$ is the phase difference between $\dot{I}_{1}$ and $\dot{I}_{2}$. The system shown in figure 3.2. presents a bidirectional system which can transfer active power in both directions. Without the loss of generality, can be assumed that power is transferred from $L_{1}$ to $L_{2}$. The active power transferred from the transmitting coils to receiving coil can be expressed as:

$$
P_{12}=\omega M I_{1} I_{2} \sin \varphi_{12}
$$

From equation (3.3), the maximum power can be transferred when $\dot{I}_{1}$ leads $\dot{I}_{2}$ by a quarter cycle or $\varphi_{12}=\pi / 2$. The total complex power passing through wireless coils can be derived as:

$$
\begin{aligned}
\dot{S}=\dot{S}_{1}+\dot{S}_{2}= & j\left(\omega L_{1} \dot{I}_{1}+\omega M \dot{I}_{2}\right) \dot{I}_{1}^{*}+j\left(\omega L_{2} \dot{I}_{2}+\omega M \dot{I}_{1}\right) \dot{I}_{2}^{*} \\
& =j \omega\left(L_{1} I_{1}^{2}+L_{2} I_{2}^{2}+2 M I_{1} I_{2} \cos \varphi_{12}\right)
\end{aligned}
$$

Hence, the total reactive power goes into wireless coils is:

$$
Q=\omega\left(L_{1} I_{1}^{2}+L_{2} I_{2}^{2}+2 M I_{1} I_{2} \cos \varphi_{12}\right)
$$

To improve wireless pads efficiency, the ratio between the active power and reactive power should be maximized. The ratio can be expressed as:

$$
\begin{gathered}
f\left(\varphi_{12}\right)=\frac{\left|P_{12}\right|}{|Q|}=\left|\frac{\omega M I_{1} I_{2} \sin \varphi_{12}}{\omega L_{1} I_{1}^{2}+\omega L_{2} I_{2}^{2}+2 \omega M I_{1} I_{2} \cos \varphi_{12}}\right| \\
=\frac{k \sqrt{1-\cos ^{2} \varphi_{12}}}{\frac{I_{1}}{I_{2}} \sqrt{\frac{L_{1}}{L_{2}}}+\frac{I_{2}}{I_{1}} \sqrt{\frac{L_{2}}{L_{1}}}+2 k \cos \varphi_{12}}=\frac{k \sqrt{1-\cos ^{2} \varphi_{12}}}{x+\frac{1}{x}+2 k \cos \varphi_{12}}
\end{gathered}
$$




$$
\begin{aligned}
& \text { Where } \frac{\pi}{2}<\varphi_{12}<\pi, \\
& x=\frac{I_{1}}{I_{2}} \sqrt{\frac{L_{1}}{L_{2}}}>0
\end{aligned}
$$

and $k$ is the coupling coefficient between $L_{1}$ and $L_{2}$.

$$
k=\frac{M}{\sqrt{L_{1} L_{2}}}
$$

In order to achieve peaks values of $f\left(\varphi_{12}\right)$, the following equations should be solved:

$$
\frac{\partial}{\partial \varphi_{12}} f\left(\varphi_{12}\right)=0, \quad \frac{\partial^{2}}{\partial^{2} \varphi_{12}} f\left(\varphi_{12}\right)<0
$$

Which leads to solutions of:

$$
\cos \varphi_{12}=-\frac{2 k}{x+\frac{1}{x}}, \quad \sin \varphi_{12}=\sqrt{1-\frac{4 k^{2}}{\left(x+\frac{1}{x}\right)^{2}}}
$$

For a conventional transformer, $\mathrm{k}$ is close to 1 . For this application, if $\dot{I}_{2}$ is an induced current by $\dot{I}_{1}, x$ will be close to 1 . Thus, $\cos \varphi_{12} \approx-1$ or the phase difference between $\dot{I}_{1}$ and $\dot{I}_{2}$ is very close to $180^{\circ}$. On the other hand, for induction power transfer systems, the ideal $k$ is very close to zero. $f\left(\varphi_{12}\right)$ is maximized at $\sin \varphi_{12}=1$, which also leads to maximum power transferring through wireless pads. Also, the phase angle between $\dot{I}_{1}$ and $\dot{I}_{2}$ is about $90^{\circ}$ instead of $180^{\circ}$.

Every wireless power transfer system needs at least two magnetic pads to transfer power from primary side (transmitting coil) to secondary side (receiver coil). In order to achieve higher efficiency, high coupling coefficient factor, k, and high quality factor, Q, are required. The quality factor, $\mathrm{Q}$, is defined by the ratio of inductance, $\mathrm{L}$, to resistance, $\mathrm{R}$, for a coil which remains constant for winding arrangements in the same volume and shape.

$$
Q=\frac{\omega L}{R}
$$

In order to achieve a higher $\mathrm{k}$, it should be considered that an increase in the ratio of size to gap for a particular wireless pad would cause a corresponding increment in coupling coefficient factor, $\mathrm{k}$. Furthermore, the value of quality factor depends on the thickness of the wire and the ferrite section area as, thicker the wire and larger the ferrite section area is, higher the $\mathrm{Q}$ is. On the other hand, the values of $\mathrm{k}$ and $\mathrm{Q}$ are limited by engineering design consideration, such as dimensions and costs. According to the equation (3.11), by adopting high frequencies, Q would be increased [3]. 
One of the most important factors in WPT systems is coupling coefficient factor k, which is remarkably affected by the design of wireless pads. With similar dimension and materials, coupling coefficient is highly dependent on wireless pads geometry and configuration. A better wireless pad design may lead to a $50 \%$ to $100 \%$ improvement compared with some non-optimal design topologies.

\subsubsection{Self-Induction}

A wireless coil is used to run a current through a closed circuit. Assuming a coil has $N$ turns and the current, $I$ is passing through each turn, As a result the magnetic flux density $B$, is proportional to the number of turns, $N$ carrying the current $I$ :

$$
B \propto N I
$$

The flux leakage is determined by:

$$
\Psi=N \Phi
$$

The flux leakage $\Psi$ can be used to calculate the self-inductance $L$ of the coil:

$$
L=\frac{\Psi}{I}
$$

Since, $\mathrm{L}$ is proportional to $N \Phi, \Phi$ is proportional to $B$ and finally $B$ is proportional to $N I$, the self-inductance is proportional to the square of $\mathrm{N}$ (the number of turns of the coil):

$$
L \propto N^{2}
$$

An air-core inductor is an inductor that does not depend upon a ferromagnetic material to achieve its rated inductance, some inductors are wound without a bobbin and only air is used as the core. Some others are wound on a bobbin made of Bakelite, plastic, ceramic etc. In contrast with coils using ferromagnetic, cores which inductance tends to reach a peak at moderate field strengths before dropping towards zero as saturation approaches, the inductance of an air-core coil is unaffected by the current it carries. Furthermore, air-cores have no iron losses, which is another issue with ferromagnetic coils. As frequency is increased, this advantage becomes progressively more important, as it gains a better Q-factor. Additionally, greater efficiency, greater power handling and less distortion are the other outcome results of using an air-core coil operating at high frequencies. Lastly, air-core coils can be designed to perform at frequencies as high as $1 \mathrm{GHz}$ while mostly ferromagnetic cores tend to be rather loosely above $100 \mathrm{MHz}$ [51].

On the other hand, without a high permeability core, higher number of turns are required to achieve a given inductance value. Having more turns leads to larger coils, lower self-resonance 
due to higher inter-winding capacitance and higher copper loss but, generally, at higher frequencies there is no need for high inductance so this is then less of a problem.

Using "Harold A. Wheeler" approximation [50], according to the schematic of a wireless pad shown in Figure 3.3, the self-inductance of a flat spiral coils can be calculated as:

$$
L=\frac{N^{2} \cdot A^{2}}{30 A-11 D_{i}}
$$

Where,

$$
A=\frac{D_{i}+N(W+S)}{2}
$$

and $D_{i}$ represents inner diameter in inches; $S$ is the distance between windings in inches; $W$ shows wire diameter in inches; $N$ is the number of the turns; $D_{o}$ represent the outer diameter.

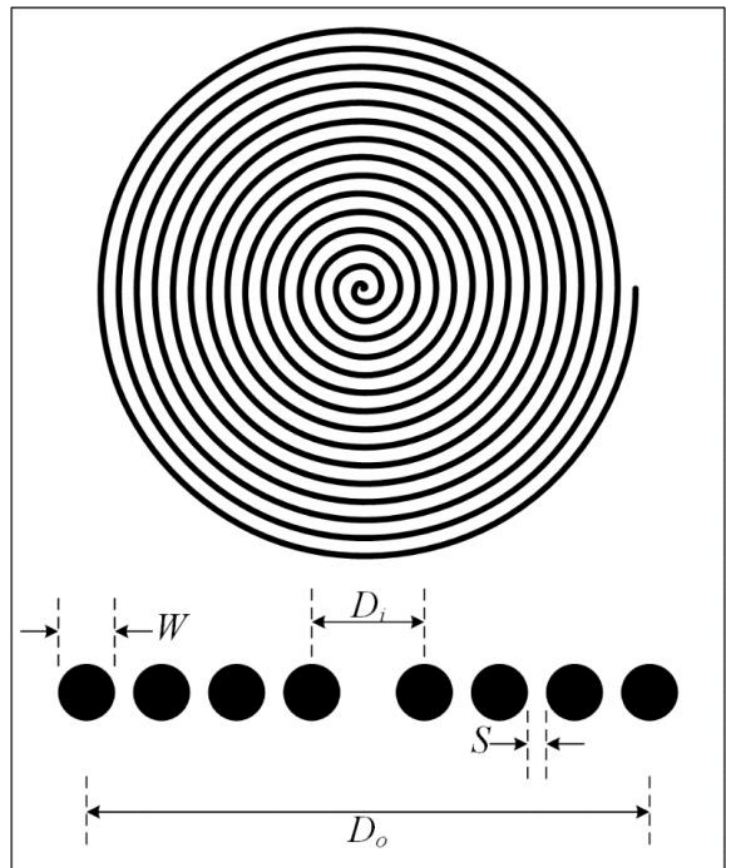

Figure 3.3. Wireless Pads Schematic

It should be noticed that "Harold A. Wheeler" approximation applies at low frequencies $(<30 \mathrm{MHz})$ using enameled copper wire.

\subsubsection{Mutual Induction}

Mutual induction is a phenomenon when a coil gets induced in EMF across it, due to the rate of change current in adjacent coil, in such a way that the flux of one coil current gets linkage of another coil. Mutual inductance can also be defined as:

$$
M_{12}=M_{21}=\frac{\lambda_{12}}{I_{2}}=\frac{\lambda_{21}}{I_{1}}
$$


Where $\lambda_{12}$ and $\lambda_{21}$ are the flux linkages from the first coil to the second one and contrariwise, respectively. The mutual inductance for two circular single turn wire coils which are parallel and perfectly aligned is related to their distance as $M_{12} \propto 1 / d_{12}^{3}$. For two circular single coils with radius $r_{1}$ and $r_{2}$ the mutual inductance can be formulated by:

$$
\begin{aligned}
& M_{12}=\frac{2 \mu}{\alpha} \sqrt{r_{1} r_{2}}\left[\left(1-\frac{\alpha^{2}}{2}\right) K(\alpha)-E(\alpha)\right] ; \alpha=2 . \sqrt{\frac{r_{1} r_{2}}{\left(r_{1}+r_{2}\right)^{2}+d_{12}^{2}}} \\
& K(\alpha)=\int_{0}^{\frac{\pi}{2}} \frac{d \phi}{\sqrt{1-\alpha^{2} \sin ^{2}(\phi)}} ; E(\alpha)=\int_{0}^{\frac{\pi}{2}} \sqrt{1-\alpha^{2} \sin ^{2}(\phi)} d \phi
\end{aligned}
$$

Hence, the equation of mutual inductance for multiple turn coils is given by:

$$
M_{t o t}=\sum_{i=1}^{N_{1}} \sum_{j=1}^{N_{2}} M_{i j}
$$

\subsubsection{Compensation Network}

In a WPT system, the pads are loosely coupled with a large leakage inductance. In order to reduce the VA rating in the coil and power supply, a compensation network is required. In early inductive charging technologies, the compensation network was set either on primary side or secondary side. When the coupling coefficient is reduced to less than 0.3 , it is recommended to employ compensation network at both sides in order to have more flexibility and advanced characteristic. To compensate a leakage inductance, an insure way is to add a capacitor at each side. Depending on how the capacitors are connected to the coils there are four basic compensation topologies as is shown in Figure 3.4:

- Series-Series (SS)

In order to apply series-series topology as a compensation network the capacitors in both primary and secondary side should be connected in series with the wireless pads, which is shown in Figure 3.4(a). SS topology is the simplest topology among four basics in terms of designing. However, during no load, or light load the series RC tank network provides almost zero reflected impedance to TC coil. Hence, when TC side tank is LC series type, the Voltage Source Inverter (VSI) output current surges when $\mathrm{RC}$ is uncoupled to TC the system becomes unstable. This problem is generally solved by very fast closed loop control.

- Series-Parallel (SP)

Primary series and secondary parallel compensation, which is shown in Figure 3.4(b), is also one of the four basic compensation topologies. The parallel LC tank at 
receiver side in series-parallel compensation always reflects some impedance to transmitter coil, hence current flow does not appear. However, surge current will also appear at voltage source inverter output for this case if RC coil is moved out.

- Parallel-Series (PS)

Generally the PS and PP compensation networks are quite limited to low power. However in an application where stiff current is readily available these compensation topologies are comparatively more suitable than the SS and PP topologies. PS topology is presented in Figure 3.4(c).

- Parallel-Parallel (PP)

The parallel-parallel topology is shown in Figure 3.4 (d). The major advantages of the parallel-series and parallel-parallel compensation network topologies are discussed in [3].

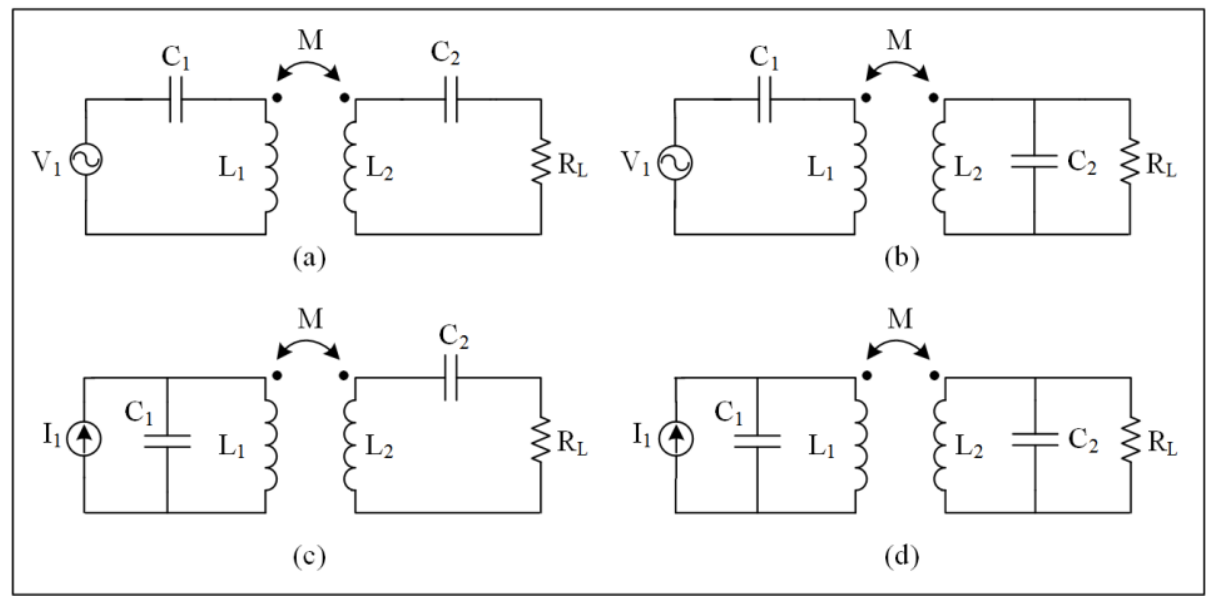

Figure 3.4. Basic Compensation Network Topologies, (a) SS, (b)SP, (c) PS, (d) PP

At primary side, if the capacitor is connected in series, a voltage source converter could be connected directly to the coil and if the capacitor is connected in parallel, usually an inductor is inserted to change the converter to a current source.

At secondary side, the capacitor is usually designed to resonant with $\mathrm{L}_{2}$ to reduce the VA capacity of the coils. When the transmitter coil has a constant current, a series compensation at the receiver side makes the output as a voltage source, while a parallel compensation makes the output like a current source. Several works highlighted the compensation using Series (S) or Parallel (P) connections and made comparisons between them [10], [41], [42]. The design of the resonant IPT system will depend upon the chosen topology. In some applications, the type of resonant topology is imposed by the designer. However, comparisons between the topologies can be made, and a decision for a suitable type will be drawn depending on the result obtained from numerical calculations, simulations and experimental tests [3]. 


\subsubsection{Analysis and study approach}

In general, to study WPT systems, 5 steps should be considered:

- Analysis of circuit topology and calculation of mutual inductances through analytical approaches.

- Numerical tools such as finite element method, finite boundary method, high-frequency system analysis.

- Simulation of WPT topology involving designed parameters and the relationship of coupling coefficient with overall efficiency.

- Experimental results for confirmation of mathematical analysis and simulation results.

- Soft switching of the applicable power converters in a wireless power transfer system which contains a variety of methods to study power electronics circuits.

\subsubsection{Safety Concerns}

In contrast with the traditional contact charging method, WPT avoids the electrocution danger. The main concern of safety for WPT is the high-frequency magnetic field existing between the transmitting and receiving coils, during charging process. Generally, the air gap between wireless coils varies from $15 \mathrm{~cm}$ to $30 \mathrm{~cm}$, which causes a high leakage field. The frequency and amplitude of the leakage magnetic field should be intricately controlled to meet the safety regulation. Furthermore, a safe area should always be defined for a wireless charging of EVs. In other words, it should be always ensured that the magnetic flux density meets the safety guidelines when people are in expected positions, such as standing outside a car or sitting inside. Fortunately, transport vehicles are usually made of steel, which is a considerably effective shielding material. In this thesis no research was done according to the safety of wireless chargers, yet a variety of researches on safety issues of WPTs can be find in [51].

\subsection{Wireless Power Transfer with Diode Rectification}

A variety of wireless inductive power transfer (IPT) topologies based on different types of transmitter and receiver coils resonances are discussed in [2], [7]-[9]. A new inductive WPT topology using current-fed half bridge CLC transmitter LC receiver configuration has been proposed in [10], where a passive rectifier and a voltage doubler is used to get the DC output voltage. Owing to diode rectification, the conduction loss of rectifier diodes are significantly high for low voltage battery charging applications. 


\subsubsection{Analysis of Wireless Power Transfer Using a Diode Rectifier}

Figure 3.5 presents an IPT topology using a full-bridge diode rectifier. A current-fed halfbridge inverter is used on the transmitter (TC) side to convert the DC input voltage to AC voltage as an input of compensation network. To make this topology suitable for higher power application, as a charger for EVs, some topological changes have been made. Instead of using a series or parallel capacitor as the compensation network a series-parallel compensation topology is selected. Also a capacitor, $\mathrm{C}_{\mathrm{s}}$ is connected in series with the transmitter coil to reduce the impedance of TC due to high leakage, decreased to:

$$
\omega L_{1}-\frac{1}{\omega C_{s}}
$$

Where $\mathrm{L}_{1}$ represents the transmitter coil impedance.

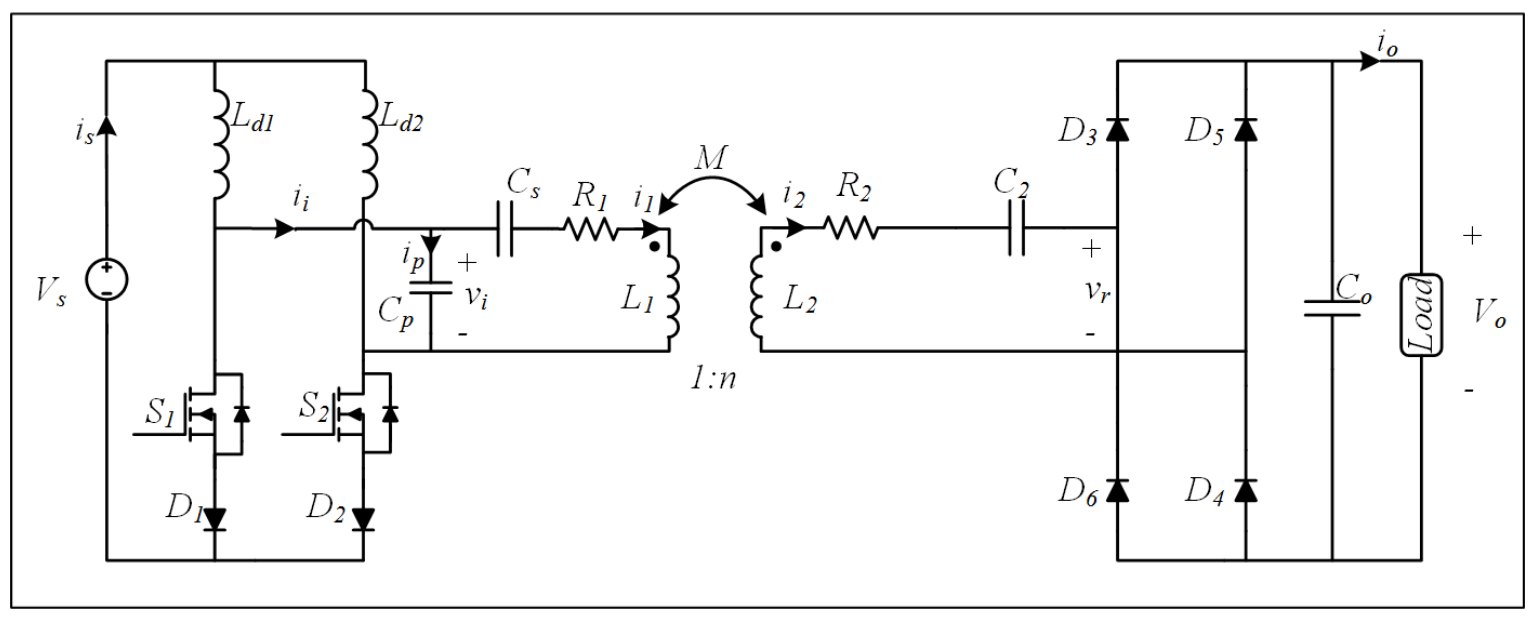

Figure 3.5. Wireless Power Transfer Topology using diode Rectifier

Another capacitor, $C_{p}$ in connected in parallel with $T C$ and $C_{s}$ to deliver the remaining reactive power consumed by transmitter coil. Furthermore, a square wave current is injected from the half-bridge current-fed inverter to the transmitter side resonant tank network. In order to achieve the minimum value of the input current magnitude, $\mathrm{I}_{\mathrm{i}}$, the series-parallel compensation network capacitors, $\mathrm{C}_{\mathrm{s}}$ and $\mathrm{C}_{\mathrm{p}}$ should be designed carefully. The higher harmonic current in $\mathrm{I}_{\mathrm{i}}$ passes through the capacitor $\mathrm{C}_{\mathrm{p}}$ and $\mathrm{TC}$ gets almost pure sinusoidal currents, since the parallel capacitor, $\mathrm{C}_{\mathrm{p}}$, implements much lower impedance to the higher order harmonics comparing with the TC branch 10].

In the receiver side capacitor, $\mathrm{C}_{2}$ is connected in series with the receiver coil to compensate the reactive power consumed by the receiver coil. Because of mutual coupling between transmitter coil and receiver coil, a voltage proportional to mutual inductance (M), TC coil 
current $\left(\mathrm{I}_{1}\right)$ and operating frequency $(\omega)$ is induced to the receiver coil. Finally, the power at the secondary side compensation network is rectified though a full bridge passive rectifier and feeds the load. The steady state analysis of the converter is described in the following section.

\subsubsection{Steady State Operation}

Figure 3. 6 shows steady state waveforms of voltages and currents of different components for one switching cycle. To explain the steady state analysis of this converter, consider the inverter leg switches, $S_{1}$ and $S_{2}$, are conducting at fixed duty cycle of 0.5 and their gating signals are complimentary. To ensure that the DC link current, remains continuous, a slight overlap is applied to $S_{1}$ and $S_{2}$. This small overlap is considered in steady state operation. Furthermore, to achieve Zero Voltage Switching (ZVS), the operating power factor at the output of the half bridge current fed inverter is considered to be lagging.

\section{Interval $1\left[\mathbf{t}_{0}-\mathbf{t}_{1}-\mathbf{t}_{2}\right]$ :}

Consider at $t_{0}$ instant switch $S_{1}$ is on and switch $S_{2}$ is off. During $t_{0}-t_{1}-t_{2}$, the complete DC link current passes through $S_{1}$, while at the same time period the voltage across $\left(S_{2}-D_{2}\right)$ is equal to $v_{i} . S_{2}$ blocks this positive voltage. On the rectifier side during $t_{0}-t_{1}$ period, the rectifier input current, $i_{2}$ is negative. During the interval $t_{0}-t_{1}$ the RC current, $i_{2}$ goes through $D_{5}$ and $D_{6}$ as shown in Figure 3.7(a). At instant $\mathrm{t}_{1}$, the diodes $\mathrm{D}_{5}$ and $\mathrm{D}_{6}$ turn off since the RC current crosses zero. From $t_{1}$ to $t_{2}$ diodes $\mathrm{D}_{3}$ and $\mathrm{D}_{4}$ rectify the $\mathrm{RC}$ current as represented in Figure $3.7(\mathrm{~b})$.

\section{Interval 2 [t2-t3]:}

The power factor at the output of inverter is considered to be slightly lagging. Hence, at instant $t_{2}$, the inverter output voltage, $v_{i}$ changes polarity. During $t_{2}-t_{3}$ a negative voltage appears at the second leg of inverter $\left(\mathrm{S}_{2}-\mathrm{D}_{2}\right)$ and $\mathrm{D}_{2}$ blocks this voltage. Yet the equivalent circuit remains the same during this time interval, as shown in Figure 3.7(b).

\section{Interval 3 [t3-t4-t5]:}

At instant $t_{3}$, switch $S_{2}$ is triggered due the mentioned overlap, but the first leg of inverter keeps conducting since the voltage across the other leg is still negative. Thus, simultaneous zero voltage and zero current turn on, is achieved for $S_{2}$. Furthermore, switch $S_{1}$ is turned off at instant $t_{4}$ and the total DC link current passes through the led $S_{2}-D_{2}$ as shown in Figure 3.7(c). A positive voltage, $\mathrm{v}_{\mathrm{i}}$ appears on the first leg of the inverter and $\mathrm{S}_{1}$ blocks this voltage. It should be considered that the overlap for $S_{1}$ and $S_{2}$ is exaggerated in Figure 3.6 for time interval 
analysis and in practical experiments this overlap is less than $0.5 \mu \mathrm{s}$, but sufficient enough to turn on switch $\mathrm{S}_{2}$. During this time period on the rectifier side, diodes $\mathrm{D}_{3}$ and $\mathrm{D}_{4}$ are conducting as presented in Figure 3.7(c).

\section{Interval 4 [t5-t6-t7-ts]:}

At instant $t_{5}$ the polarity of the current at the receiver side is changed and the second pair of diodes $\left(\mathrm{D}_{5}-\mathrm{D}_{6}\right)$ rectifies this current to the output resistive load. At instant $\mathrm{t}_{6}$ the output voltage of inverter crosses the zero point and enters to its negative cycle which leads to a situation that the first leg of inverter $\left(S_{1}-D_{1}\right)$ gets a negative voltage and diode $D_{1}$ takes this voltage. At instant $t_{7}, S_{1}$ is triggered but due to presence of negative voltage across $S_{1}-D_{1}$, the second leg $\left(\mathrm{S}_{2}-\mathrm{D}_{2}\right)$ keeps on conducting which leads to soft switching of $\mathrm{S}_{1}$. Finally, at instant $\mathrm{t}_{8}, \mathrm{~S}_{2}$ turns off and $\mathrm{S}_{1}$ takes the total DC link current again as shown in Figure 3.7(d).

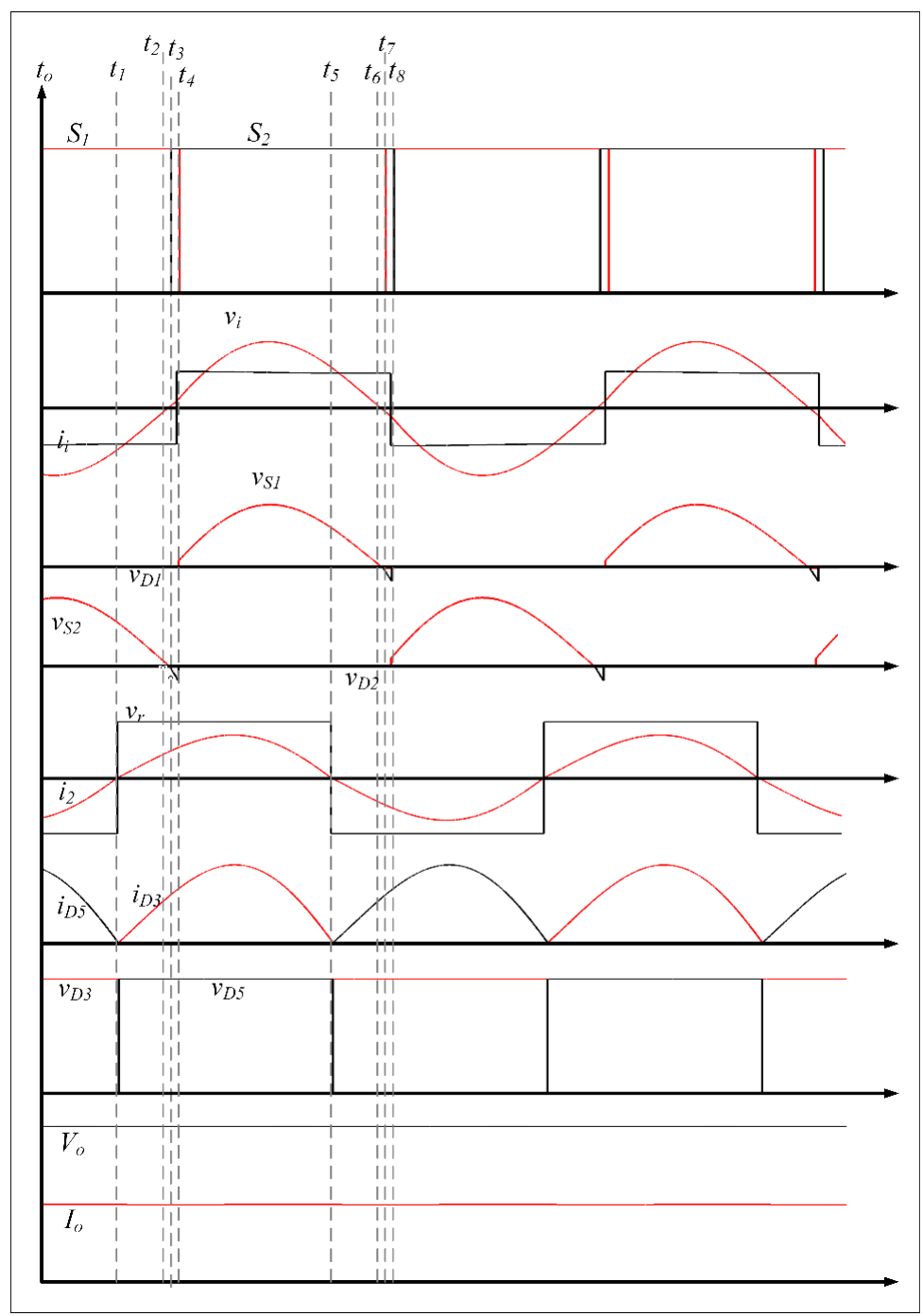

Figure 3.6. Steady State Voltage and Current Waveforms of Different Components 


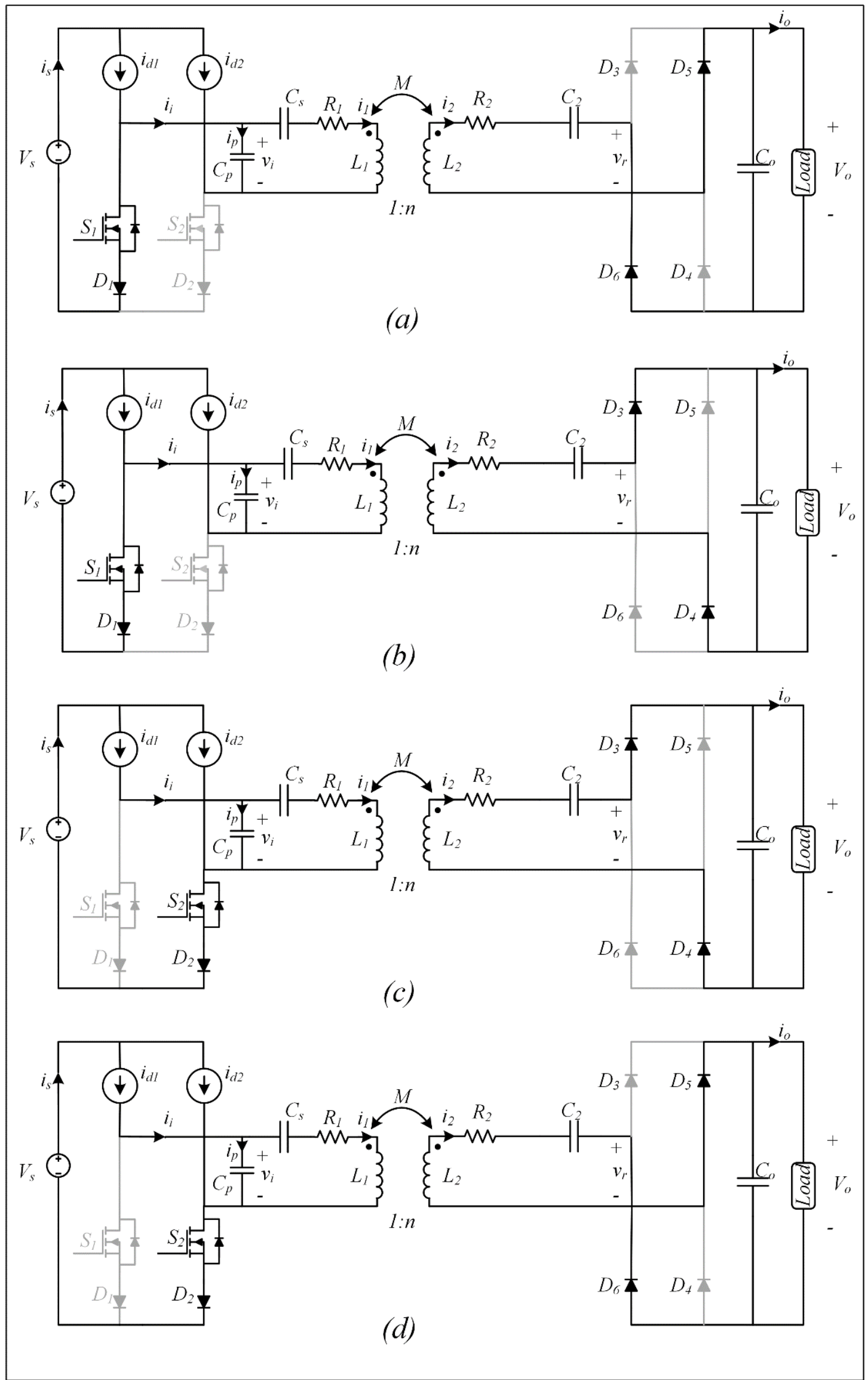

Figure 3.7. Equivalent Circuits for Different Intervals of WPT Converter with Diode Rectification 


\subsubsection{AC Circuit Analysis}

The AC side equivalent circuit of the converter is shown in Figure 3.8 where $R_{1}$ and $R_{2}$ are the transmitter coil and receiver coil resistances, respectively. The main application of this converter is low-voltage and light-load EV battery charging. In order to achieve higher current, $\mathrm{TC}$ to $\mathrm{RC}$ turns ratio has to be greater than unity or in other words n, as shown in Figure 3.8 should be less than 1 .

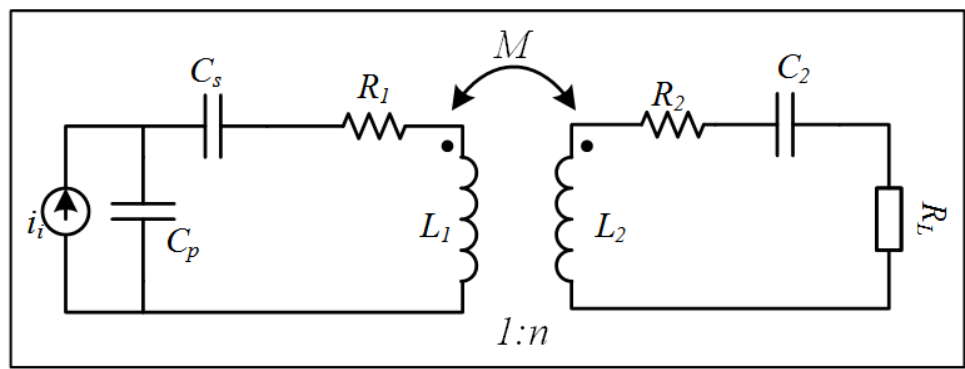

Figure 3.8. AC side equivalent circuit of the converter

Figure 3.9 shows the $\mathrm{T}$ equivalent circuit of the transformer referred to primary side. The equivalent impedance at the transmitter side, $Z_{1}$, and the secondary side, $Z_{2}$, shown in the box in Figure 3.9 are derived by:

$$
\begin{aligned}
& Z_{1}=\frac{1}{j \omega C_{s}}+R+j \omega\left(L_{1}-M \cdot n\right) \\
& Z_{2}=\frac{1}{j \omega C_{2} n^{2}}+\frac{R_{2}}{n^{2}}+j \omega \frac{L_{2}-M \cdot n}{n^{2}}
\end{aligned}
$$

Where $\mathrm{M}$ is the mutual inductance between $\mathrm{TC}$ and $\mathrm{RC}$ and $n$ is the turn ratio of the transformer which is always less than one, for the mentioned application. Furthermore, the total impedance at the output of the inverter, i.e. input to the TC tank network, is derived as:

$$
Z_{i}=\frac{1}{j \omega C_{p}} \|\left[j \omega\left(L_{1}-M n\right)+R_{1}+\frac{1}{j \omega C_{s}}+\left\{j \omega \frac{M}{n} \|\left[j w \frac{L_{2}-M n}{n^{2}}+\frac{R_{2}}{n^{2}}+\frac{1}{j \omega C_{2} n^{2}}+\frac{R_{L}}{n^{2}}\right]\right\}\right]
$$

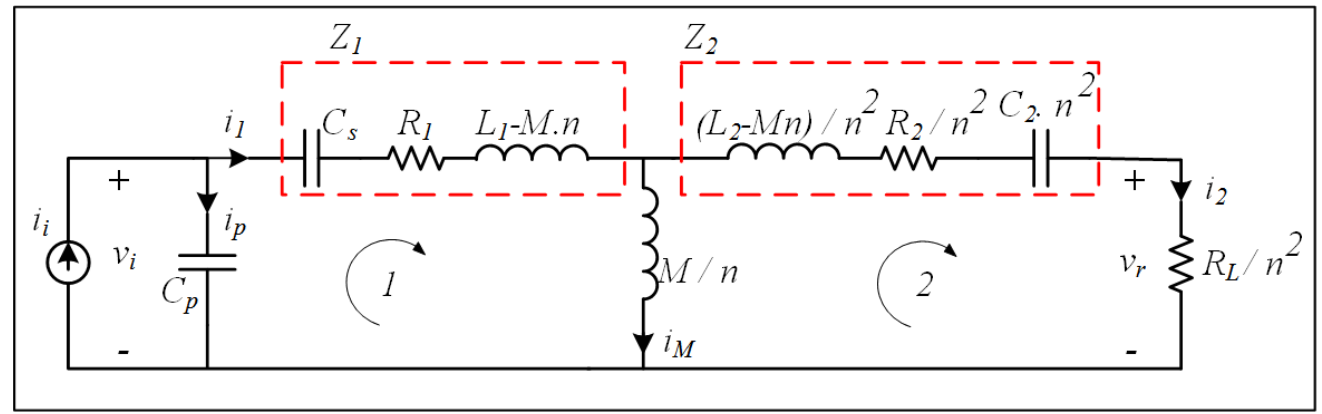

Figure 3.9. T equivalent circuit of the transformer referred to primary side 
According to the waveforms of the diode single phase rectifier the input current and voltage presented in Figure 3.5, rectifier switches operate in a way to keep the input voltage, $V_{r}$ and current, $I_{2}$ of diode rectifier in the same phase. The DC output current, $I_{0}$ is filtered by the output capacitor $C_{o}$ and the DC output Voltage, $V_{o}$ can be derived by:

$$
\begin{aligned}
& I_{o}=\frac{2 \sqrt{2}}{\pi} I_{2} \\
& V_{o}=\frac{\pi}{2 \sqrt{2}} V_{r}
\end{aligned}
$$

Using equations (3.26) and (3.27), the equivalent load from rectifier input side according to the output resistive load, $R$, can be given as:

$$
R_{L}=\frac{8}{\pi^{2}} R
$$

The inverter output current $i_{i}$ can be calculated by applying Kirchhoff's current law (KCL) at transmitter side in Figure 3.9 as:

$$
i_{i}=\frac{\pi}{2 \sqrt{2}} \omega_{o}^{2} \frac{M}{n} C_{p} I_{o}-j \frac{2 \sqrt{2}}{\pi} \frac{n C_{p} V_{o}}{M}\left(\frac{1}{\omega_{o} C_{s}}+\frac{1}{\omega_{o} C_{p}}-\omega_{o} L_{1}\right) .
$$

Similarly by applying Kirchhoff's voltage law (KVL), RMS value of inverter output voltage, $v_{i}$ can be derived by:

$$
v_{i}=\frac{2 \sqrt{2}}{\pi} \frac{V_{o} n}{\omega_{o} M}\left(\omega_{o} L_{1}-\frac{1}{\omega_{o} C_{s}}\right)-j \frac{\pi}{2 \sqrt{2}} I_{o} \omega_{o} \frac{M}{n}
$$

Furthermore, by applying KCL at the node between $Z_{1}$ and $Z_{2}$ and using KVL at the secondary loop shown in Figure 3.9 the current, $I_{1}$, passing by the transmitter side inductance $Z_{1}$, is derived by :

$$
I_{1}=\frac{\pi}{2 \sqrt{2}}\left(\frac{Z_{2} \cdot n^{2}+R_{L}}{j \omega M n}+1\right) I_{o}
$$




\subsubsection{Simulation Results}

Simulation results obtained from Matlab Simulink are reported to validate the analysis and performance of the mentioned wireless converter using a diode rectifier shown in Figure 3.5. Impedance and power factor angle at the input of transmitter coil resonance network for $V_{o} / I_{o}=2$ is shown in Figure 3.10. It is clear that when the inverter switching frequency is decreased from unity power factor line, the input impedance will be reduced. Therefore, power transferred is also diminished. Operating frequency is calculated through Figure 3.10 which shows the best power factor appears at $46.8 \mathrm{kHz}$. Moreover, based on the main application of the converter, which is light-load low-voltage EV charger, the step-down transformer ratio is designed to be 1: 0.33 . The converter is being fed by a $200 \mathrm{~V}$ DC voltage source. The output voltage $\mathrm{V}_{\mathrm{o}}$, output current $\mathrm{I}_{\mathrm{o}}$ and rated power are $50 \mathrm{~V}, 25 \mathrm{~A}$ and $12.5 \mathrm{~kW}$ respectively. Table 3.1 shows the selected values of different components for simulation based on the mathematical analysis.

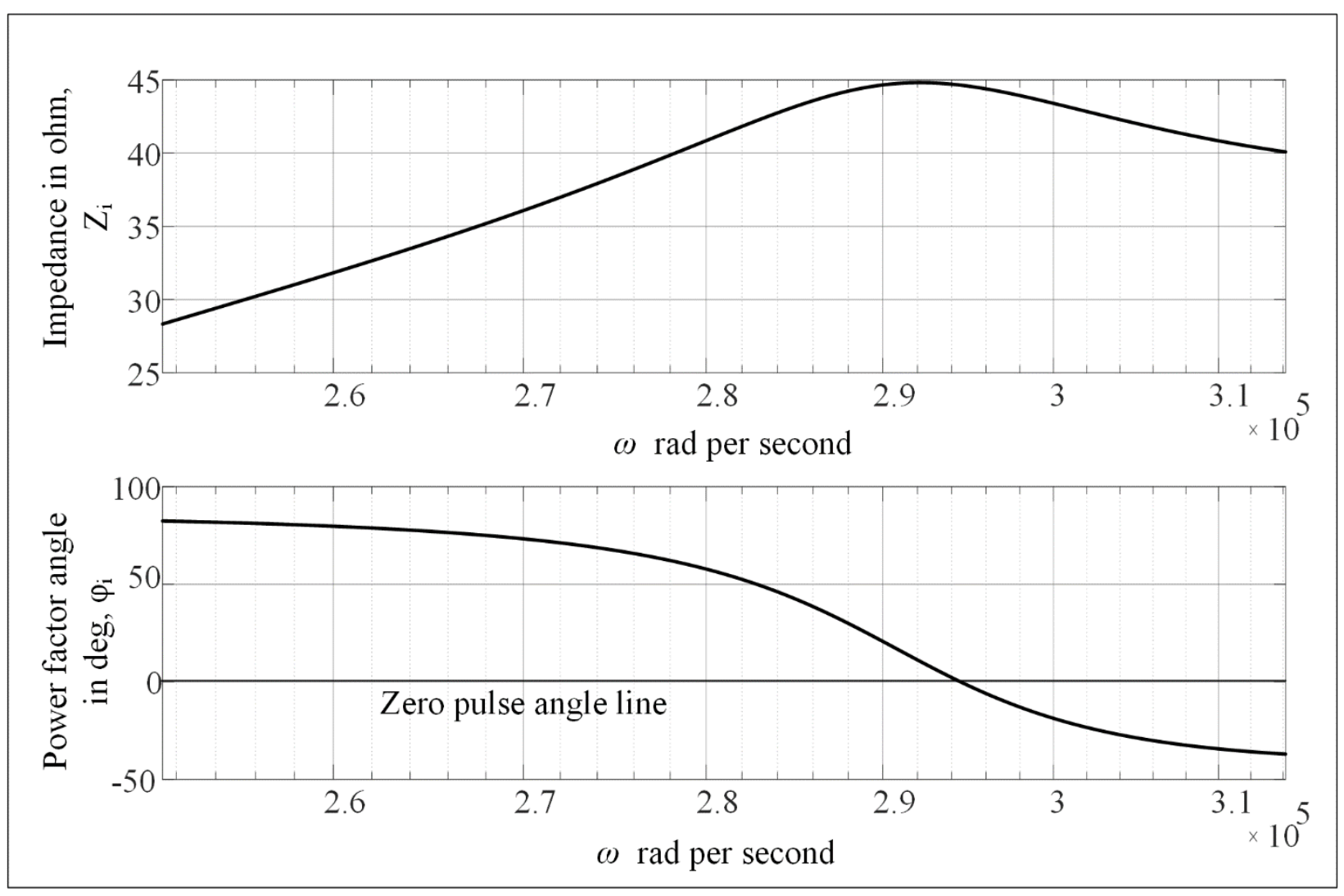

Figure 3.10. Impedance and phase angle at the output of inverter for $\mathrm{V}_{0} / \mathrm{I}_{\mathrm{o}}=2$ 
Table 3.1. Selected values of different components for simulation

\begin{tabular}{|l|c|}
\hline Parameters & Selected values \\
\hline Input DC current, $i_{s}$ & $6.9 \mathrm{~A}$ \\
\hline DC link inductor, $L_{d l}, L_{d 2}$ & $15 \mathrm{mH}$ \\
\hline TC, RC inductance, $L_{l}, L_{2}$ & $206 \mu \mathrm{H}, 23.4 \mu \mathrm{H}$ \\
\hline TC resonating capacitors, $C_{p}, C_{s}$ & $100 \mathrm{nF}, 100 \mathrm{nF}$ \\
\hline RC resonating Capacitor, $C_{2}$ & $420 \mathrm{nF}$ \\
\hline Switching frequency, $f_{s}$ & $46.8 \mathrm{kHz}$ \\
\hline Coils turn ratio & $3: 1$ \\
\hline Output voltage, $V_{o}$ & $51.5 \mathrm{~V}$ \\
\hline Output load, $R_{o}$ & $2 \Omega$ \\
\hline
\end{tabular}

Figure 3.11 shows the simulation waveforms of gating signals for inverter switches $\left(\mathrm{S}_{1}\right.$, $\mathrm{S}_{2}$ ). The gating signals are applied with a slight overlap, as discussed in 3.3.1, to make sure that the DC link current remains continuous.

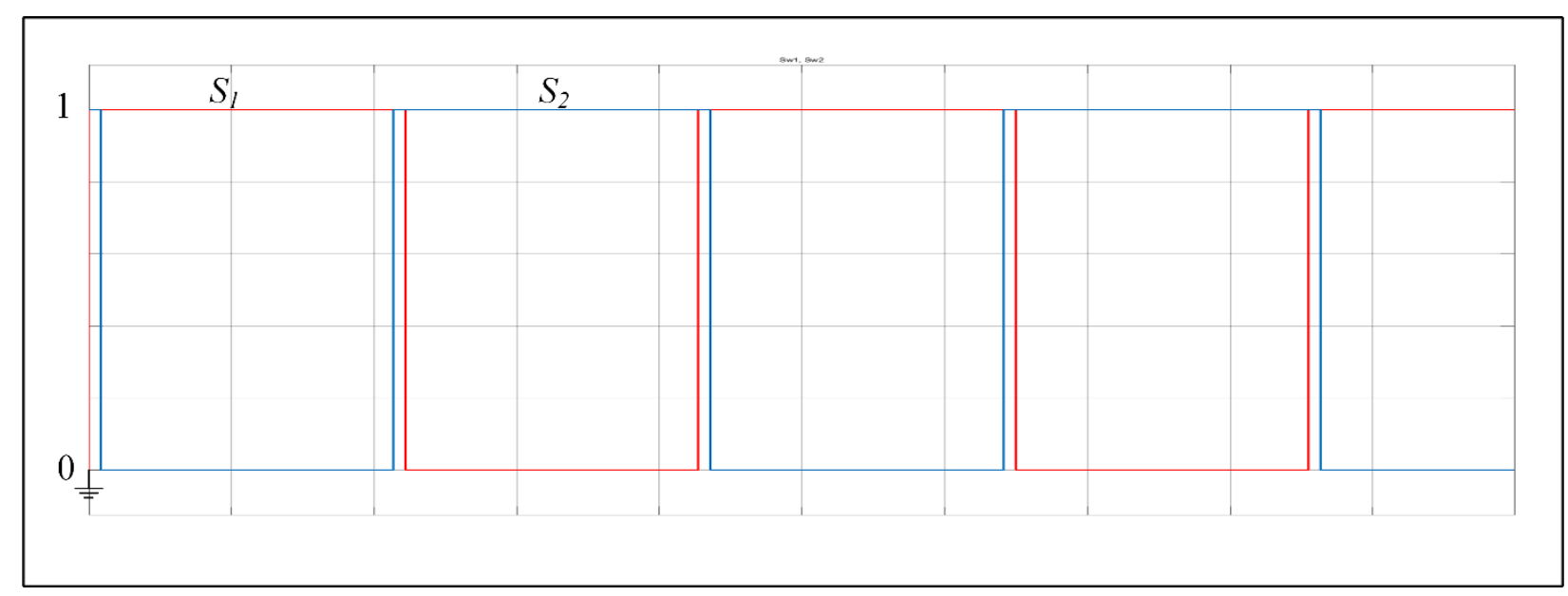

Figure 3.11. Simulation results of gating signals for inverter switches $S_{1}$ and $S_{2}$

Figure 3.12 represents the voltage across the first leg of inverter. After this voltage crosses zero, a negative voltage appears on the first leg, which is taken by $\mathrm{D}_{1}$. Similarly the voltage across the second leg of inverter $\left(\mathrm{S}_{2}, \mathrm{D}_{2}\right)$ is shown in Figure 3.13. 


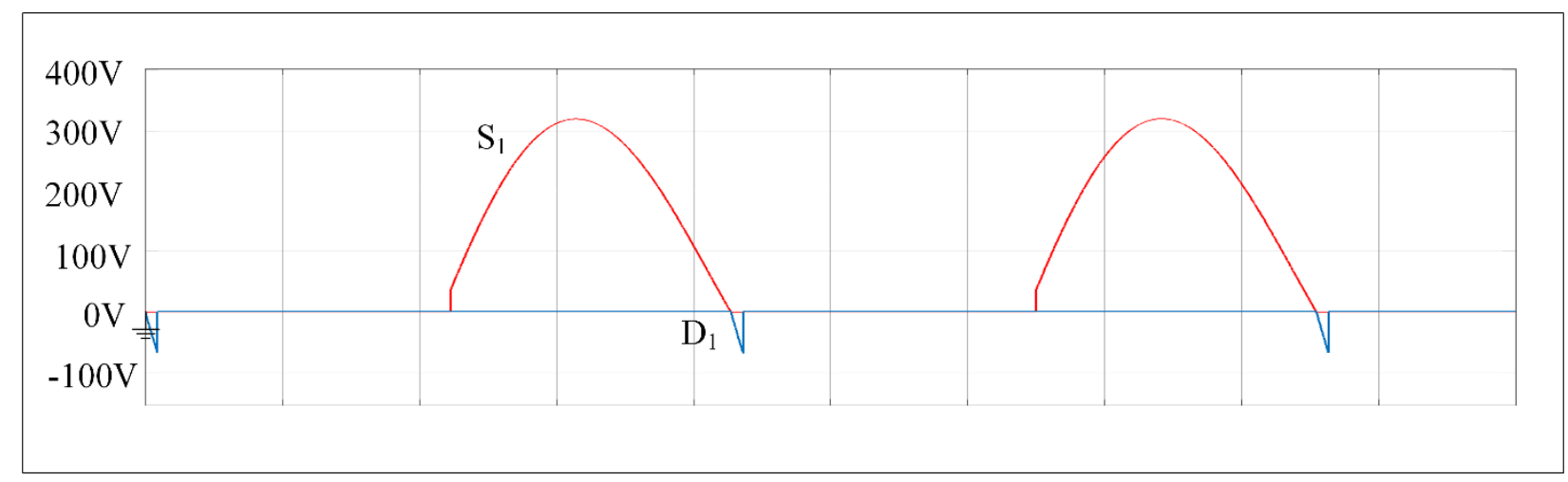

Figure 3.12. Simulation results of the voltage across the first leg of inverter $S_{1}$ and $D_{1}$

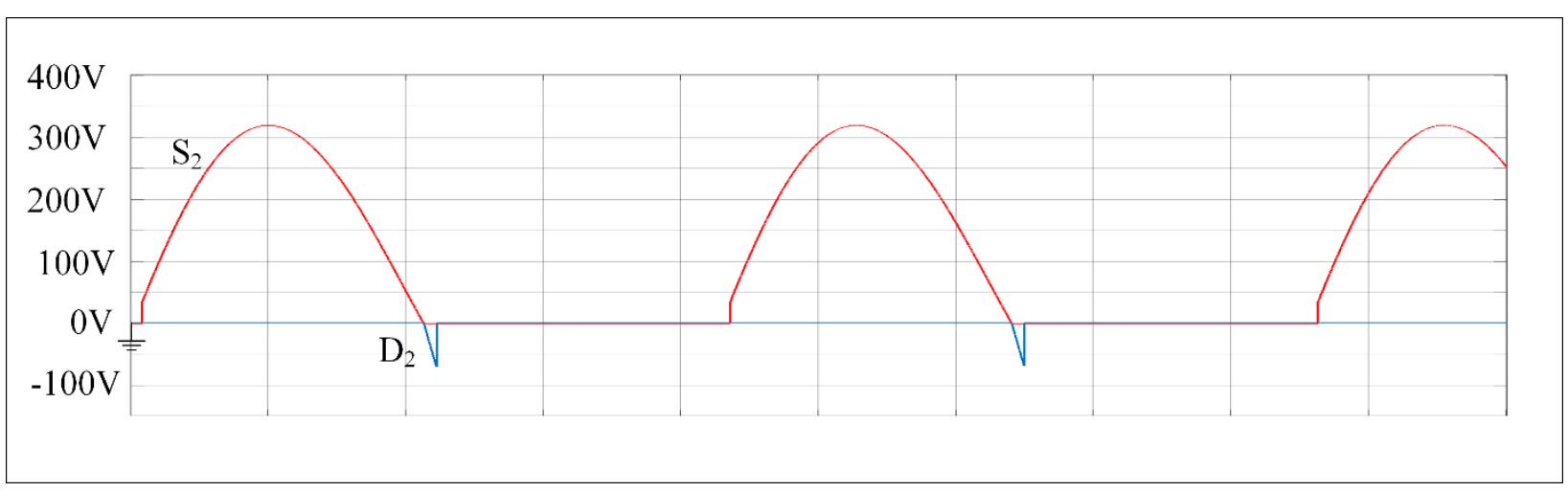

Figure 3.13. Simulation results of the voltage across the second leg of inverter $S_{2}$ and $D_{2}$

Figure 3.14 shows the simulation results of inverter output current and voltage at rated load. The operating power factor at the output of the half-bridge current-fed inverter is designed to be lagging to achieve zero voltage switching.

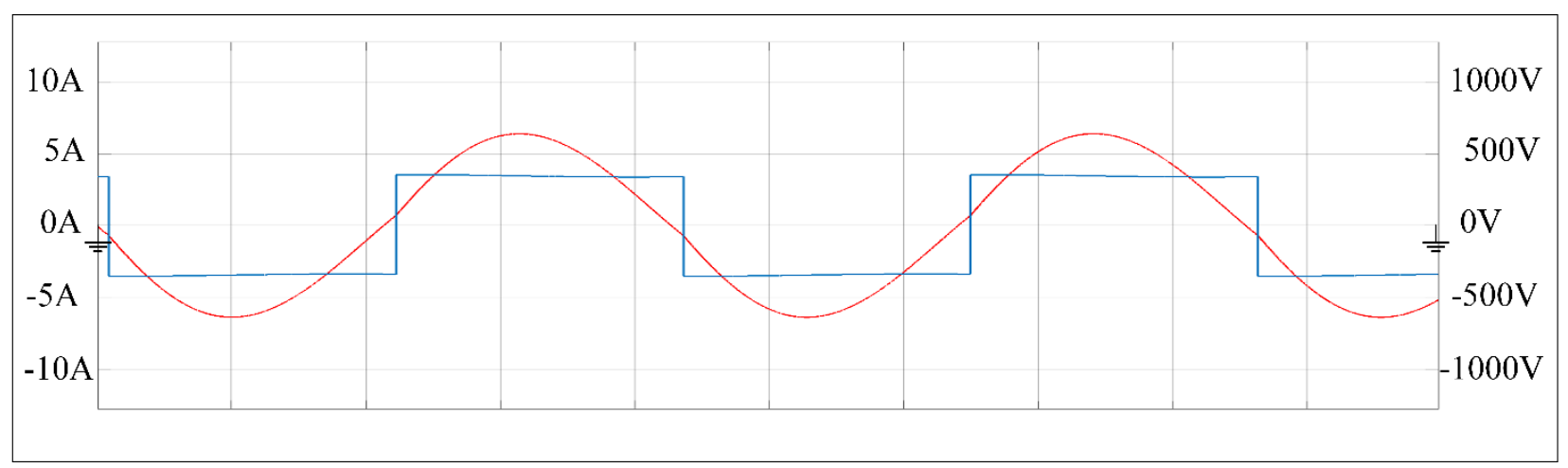

Figure 3.14. Simulation results of inverter output current and voltage at rated load

Figure 3.15 represents the voltage across the transmitter pad and receiver pad. As it is mentioned before, according to the main application of this converter (low-voltage, light-load electrical vehicles charging), the wireless pads are designed to operate as step down transformer with the turn ratio of $3: 1$. Based on Figure 3.15 , the peak voltages across the 
transmitter pad and receiver pad are $1270 \mathrm{~V}$ and $400 \mathrm{~V}$, respectively. The two steps shown in Figure 3.15 happens because of the rectifier mode of operation. Step 1 occurs when the first leg $\left(\mathrm{D}_{3}, \mathrm{D}_{4}\right)$ stops rectifying and the second leg $\left(\mathrm{D}_{5}, \mathrm{D}_{6}\right)$ starts conducting. In this case, a DC voltage is subtracted from the waveform. In contrast with this condition step 2 happens when the second leg stops conducting and the output voltage is rectified through the first leg. Furthermore, at step 2, a DC voltage is added to the voltage across the secondary pad.

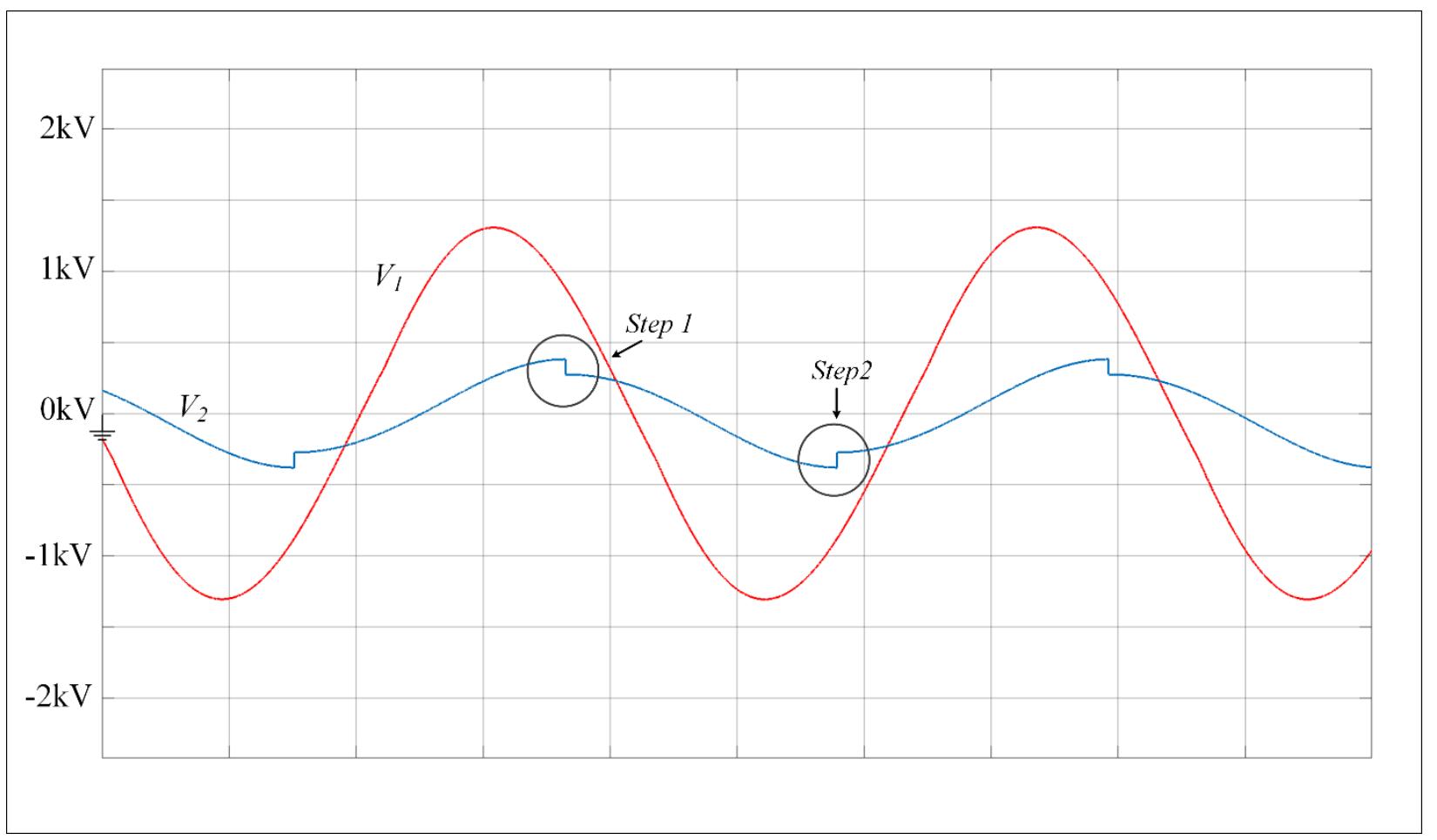

Figure 3.15. Simulation results of voltages across the transmitter coil and receiver coil

Simulation Result of rectifier input current and voltage is presented in Figure 3.16. It is clear that the passive rectifier provides almost pure resistive load at the receiver side of WPT converter since, $\mathrm{V}_{\mathrm{r}}$ and $\mathrm{I}_{2}$ are at the same phase.

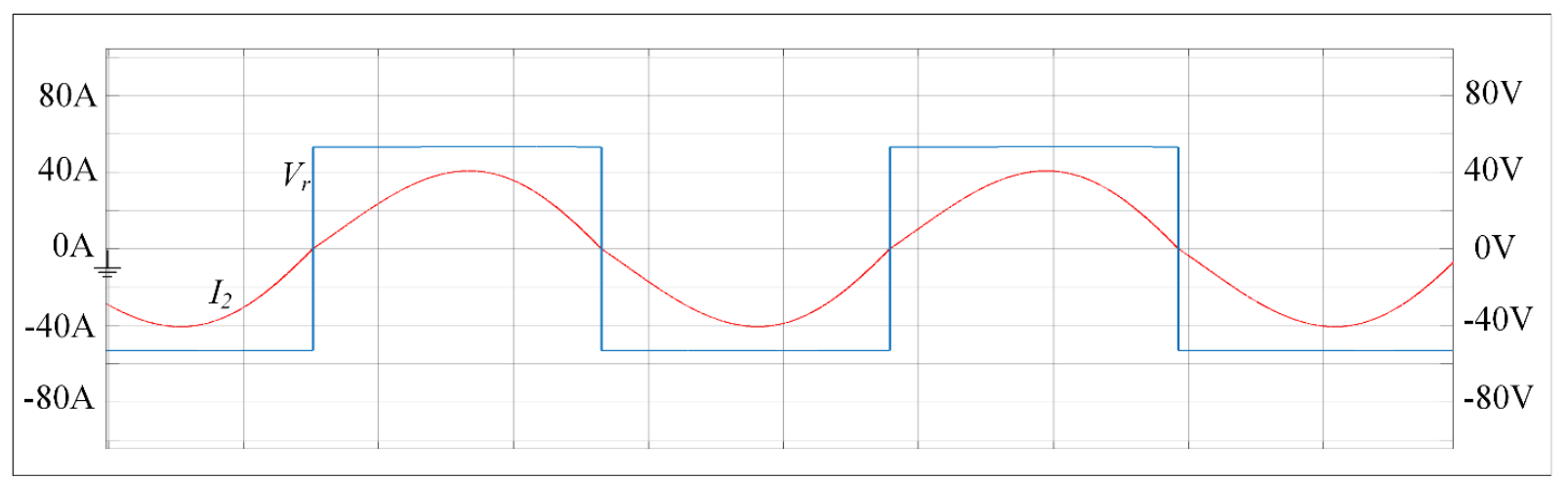

Figure 3.16. Simulation results of rectifier input current and voltage 
Figure 3.17 illustrates the voltage across the first leg $\left(D_{3}, D_{4}\right)$ and the second leg $\left(D_{5}, D_{6}\right)$ of passive rectifier. After the AC voltage is rectified by the rectifier it is filtered by a DC capacitor and the output current and voltage is presented in Figure 3.18. The output current and voltage are $25 \mathrm{~A}$ and $50 \mathrm{~V}$, respectively which suits the main application, low-voltage light-load electric vehicles recharging.

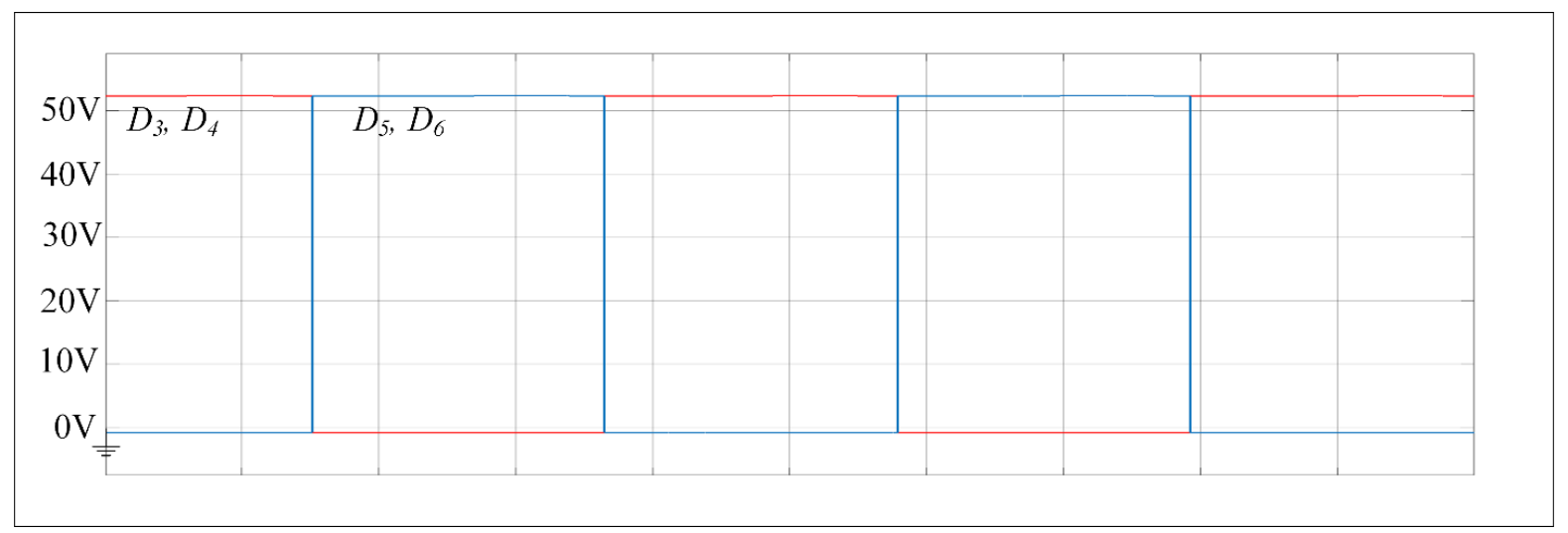

Figure 3.17. Simulation results of voltage across the first leg (D3, D4) and the second leg (D5, D6) of passive rectifier

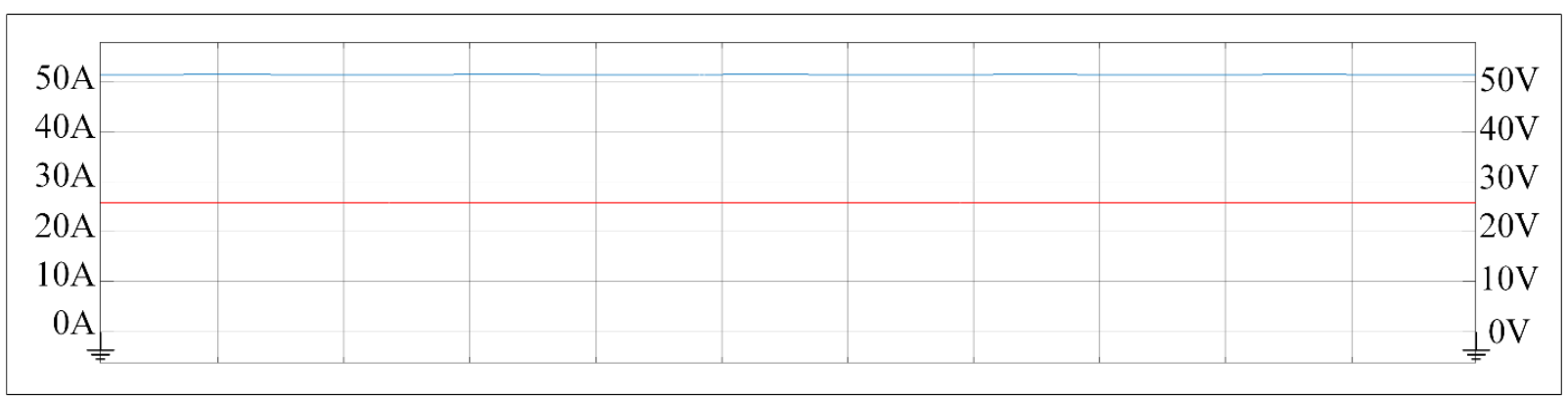

Figure 3.18. Simulation results of steady state waveforms of load current and voltage 


\subsubsection{Experimental Results}

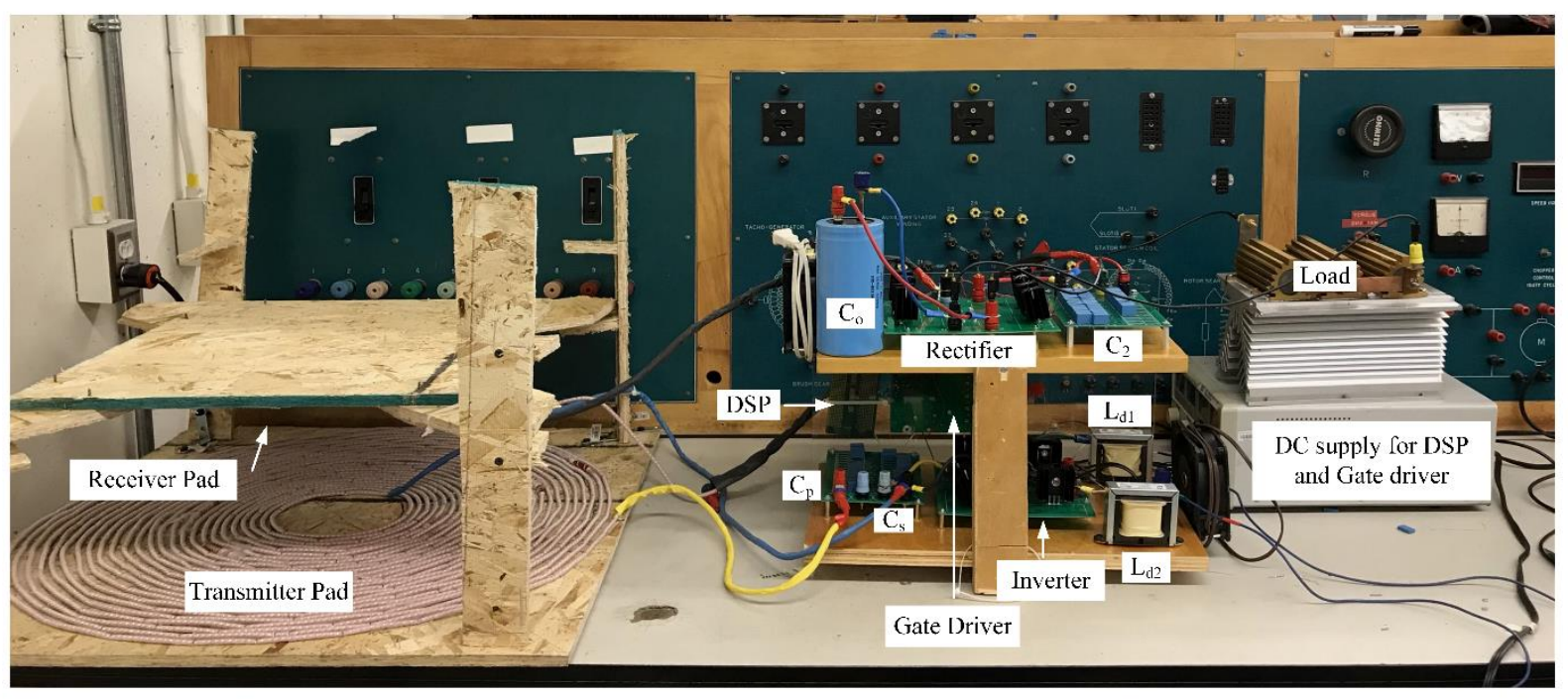

Figure 3.19. Experimental setup

To verify the simulation results and mathematical analysis, a scale down lab prototype is developed. Figure 3.19 shows the experimental set-up, where DSP TMS320F28335 is used as digital controller and SKHI 61(R) is used as a gate driver. Selected circuit parameter values for converter are listed in Table 3.2.

Table 3.2. Selected circuit parameter for experimental setup

\begin{tabular}{|l|c|}
\hline Parameters & Selected values \\
\hline Input DC current, is & $3.5 \mathrm{~A}$ \\
\hline DC link inductor, $L_{d l}, L_{d 2}$ & $10 \mathrm{mH}$ \\
\hline TC, RC inductance, $L_{1}, L_{2}$ & $217 \mu \mathrm{H}, 24 \mu \mathrm{H}$ \\
\hline TC resonating capacitors, $C_{p}, C_{s}$ & $100 \mathrm{nF}, 100 \mathrm{nF}$ \\
\hline RC resonating Capacitor, $\mathrm{C}_{2}$ & $410 \mathrm{nF}$ \\
\hline Switching frequency $f_{s}$ & $46.8 \mathrm{kHz}$ \\
\hline Coils turn ratio, $n$ & $3: 1$ \\
\hline Output voltage, $\mathrm{V}_{\mathrm{o}}$ & $20.4 \mathrm{~V}$ \\
\hline Output load, $\mathrm{R}$ & $2.33 \Omega$ \\
\hline
\end{tabular}




\subsubsection{Wireless Pads Implementation}

IPT pads come in a variety of shapes with their own special advantages and disadvantages such as U-cores, E-cores, S-cores, pot-cores and ferrite discs. To improve the magnetic field of pads, ferrite cores are often used although they are bulky, expensive and fragile. The pads on receiver and transmitter side must be compatible with each other. Also they must operate at the same frequency. Furthermore, connections and power rating of two pads must be compatible. The maximum efficiency can be reached is determined by the Figure Of Merit (FOM) which is formulated as:

$$
F O M=k Q
$$

where, $k$ is coupling coefficient and $Q$ represents the quality factor. Since FOM is specified by $k$ and $Q$, it limits the maximum efficiency:

$$
\eta_{\max }=1-2 k Q
$$

By increasing $\mathrm{k}$ and $\mathrm{Q}$, maximum efficiency can be achieved. However, $\mathrm{k}$ is limited due to the distance between receiver and transmitter coils. On the other hand, designing the high value of factor $\mathrm{Q}$ is considerably important to improve efficiency. Higher switching frequency will directly increase the value of $\mathrm{Q}$, but this will be at the expense of higher switching losses. Additionally, to achieve high $\mathrm{Q}$ increasing the inductances can cause efficiency reduction, since the resistance of coil will be increased depending on the inductance. A 2D Finite Element Analysis (FEA) can be used to calculate self and mutual inductance between primary and secondary pads, ohmic loss in coils, core loss in ferrites, stray loss in aluminum shield and electromagnetic field emission of the system. Detail design and performances are reported in [52].

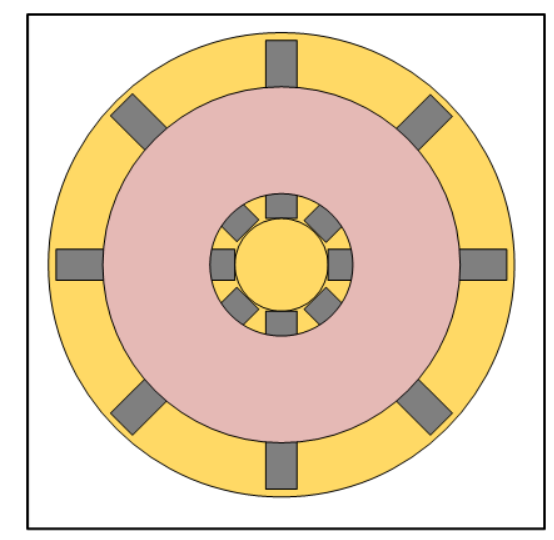

Figure 3.20. Structure of a circular power pad

Skin effect is one of the main issues occurring in conductors carrying alternating current. As a copper wire caries an AC current, the magnetic field produced by this current leads to the 
generation of opposing eddy current. These eddy currents, in turn, cause the main AC current to form in greater densities along the surface of the conductor. Skin depth, the depth from the outer diameter of the wire through which the current flows, decreases with frequency. By using a number of wires within a single cable as Litz wires are made the skin effect is minimizes by ensuring that the AC current is carried more evenly throughout the wire. Smaller-diameter copper wires are used so that the radius of each individual strand is smaller than their skin depth, so the higher the frequency, the smaller the individual conductor. Wireless pads inductance value is designed using Harold A. Wheeler approximation mentioned in section 3.2.1. Figure 3.20 shows the structure of a circular power pad.

\subsubsection{Steady State Waveforms of Experimental Setup}

It should be noticed that the scale down lab prototype operates at the same operating frequency as simulation. The digital controller, DSP TMS320F28335, is programmed by PSIM software using SimCoder, F2833x Target library. Figure 3.21 shows the experimental results of gating signals for inverter switches $\left(\mathrm{S}_{1}, \mathrm{~S}_{2}\right)$. The gating signals have slightly overlap as mentioned in Figure 3.21.

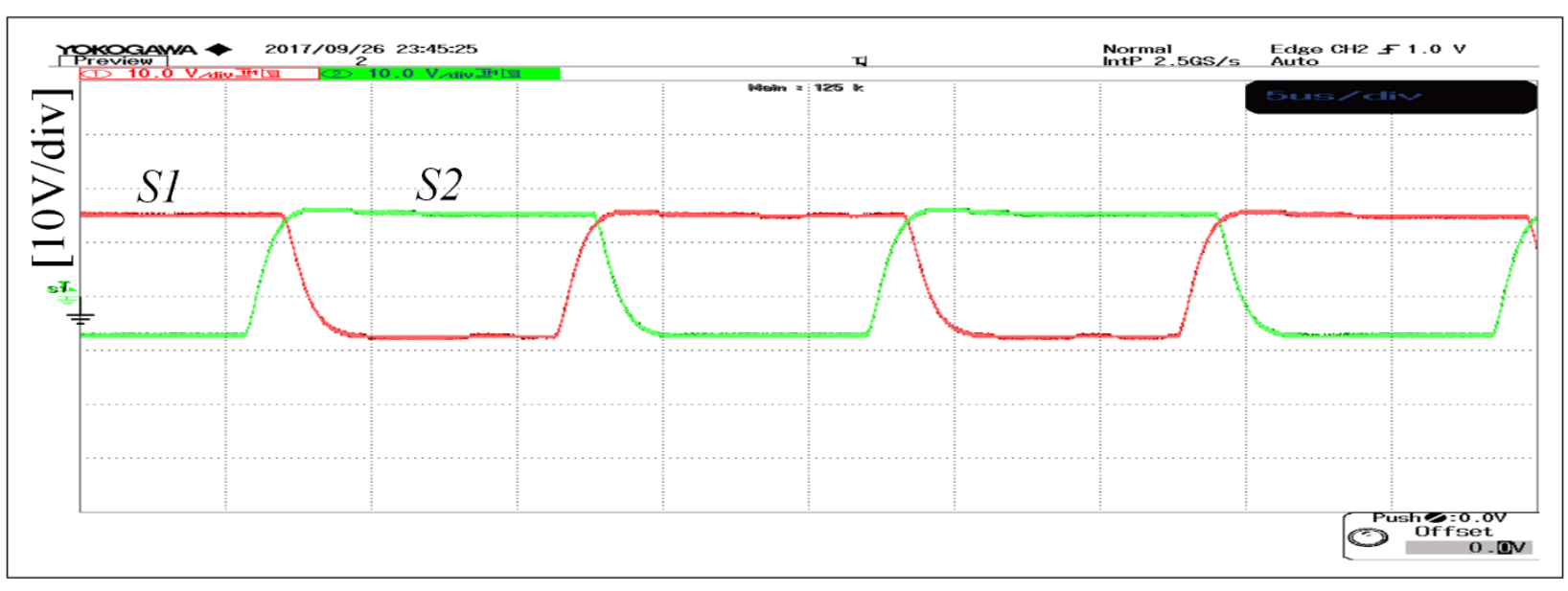

Figure 3.21. Experimental results: gating signals for inverter switches S1 and S2

Figure 3.22 represents experimental results of AC current and voltage at the output of current-fed half-bridge inverter which the inverter output voltage, $\mathrm{V}_{\mathrm{i}}$, lags the output current, $\mathrm{I}_{\mathrm{i}}$, when converter operates in rectifier mode. 


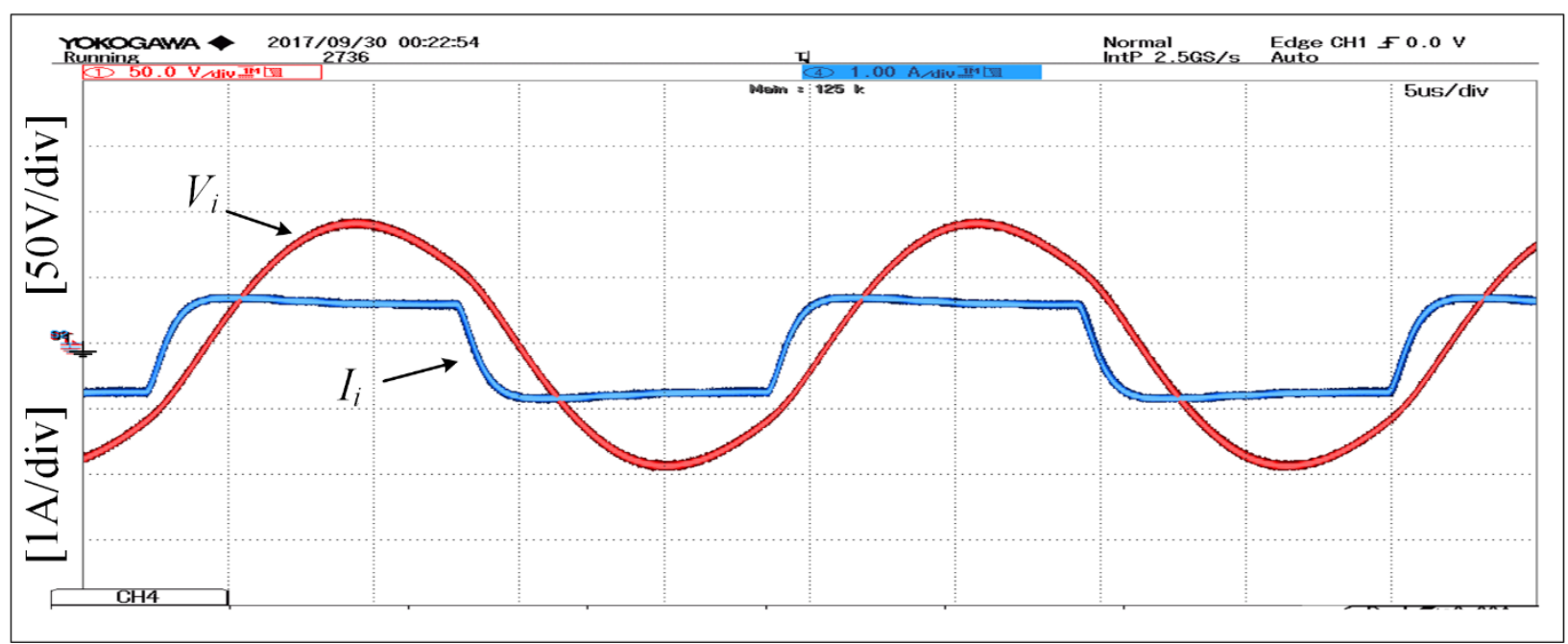

Figure 3.22. Experimental results: inverter output current and voltage at $\mathrm{R}_{0}=2.33$

Figure 3.23 shows experimental results of voltages across transmitter and receiver coils when the output power is $178 \mathrm{~W}$. Also, wireless pads are built to operate as a transformer, for required application with turn's ratio of 1: 0.33 . The peak to peak value of voltages across transmitter coil and receiver are $820 \mathrm{~V}$ and $285 \mathrm{~V}$, respectively, which confirms that the wireless pad operates as a stepdown transformer with the turn's ratio of 1: 0.34 .

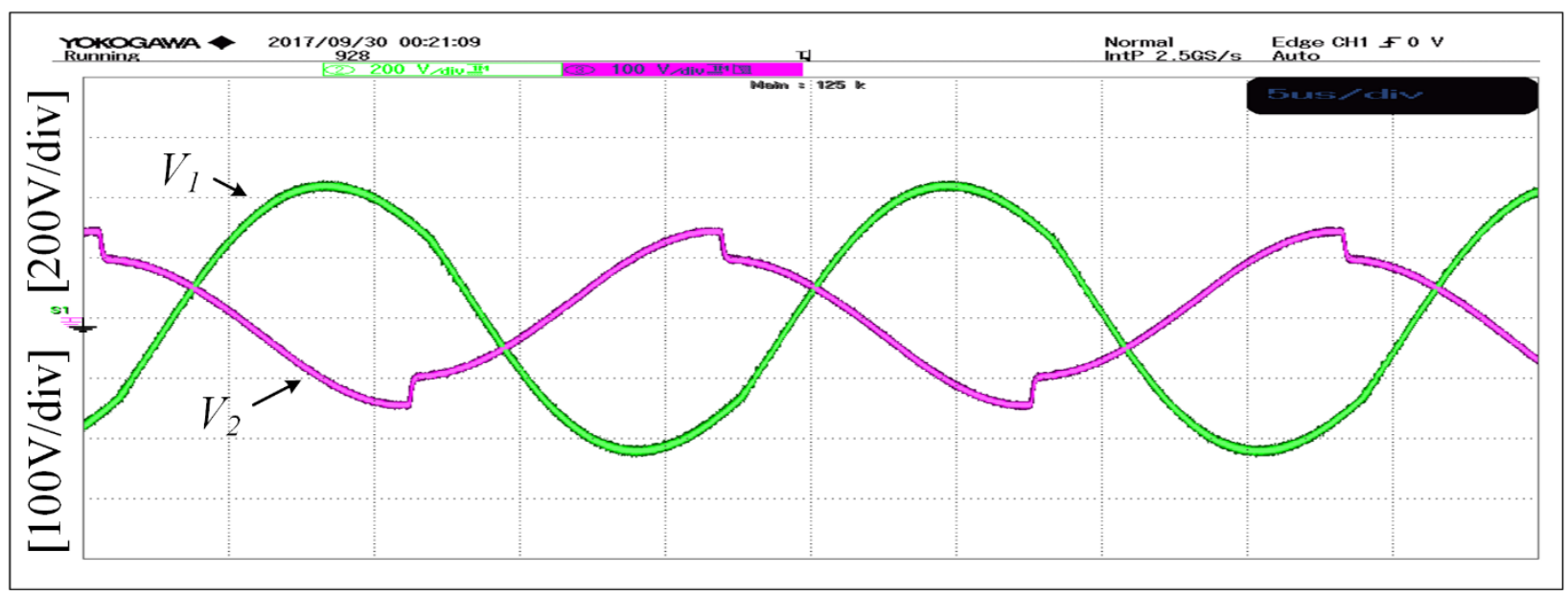

Figure 3.23. Experimental results: voltages across the transmitter coil and receiver coil

Figure 3.24 shows the experimental results of voltage and current at the input of diode single phase rectifier. It is clear that $V_{r}$ leads $I_{2}$ and the output load provides inductive reactance for the IPT system. 


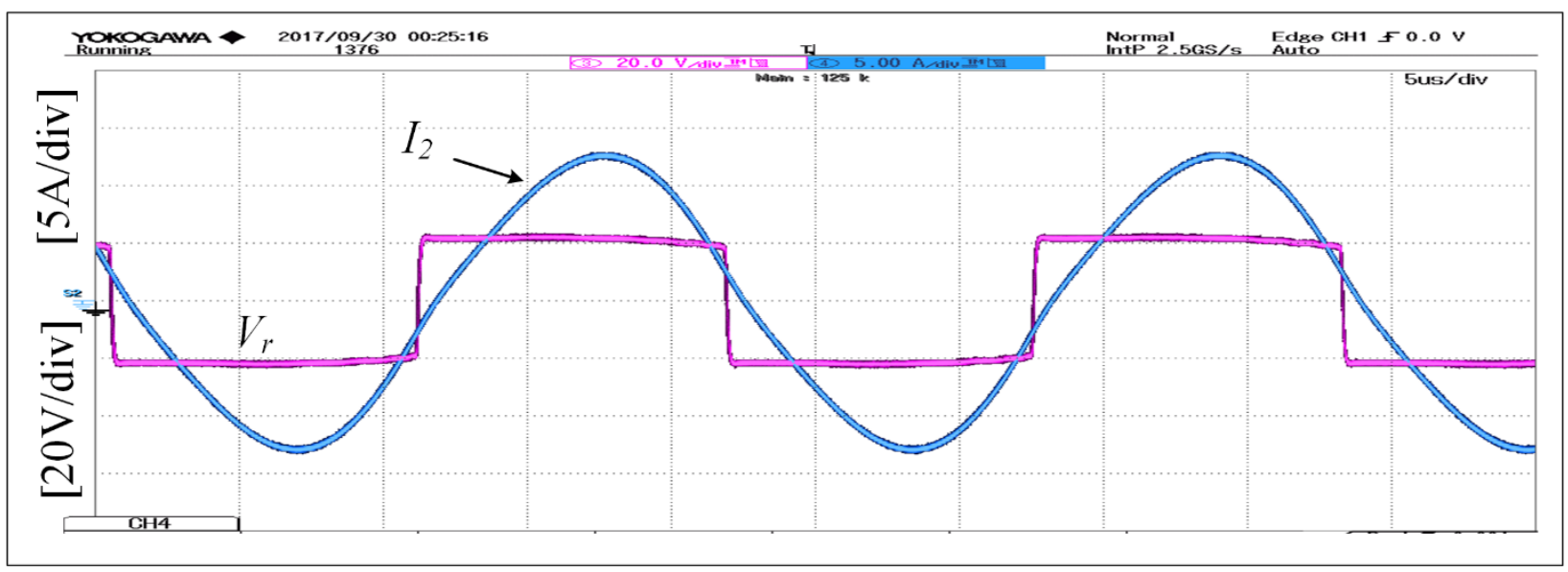

Figure 3.24. Experimental results: rectifier input current and voltage

Figure 3.25 shows the DC current and the voltage at the output side of passive single phase rectifier where a resistive load of $2.33 \Omega$ and a filter capacitor of $100 \mu \mathrm{F}$ have been connected in parallel with the rectifier output. The voltage and current are $24 \mathrm{~V}$ and $8.7 \mathrm{~A}$, respectively.

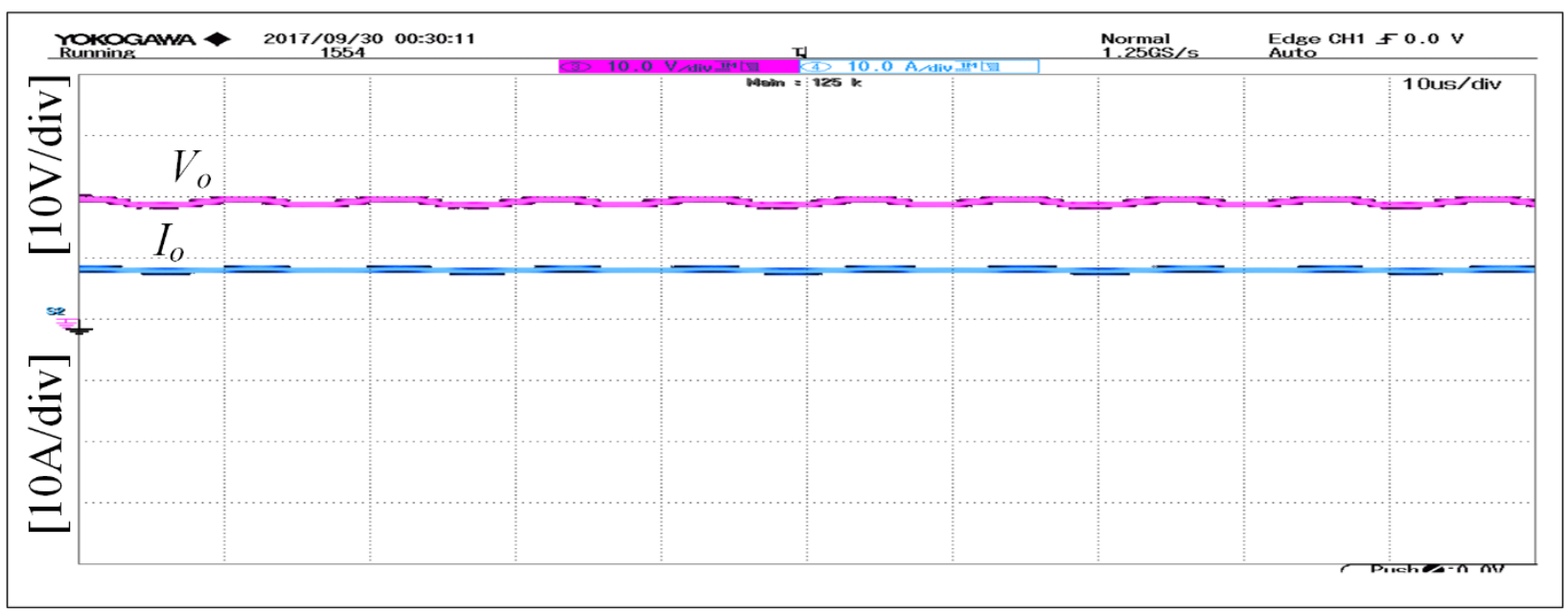

Figure 3.25. Experimental results: steady state waveforms of load current and voltage

\subsection{Concluding Remarks}

In this chapter, the basics of wireless charging theory has been briefly discussed in two main parts, wireless pads power transform and compensation networks topology. Following by section 3.2, a wireless power transfer topology with passive rectification is introduced and analyzed in details in section 3.3. In order to analyze the steady state operation of the WPT system, a time interval analysis is performed in section 3.3.1 and followed by the AC equivalent circuit analysis to design components values for the mentioned topology.

Operating frequency, rating values, selected values of different components and simulation results of the steady state waveforms of the wireless power transfer topology using a full-bridge 
passive rectifier is given in section 3.3.2. Finally, to confirm the simulation results and mathematical analysis, a scale down lab prototype is implemented and the results are presented in 3.3.3. In the following chapter, a new topology of wireless charger using active rectification for electrical vehicles is proposed and compared with the mentioned topology in chapter 3. 


\section{Chapter 4}

\section{WIRELESS POWER TRANSFER USING AN ACTIVE SINGLE PHASE RECTIFIER}

\subsection{Introduction}

In this chapter a new WPT topology with an Active Single Phase Rectifier (ASPR) has been proposed in section 4.2, where the steady state operation analysis and AC circuit analysis are also given. Furthermore, since the rectification process of the converter is done by an active single phase rectifier, the equivalent impedance at the input of the rectifier is calculated and analyzed in details in 4.2.3.

In order to get the confirmation for analysis and performance of the proposed converter, the circuit shown in Figure 4.1 is simulated in Matlab Simulink and the steady state results are given in 4.3. The operating frequency for simulation is calculated as $46.8 \mathrm{kHz}$ and applied to the experimental setup as well. A scale down lab prototype is used to verify the simulation results and the mathematical analysis of the converter and the steady state waveforms are given in section 4.4.

Section 4.5 discusses the efficiency analysis of wireless converters in general and the advantages of using an active rectifiers over a passive rectifiers regarding to overall efficiency. Furthermore, the conduction losses of MOSFETs and diodes are analyzed and a compared to each other to confirm the main motivation of replacing a single phase passive rectifier with an active single phase rectifier and the results are given in Table 4.1.

\subsection{Proposed Wireless IPT Topology with an Active Single Phase Rectifier}

The schematic of the WPT system with an active single phase rectifier (ASPR) is shown in Figure 4.1. The transmitter (TC) side converter is current-fed half bridge topology and a single phase active rectifier is used to the receiver (RC) side. To make this topology suitable for higher power applications, a series-parallel compensation topology is selected compare with conventional parallel compensation. A capacitor is connected in series with the transmitter coil to reduce the impedance of TC due to high leakage, decreased to $\left[\omega L_{1}-1 /\left(\omega C_{s}\right)\right]$, where $\mathrm{L}_{1}$ represents the transmitter coil impedance. Another capacitor, $\mathrm{Cp}$ is connected in parallel with $\mathrm{TC}$ and series capacitor. $\mathrm{C}_{\mathrm{s}}$, to deliver the remaining reactive power consumed by TC. In the 
receiver side capacitor, $\mathrm{C}_{2}$ is connected in series with the receiver coil to compensate the reactive power consumed by the receiver coil.

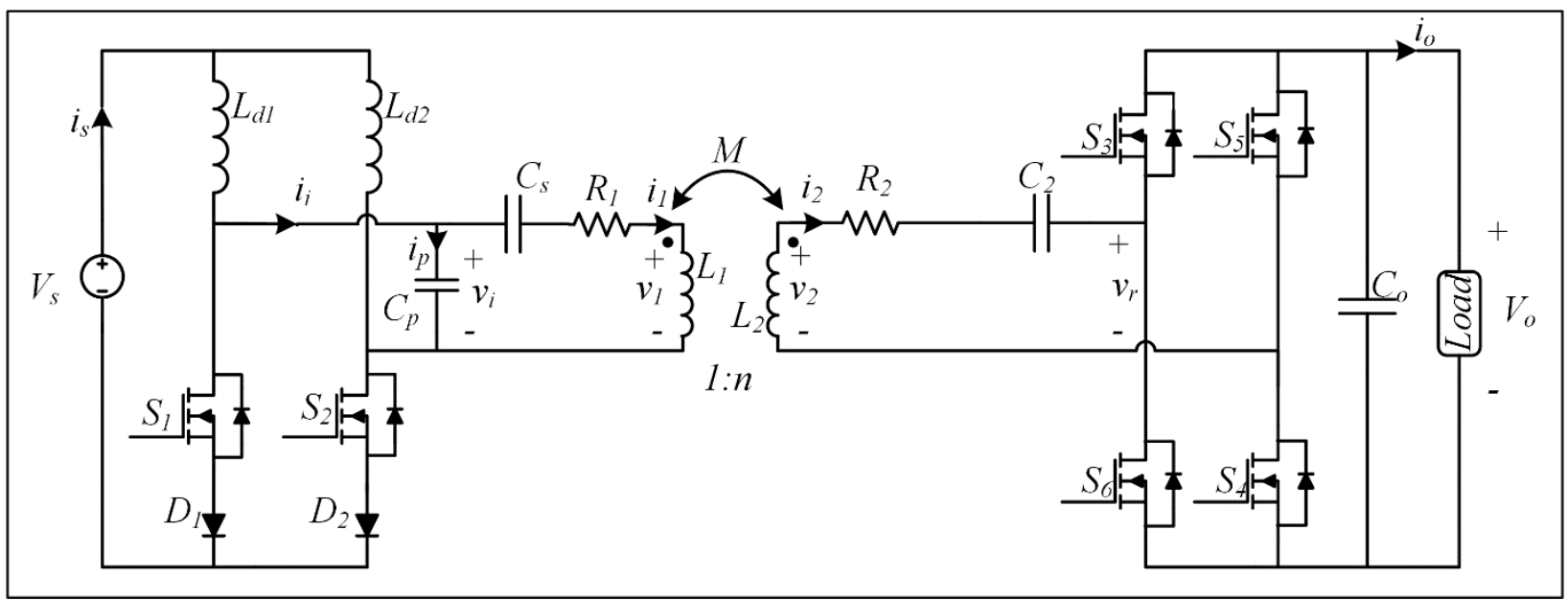

Figure 4.1. Wireless power transfer topology using active Rectifier

\subsubsection{Steady State Operation}

Figure 4.2 shows steady state waveforms of voltages and currents of different components for one switching cycle. To explain the steady state analysis of the proposed converter, consider the inverter leg switches are conducting at fixed duty cycle of 0.5 and their gating signals are complimentary. To maintain a continuous DC link current $i_{s}$, a slight overlap is applied to $S_{1}$ and $S_{2}$. This small overlap is considered in steady state operation analysis. Also, to achieve Zero Voltage Switching (ZVS), the operating power factor at the output of the half bridge current fed inverter is considered to be lagging.

\section{Interval $1\left[\mathbf{t}_{0}-\mathbf{t}_{1}-\mathbf{t}_{2}\right]$ :}

Consider at $t_{0}$ instant switch $S_{1}$ is on and switch $S_{2}$ is off. During $t_{0}-t_{1}-t_{2}$, the complete DC link current passes through $S_{1}$, while at the same time period the voltage across $\left(S_{2}-D_{2}\right)$ is equal to $v_{i} . \mathrm{S}_{2}$ blocks this positive voltage. On the ASPR side during $t_{0}-t_{1}$ period, the rectifier input current, $i_{2}$ is positive. By turning $\mathrm{S}_{3}$ and $\mathrm{S}_{4}$ on, the power is delivered to the load as it is shown in Figure 4.3. At instant $t_{1}$, since current $i_{2}$ enters the negative cycle; therefore, $\mathrm{S}_{3}\left(\mathrm{~S}_{4}\right)$ are turned off and $\mathrm{S}_{5}\left(\mathrm{~S}_{6}\right)$ conducts for half a period. The Equivalent circuits of ASPR is shown in Figure 4.3 for the time intervals $t_{0}$ to $t_{1}$ and $t_{1}$ to $t_{4}$ respectively.

\section{Interval $2\left[\mathbf{t}_{2}-\mathbf{t}_{3}-\mathbf{t}_{4}\right]$ :}

At instant $t_{2}$, although device $S_{2}$ is triggered, but the first leg of inverter $\left(S_{1}-D_{1}\right)$ keeps conducting since, the voltage across the leg $\left(\mathrm{S}_{2}-\mathrm{D}_{2}\right)$ is negative. By turning off $\mathrm{S}_{1}$ at instant $t_{3}$, the total DC link current is transferred to $\left(S_{2}-D_{2}\right)$. At the same instant, $S_{1}$ blocks the positive 
voltage appears across $\left(S_{1}-D_{1}\right)$. Also during this time interval, $S_{3}\left(S_{4}\right)$ are turned off and $S_{5}\left(S_{6}\right)$ conducts till $t_{4}$.

\section{Interval 3 [t $\left.\mathbf{t}_{\mathbf{4}}-\mathbf{t}_{5}-\mathbf{t}_{6}\right]$ :}

At instant $t_{4}$, the rectifier input current crosses zero and enter the positive cycle again. At the same time by sensing the zero crossing of receiver coil current, $\mathrm{S}_{3}\left(\mathrm{~S}_{4}\right)$ starts conducting.

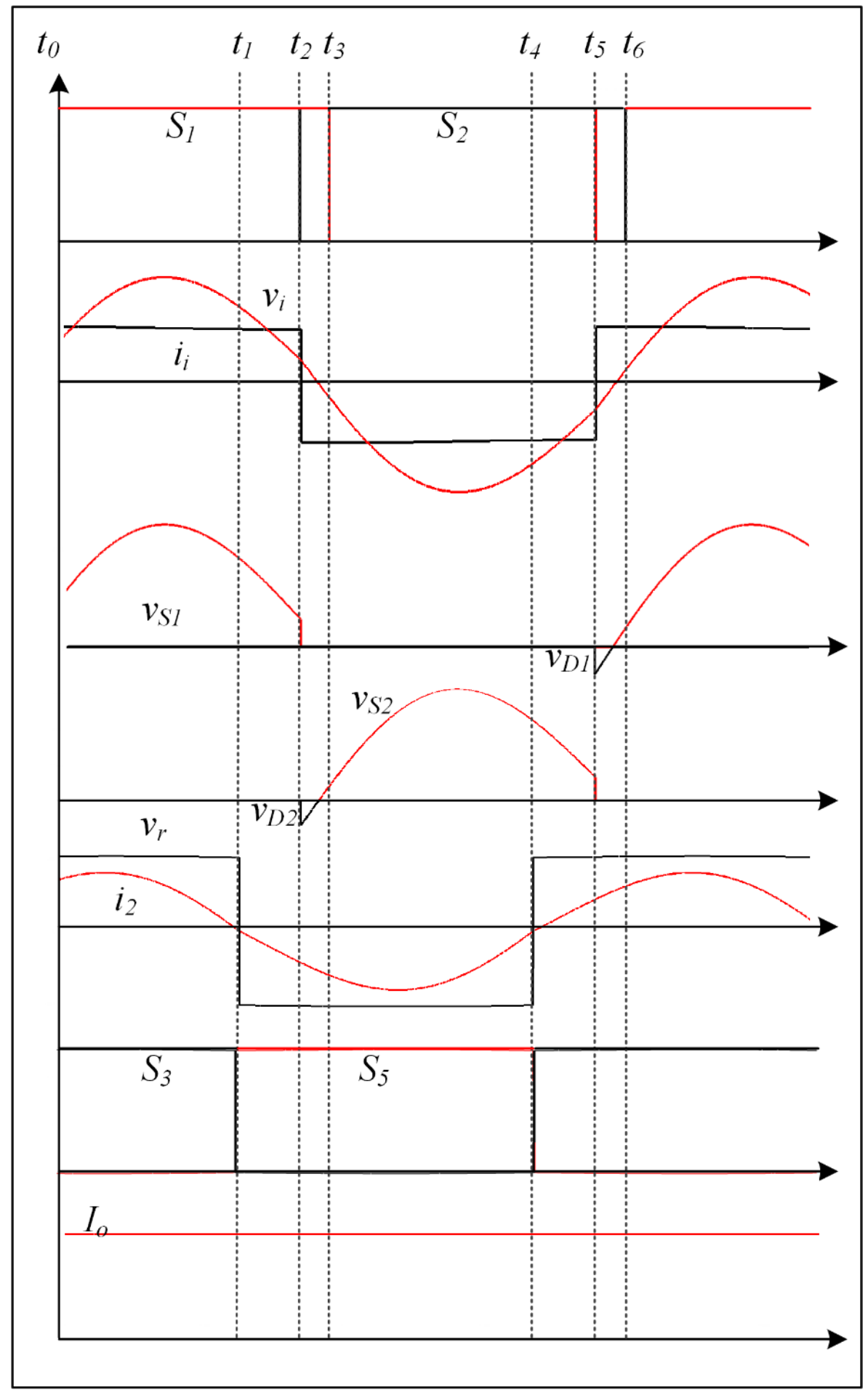

Figure 4.2. Steady state voltage and current waveforms of different components 


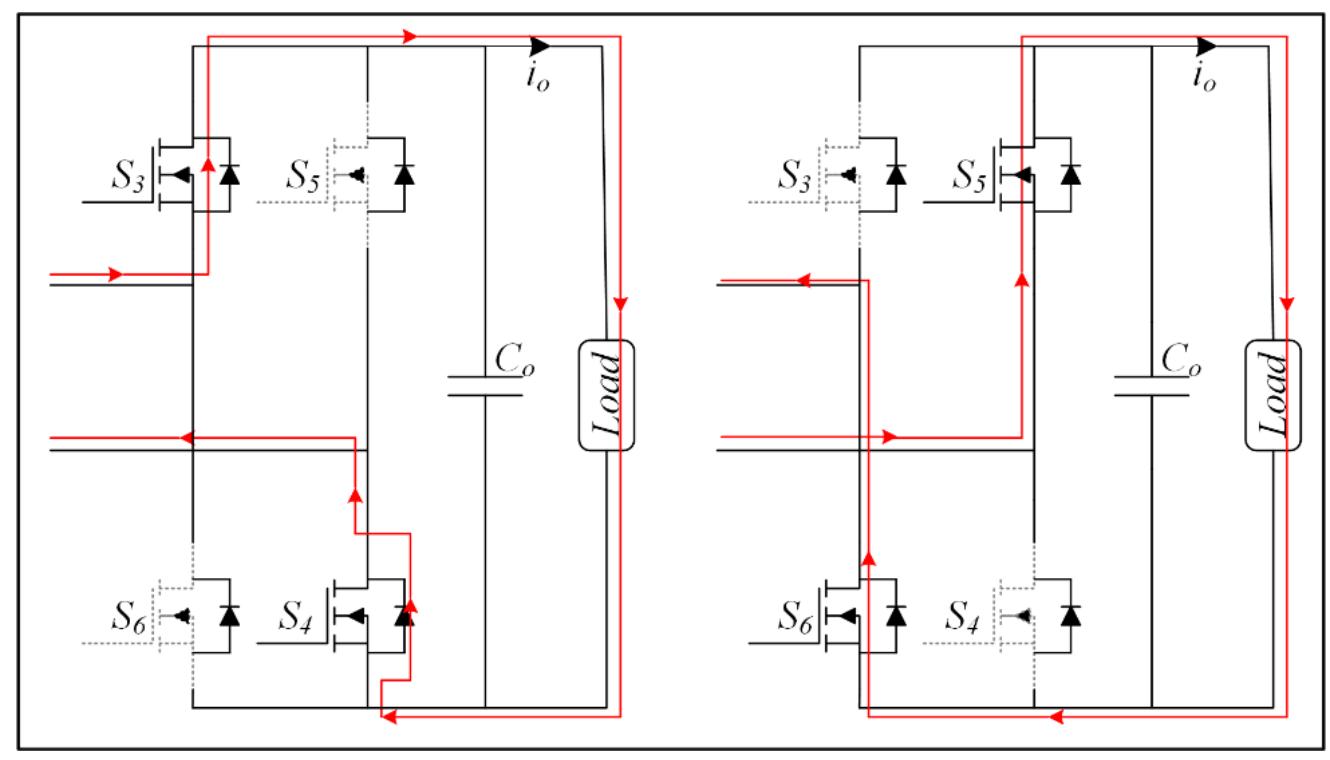

Figure 4.3. Equivalent circuit of ASPR during subintervals of a switching cycle

\subsubsection{AC Circuit Analysis}

Since the inverter leg switches are conducting at fixed duty cycle of 0.5 and their gating signals are complimentary the AC circuit analysis would be the same as WPT system with passive rectifier given in 3.3.1.2. To enhance the performance of WPT converter and to improve the overall efficiency an active single phase rectifier is adopted as a rectifier on the receiver side. By modifying the pulse width $\beta$ of the ASPR and phase shift $\varphi$ between the first harmonic of the receiver current and the input voltage of ASPR, the overall impedance of load is fully controlled. Figure 4.4 represents the operating waveform of the receiver's current and the ASPR's voltage to give an idea for ASPR's behavior with the three following assumptions:

- Taking receiver's current as reference

- All the semi-conductors are ideal without any parasitic resistance and capacitor

- The voltage of the dc load bus remains constant

Each of these three behaviors can be achieved by using unipolar switching that $S_{3}$ and $S_{6}$ $\left(\mathrm{S}_{4}\right.$ and $\left.\mathrm{S}_{5}\right)$ must operate complimentary. 


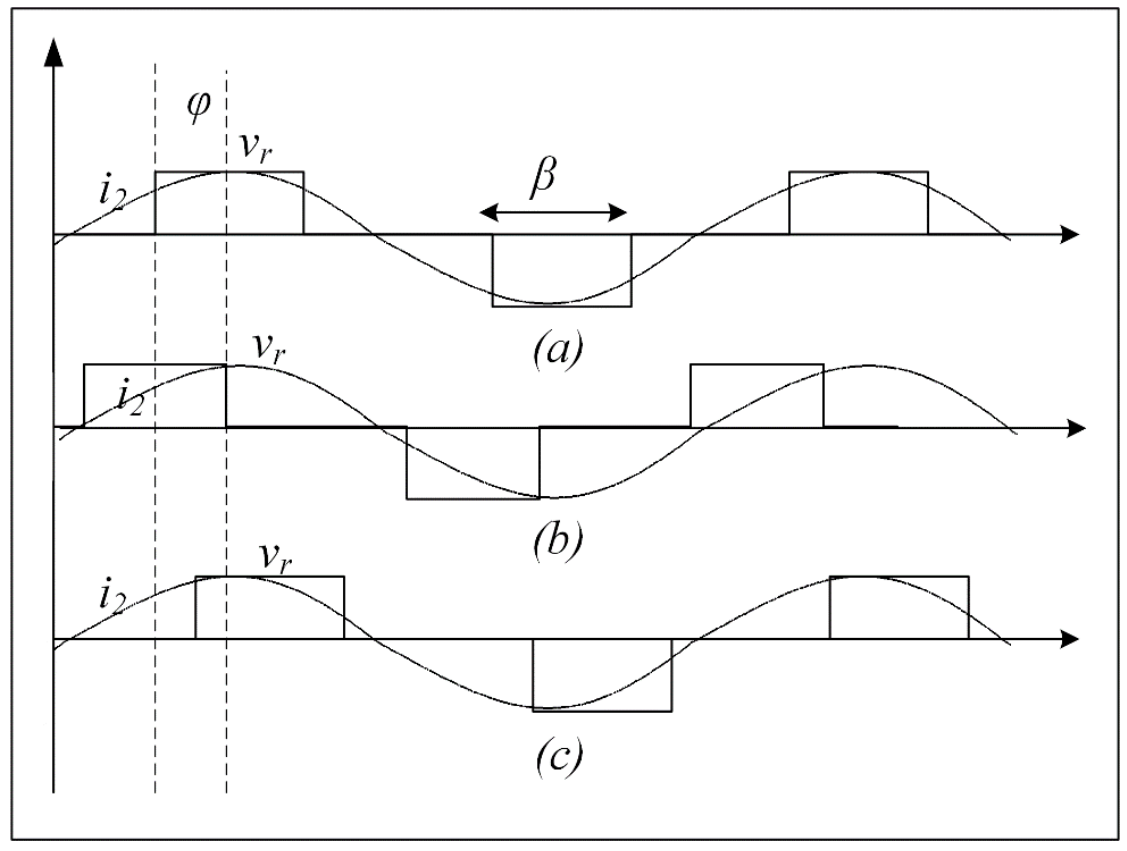

Figure 4.4. Operating waveforms of receiver current and the input voltage of ASPR. (a) Resistive mode (b) Inductive mode (c) Capacitive mode.

\subsubsection{Equivalent Impedance Calculation}

According to Figure 4.4, the phase shift, $\varphi$, represents the phase difference between the first harmonic components of $V_{r}$ and $I_{2} . \varphi$ is assumed to be positive when $V_{r}$, leads $I_{2}$ and the equivalent load at the receiver side is inductive for the WPT system. Otherwise if $\varphi$ is equal to zero it provides pure resistive impedance and when $\varphi$ has a negative value the equivalent load is capacitive. The pulse width $\beta$, shown in Figure 4.4, and the output voltage shown in Figure 4. 1 determine the magnitude of the first harmonic components of $\mathrm{V}_{\mathrm{r}}$. Thus, the input voltage of the ASPR is derived by:

$$
V_{r}=\frac{2 \sqrt{2}}{\pi} V_{o} \sin \left(\frac{\beta}{2}\right) e^{j \varphi}
$$

The DC output current, $\mathrm{I}_{\mathrm{o}}$, is filtered by the output capacitor, $\mathrm{C}_{\mathrm{o}}$, and can be calculated using the output current of ASPR as:

$$
I_{o}=\frac{1}{\pi} \int_{-\varphi+\frac{\pi}{2}-\frac{\beta}{2}}^{-\varphi+\frac{\pi}{2}+\frac{\beta}{2}} \sqrt{2} I_{S} \sin (\omega t) d \omega t=\frac{2 \sqrt{2}}{\pi} I_{S} \sin \left(\frac{\beta}{2}\right) \cos \varphi
$$

The equivalent impedance of ASPR respecting to the output load at the receiver side can be calculated by the ratio of $\mathrm{V}_{\mathrm{r}}$, and $\mathrm{I}_{2}$ : 
$Z_{L}=\frac{V_{r}}{I_{2}}=R_{L}+j X_{L}$

Where $\mathrm{R}_{\mathrm{L}}$ and $\mathrm{X}_{\mathrm{L}}$ are the equivalent resistance and reactance of the ASPR, respectively:

$$
\begin{aligned}
& R_{L}=\frac{8}{\pi^{2}} R_{o} \sin ^{2}\left(\frac{\beta}{2}\right) \cos ^{2}(\varphi) \\
& X_{L}=\frac{8}{\pi^{2}} R_{o} \sin ^{2}\left(\frac{\beta}{2}\right) \cos \varphi \sin \varphi
\end{aligned}
$$

Figure 4.5 and Figure 4.6 represent the regulation ranges of $R_{L}$ and $X_{L}$ against $\beta$ and $\varphi$, with the assumption of $R_{0}$ is equal to $2 \Omega$, respectively. From Figure 4.5 it is observed that the equivalent resistance of ASPR, $R_{L}$, become smaller as the pulse width $\beta$ is decreased. Also, when $\varphi>0, R_{\mathrm{L}}$ decreases with the increasing of phase shift, $\varphi$, and when $\varphi<0$, by reducing $\varphi$ from zero to $-90, \mathrm{R}_{\mathrm{L}}$ decreases too. Equivalent resistance of ASPR, $\mathrm{R}_{\mathrm{L}}$, reaches its maximum when the pulse width of $\mathrm{V}_{\mathrm{r}}$ is maximum at $180^{\circ}$ and the phase shift between the input voltage of ASPR, $\mathrm{V}_{2}$, and the current at the secondary side of WPT system, $\mathrm{I}_{2}$, is equal to zero. Hence by replacing $\beta=180^{\circ}$ and $\varphi=0$ in equation (4.4), it is clear that the maximum value of $R_{L}$ is equal to $\frac{8}{\pi^{2}} R_{0}$.

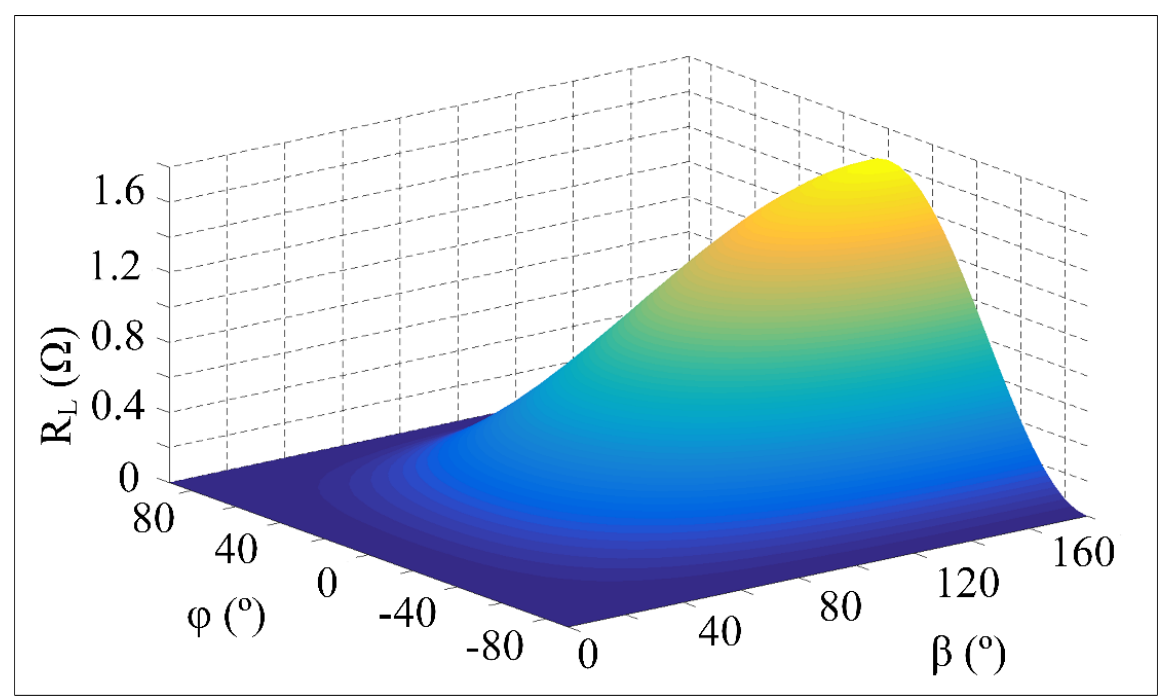

Figure 4.5. The regulation ranges of $\mathrm{R}_{\mathrm{L}}$ against $\beta$ and $\varphi$

From Figure 4.6 it is clear that by increasing $\beta$ from zero to $180^{\circ}$, the absolute value of the equivalent reactance of ASPR, $X_{L}$, is increased. Furthermore, when $\varphi>0$, the absolute value of $\mathrm{X}_{\mathrm{L}}$ increase with $\varphi$ ranging from 0 to $45^{\circ}$ and decreases with $\varphi$ ranging from $45^{\circ}$ to $90^{\circ}$. On the other hand, when $\varphi<0$, and it is changing from 0 to $-45^{\circ}$, the inductive reactance of ASPR expands to its maximum value at $-45^{\circ}$. Moreover, $\mathrm{X}_{\mathrm{L}}$ is being reduced from its maximum value to 0 with $\varphi$ changing from $-45^{\circ}$ to $-90^{\circ}$. From Figure 4.6 and using equation (4.5), it can be seen 
that on the inductive side $\left(-90^{\circ}<\varphi<0\right), \mathrm{X}_{\mathrm{L}}$ reaches to its maximum at $4 R_{o} / \pi^{2}$ when, $\beta=180^{\circ}$ and $\varphi=-45^{\circ}$. Finally, on the capacitive side $(0<\varphi<90)$, the capacitive reactance of ASPR reaches to its minimum value at $-4 R_{o} / \pi^{2}$ when $\beta=180^{\circ}$ and $\varphi=45^{\circ}$. However, while the ASPR provides the maximum inductive or capacitive reactance the maximum value of ASPR resistance, $\mathrm{R}_{\mathrm{L}}$, can only go up to $4 R_{o} / \pi^{2}$.

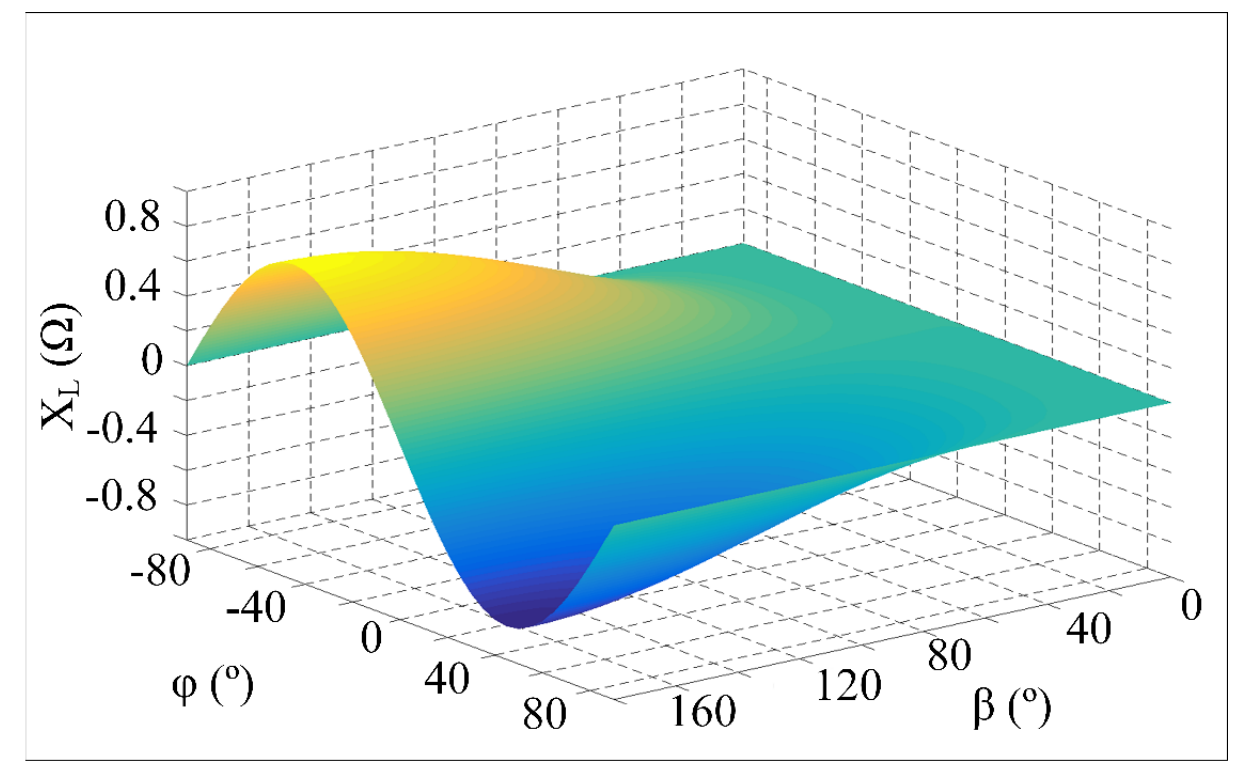

Figure 4.6. The regulation ranges of $X_{L}$ against $\beta$ and $\varphi$

The main concern of this research is to improve the overall efficiency of the WPT system topology shown in Figure 3.5, where a full bridge diode rectifier is used to rectify the voltage and current of receiver side. By replacing the passive rectifier with an active rectifier (Figure 4. 1) the overall efficiency is improved and discussed in details in section 4.5.

ASPR switches operate complementary with duty cycle of 0.5 and by sensing the ASPR input current, $I_{2}$. In order to achieve zero phase shift between the input voltage of ASPR, $V_{r}$, and the current at secondary side of WPT system, $\mathrm{I}_{2}$, the ASPR must provide a pure resistive equivalent load for the receiver side. In this case the pulse width of the input voltage of ASPR, $\beta$, is equal to $180^{\circ}$ and the phase shift between the first harmonic of the receiver's current and the input voltage of $\mathrm{ASPR}, \varphi$, is equal to 0 . Hence the equivalent resistance, $\mathrm{R}_{\mathrm{L}}$, and reactance, $\mathrm{X}_{\mathrm{L}}$, of ASPR respecting to the output load at the receiver side can be calculated by using equations (4.4) and (4.5) as:

$$
R_{L}=\frac{8}{\pi^{2}} R_{o}
$$


$X_{L}=0$

The DC output current, $\mathrm{I}_{\mathrm{o}}$, filtered by the output capacitor, $\mathrm{C}_{\mathrm{o}}$, and the input voltage of ASPR, $\mathrm{V}_{\mathrm{r}}$, can be derived using equations (4.1) and (4.2) by:

$$
\begin{aligned}
& V_{r}=\frac{\dot{2} \sqrt{2}}{\pi} V_{o} \\
& I_{o}=\frac{2 \sqrt{2}}{\pi} I_{S}
\end{aligned}
$$

\subsection{Simulation Results}

To validate the analysis and performance of the proposed wireless power transfer topology using an active single phase rectifier, the circuit shown in Figure 4.1 is simulated in Matlab Simulink. Since, the output load of the converter is considered to be the same as WPT system using a passive rectifier shown in Figure 3.5, and the rectifier legs are operating complementary with the duty cycle of 0.5 , the Impedance and power factor angle at the input of transmitter coil remains the same as the WPT topology mentioned in chapter 3 . Hence the operating frequency can be calculated through Figure 3.8 as $46.8 \mathrm{kHz}$ which the best power factor appears at.

Furthermore, since the main application of both wireless converters mentioned in this chapter and the pervious one is wireless charger for light-load low-voltage the output load remains the same as $\mathrm{V}_{\mathrm{o}} / \mathrm{I}_{0}=2$. Also, the input $\mathrm{DC}$ voltage of the converter is set to $200 \mathrm{~V}$ and the rating values of the output voltage $\mathrm{V}_{\mathrm{o}}$, output current $\mathrm{I}_{\mathrm{o}}$, and output power are $50 \mathrm{~V}, 25 \mathrm{~A}$ and $12.5 \mathrm{~kW}$, respectively. It should be mentioned that all the values for different components used in the simulations of WPT system using an ASPR, as resonating capacitors and coils turn ratio and etc., are already given in Table 3. 1 .

The simulation results of inverter output current and voltage at rated load are presented in Figure 4.7. Similar to WPT converter with passive rectifier, the operating power factor at the output of the half-bridge current-fed inverters designed to be lagging in order to achieve zero voltage switching. 


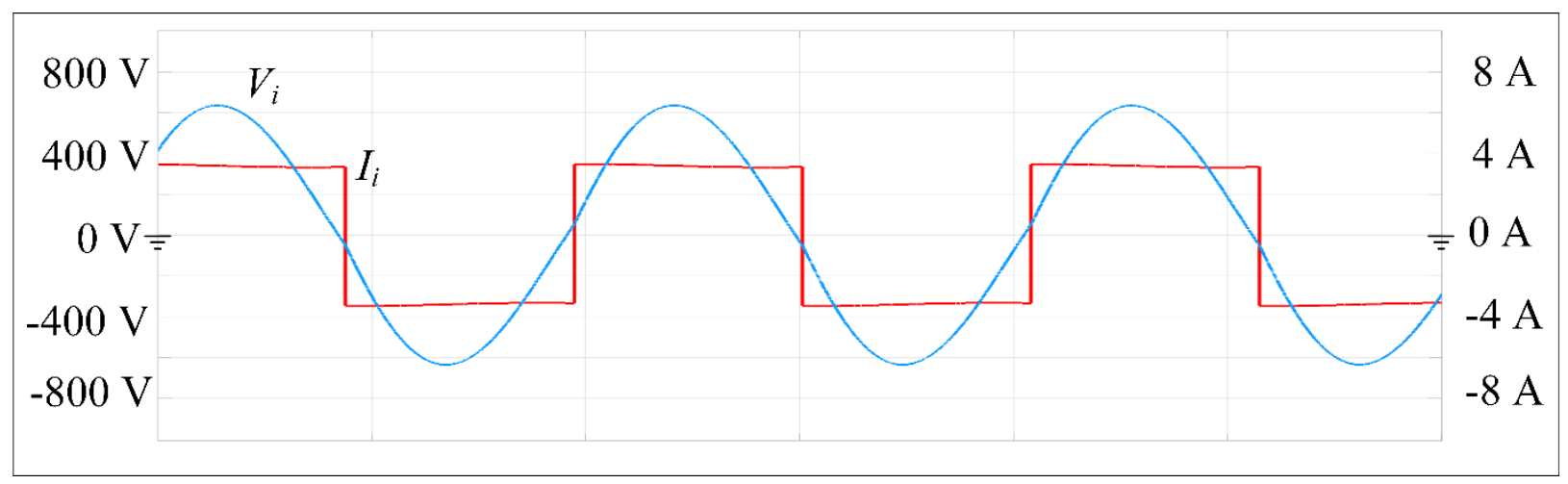

Figure 4.7. Simulation results of inverter output current and voltage at rated load

Voltages across the transmitter and the receiver pads are shown in Figure 4.8. The main application of the wireless power transfer shown in Figure 4.1 is the low-voltage, light-load EV charging. Hence, to achieve higher current at the same power range, the wireless pads are designed to perform as a step down transformer with turn's ratio of 3: 1 from primary side to secondary side. Moreover, as it is mentioned in section 3.3.2, the two steps shown in Figure 4.8 are the effect of adding and subtracting of DC voltage from the output voltage to the receiver pad when the rectifier is changing its legs due to the mode of operation.

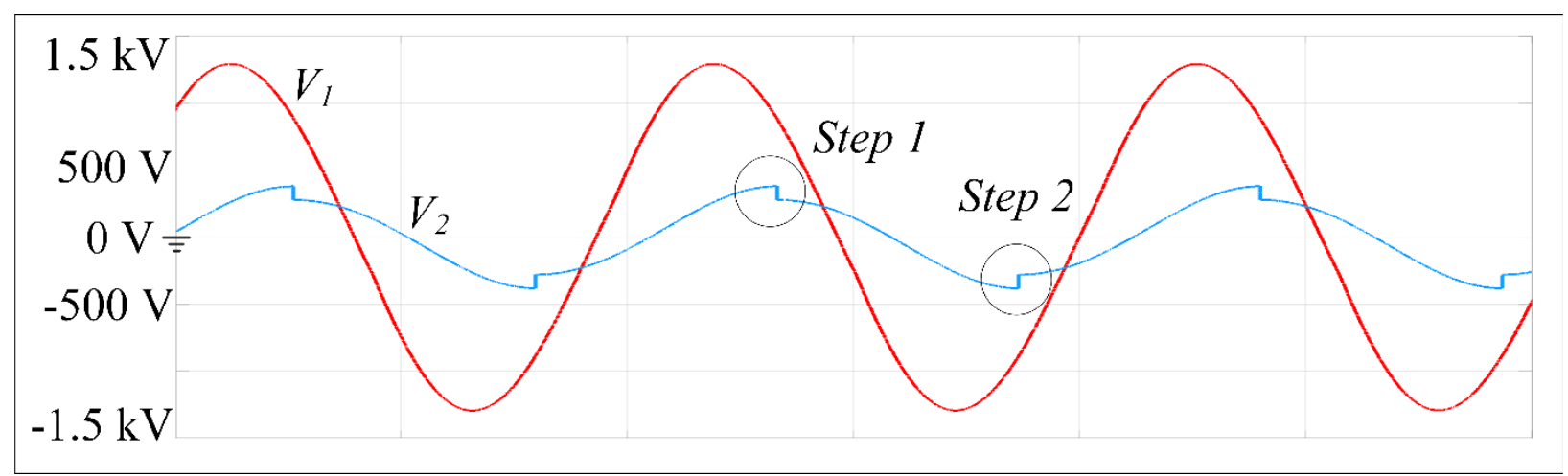

Figure 4.8. Simulation results of voltages across the transmitter coil and receiver coil

Figure 4.9 represents the simulation results of the ASPR input and current when the converter is operating from grid to vehicle. The phase shift between the input voltage of the ASPR, $V_{r}$, and the input current, $I_{2}$ is kept to zero by turning on the first leg of ASPR by sensing the zero crossing of $\mathrm{I}_{2}$. 


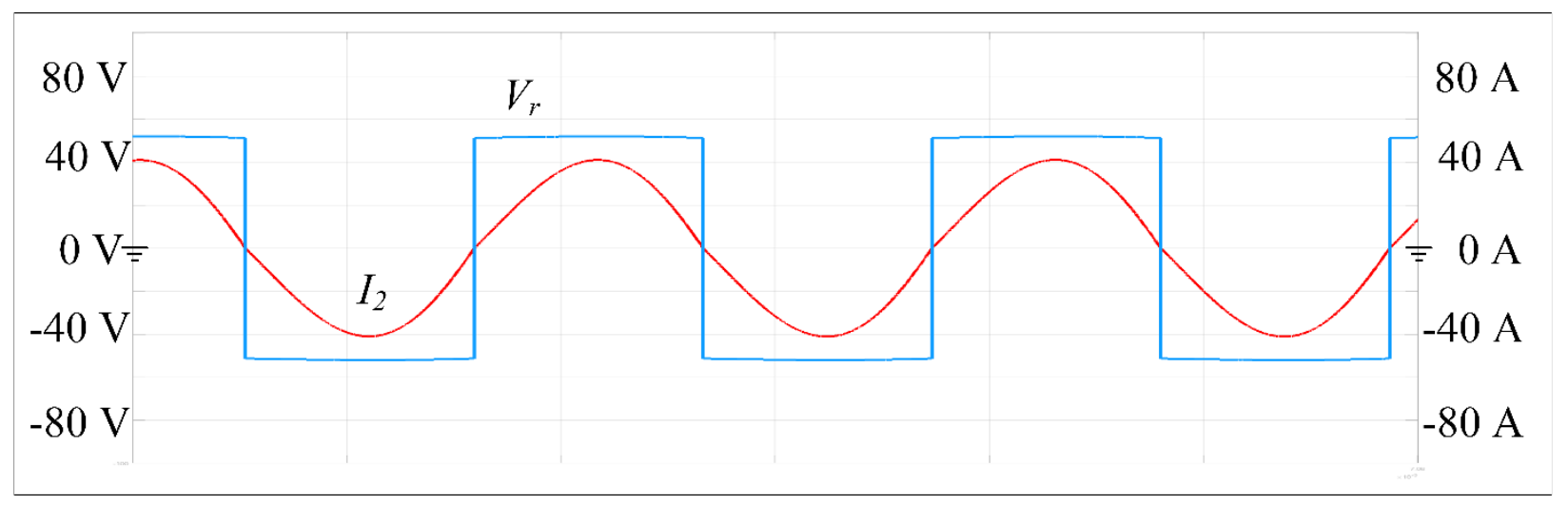

Figure 4.9. Simulation results of rectifier input current and voltage

The simulation results of gating signals with the compensated dead time for the active rectifier switches are given in Figure 4.10.

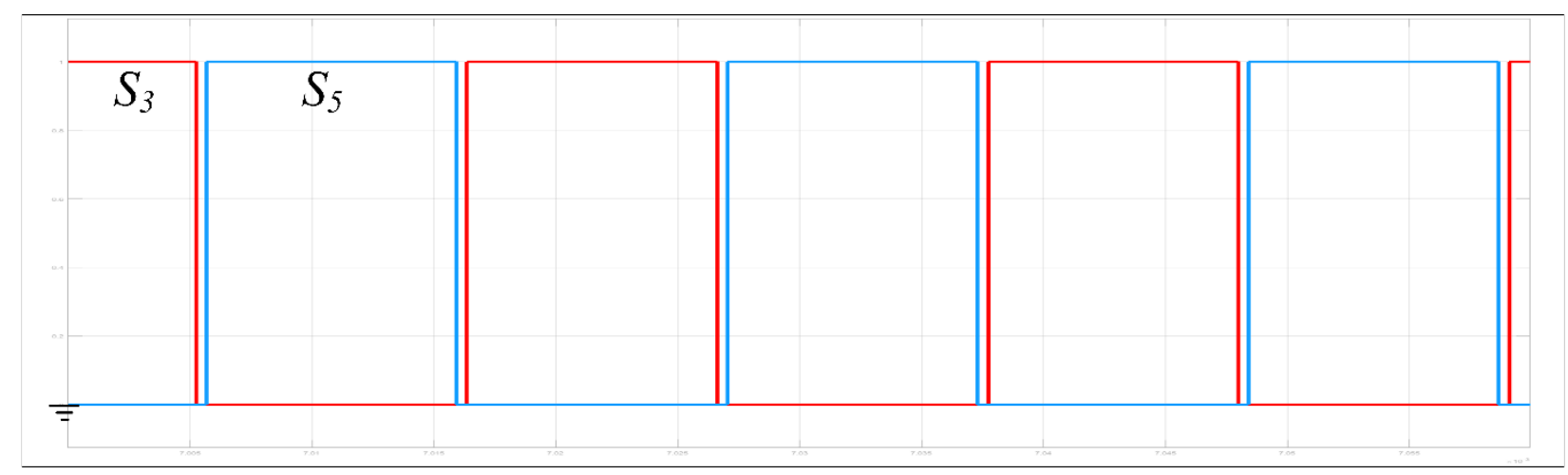

Figure 4.10. Simulation results of gating signal for rectifier switches

Finally, Figure 4.11 shows the output voltage and current of the converter with a $2 \Omega$ resistance as the output load.

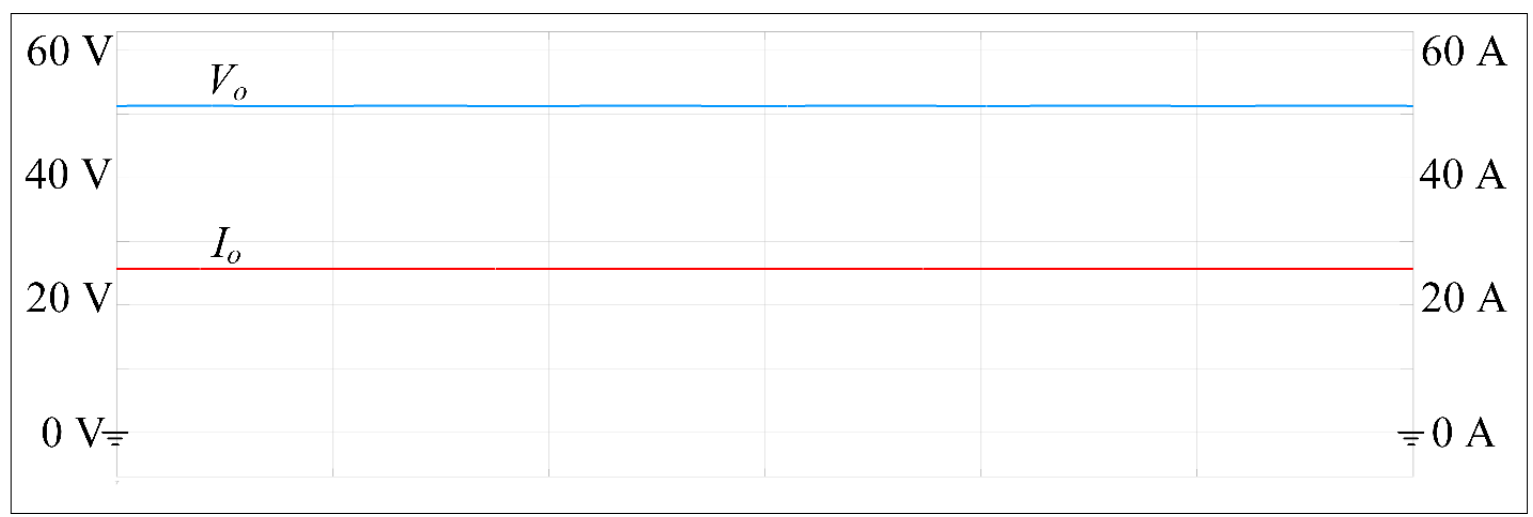

Figure 4.11. Simulation results of steady state waveforms of load current and voltage 


\subsection{Experimental Results}

The scale down lab prototype shown in Figure 3.19, is used to verify the simulation results and validate the mathematical analysis of the proposed wireless power transfer converter, with one major difference; replacing the single phase diode rectifier with an active single phase rectifier. Figure 4.12 shows the experimental board of a full-bridge single phase rectifier where DSP TMS320F28335 and SKHI 61(R) are used as a digital controller and gate driver, respectively, to provide gating signals of the MOSFETs.

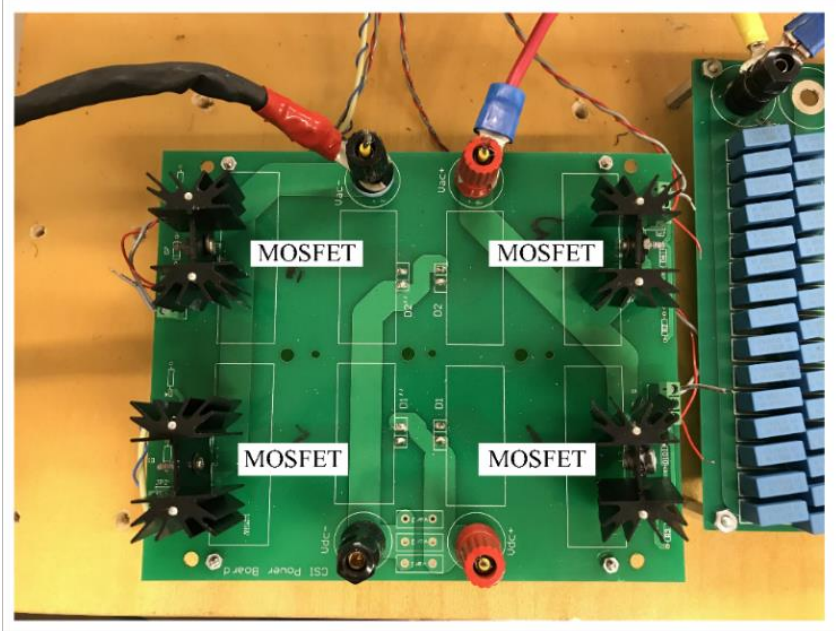

Figure 4.12. Experimental board of a full-bridge active rectifier

The experimental board of a passive full-bridge single-phase rectifier which is replaced by an active rectifier, is shown in Figure 4.13. It can be seen that the output filter capacitor is also placed on the same PCB.

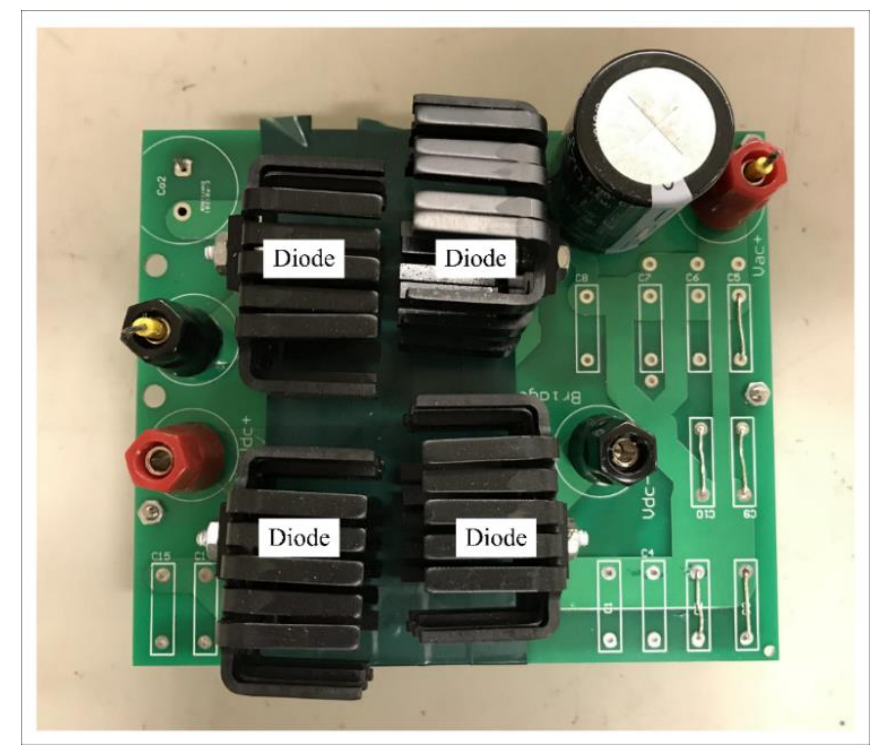

Figure 4.13. Experimental board of a full-bridge passive rectifier 
With exception of the rectifier MOSFETs, all selected circuit parameter values remain the same as converter with diode rectifier, as are described in Table 3.2. Furthermore, the operating frequency for both inverter and rectifier switches, is selected from simulation, $46.8 \mathrm{kHz}$ and the digital controller, DSP TMS320F28335, is programmed by PSIM software using SimCoder, F2833x Target. Since, the operating frequency of both converters is identical, the experimental results of gating signals for inverter switches $\left(S_{1}, S_{2}\right)$ are the same as the WPT converter using diode rectification, presented in Figure 3.21.

The experimental results of AC current and voltage at the output of current-fed half-bridge inverter, is illustrated in Figure 4.14, where the inverter output voltage, $\mathrm{V}_{\mathrm{i}}$, is slightly lagging the output current, $\mathrm{I}_{\mathrm{i}}$.

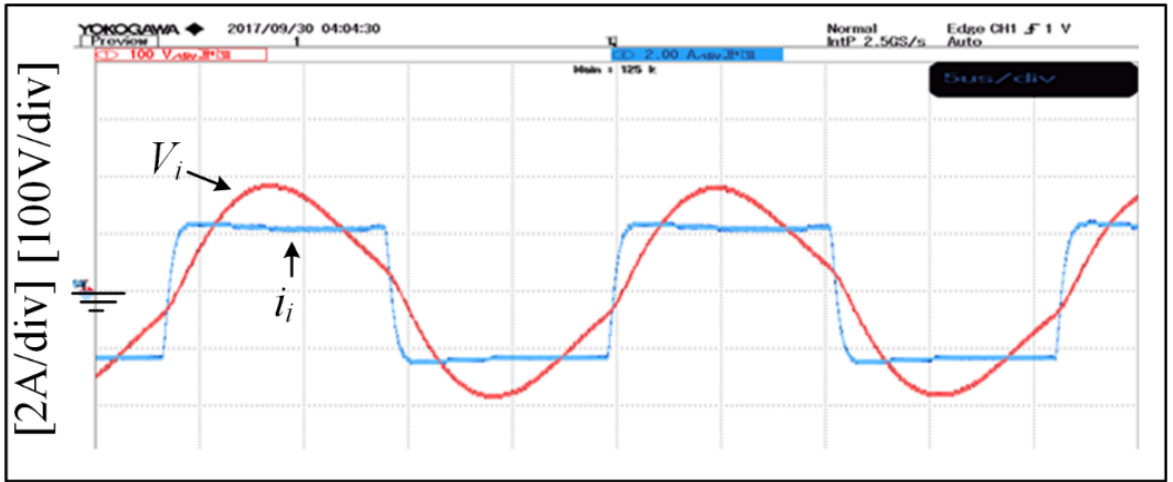

Figure 4.14. Experimental results: inverter output current and voltage at $\mathrm{R}_{0}=2.33$

The experimental results of voltages across the primary and secondary coils are presented in Figure 4.15. Furthermore, the wireless pads are designed to perform as a stepdown transformer with the turns ratio of 1: 0.33 . The peak to peak value of voltages across the transmitter and receiver coils are $628 \mathrm{~V}$ and $214 \mathrm{~V}$, respectively

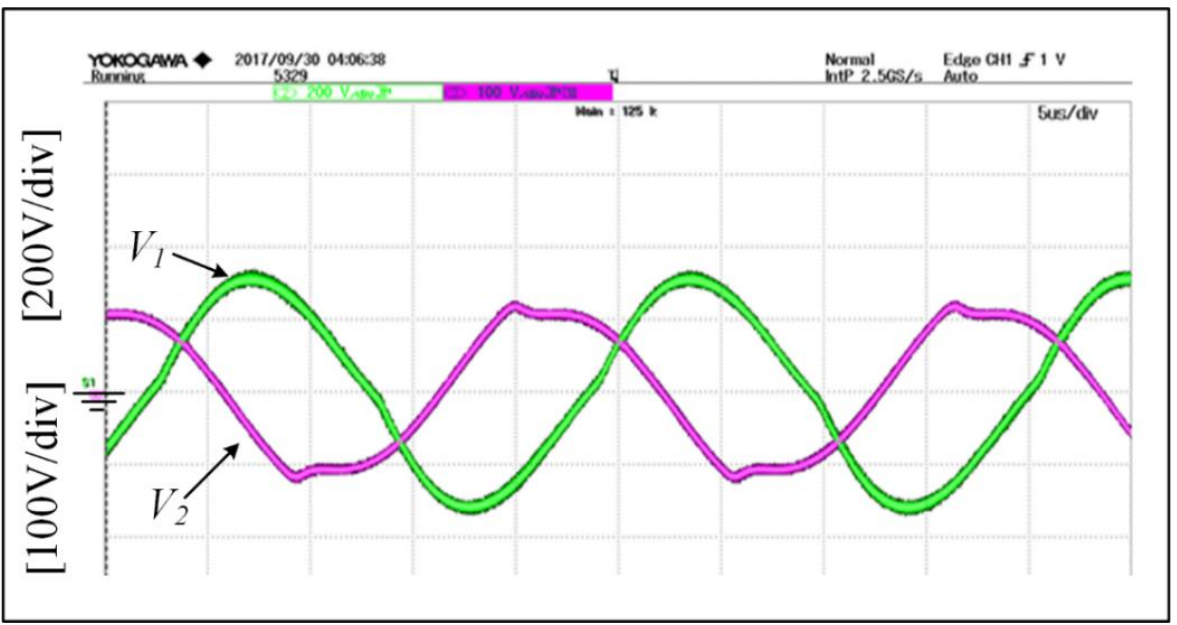

Figure 4.15. Experimental results: voltages across the transmitter coil and receiver coil 
Figure 4.16 represents the experimental waveforms of voltage and current at the input of the active single phase rectifier where $V_{r}$ is leading $I_{2}$ and the equivalent impedance at the input of the ASPR is inductive.

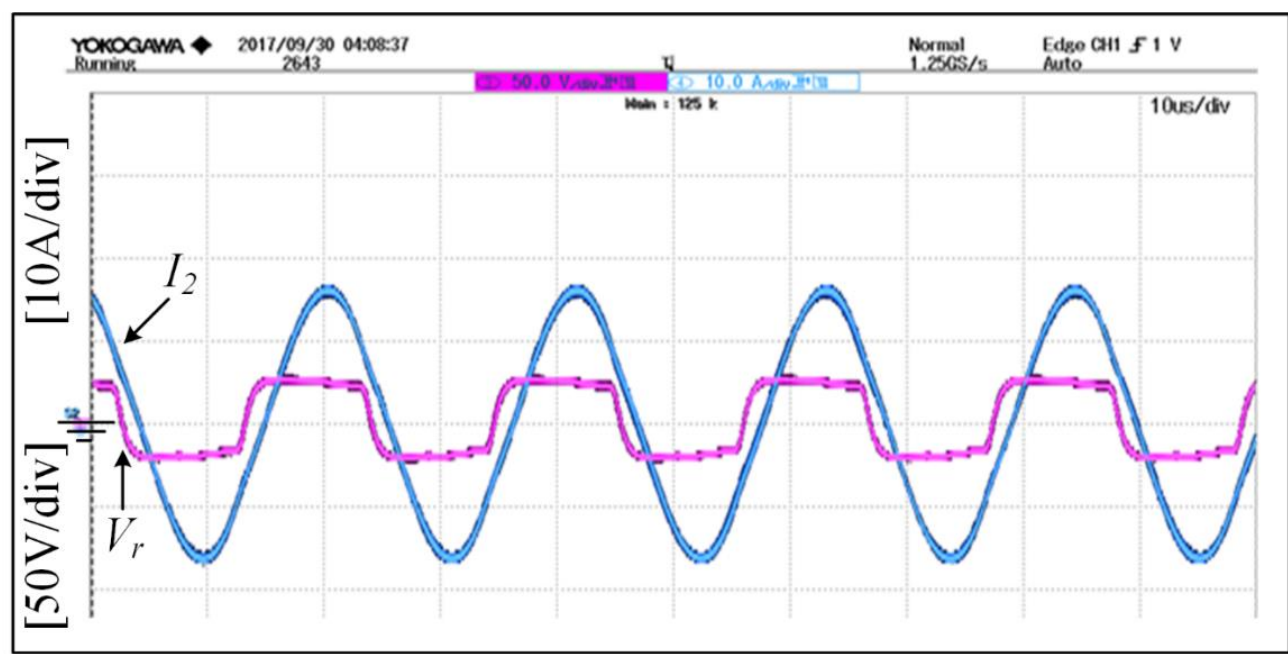

Figure 4.16. Experimental results: rectifier input current and voltage

Figure 4.17 shows the experimental results of gating signals for the active single phase rectifier switches. A small dead time, approximately $1.5 \mu \mathrm{s}$, is applied to the gating signals of MOSFETs to protect the rectifier from short circuiting the converter. The switches of the first leg of active rectifier $\left(\mathrm{S}_{3}, \mathrm{~S}_{4}\right)$ are operating with 0.5 duty cycle and complementary with respect to the switches of the second leg $\left(\mathrm{S}_{5}, \mathrm{~S}_{6}\right)$. The gating signals of MOSFETs are applied through a digital controller and a gate driver by sensing the zero crossing of the current at the input of the active single phase rectifier.

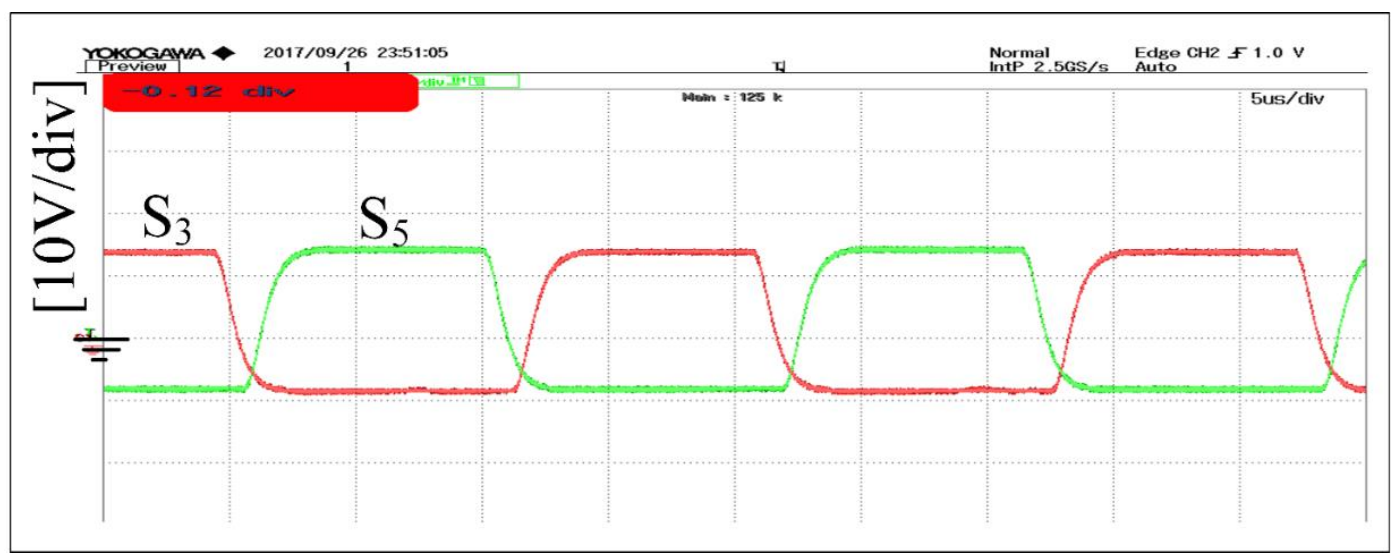

Figure 4.17. Experimental results: gating signals for active rectifier switches $S_{3}$ and $S_{5}$ 
Figure 4.18 shows the DC current and the voltage at the output side of active single phase rectifier where a resistive load of $2.33 \Omega$ and a filter capacitor of $100 \mu \mathrm{F}$ have been connected in parallel with the rectifier output. The voltage and current are $24 \mathrm{~V}$ and $9 \mathrm{~A}$, respectively.

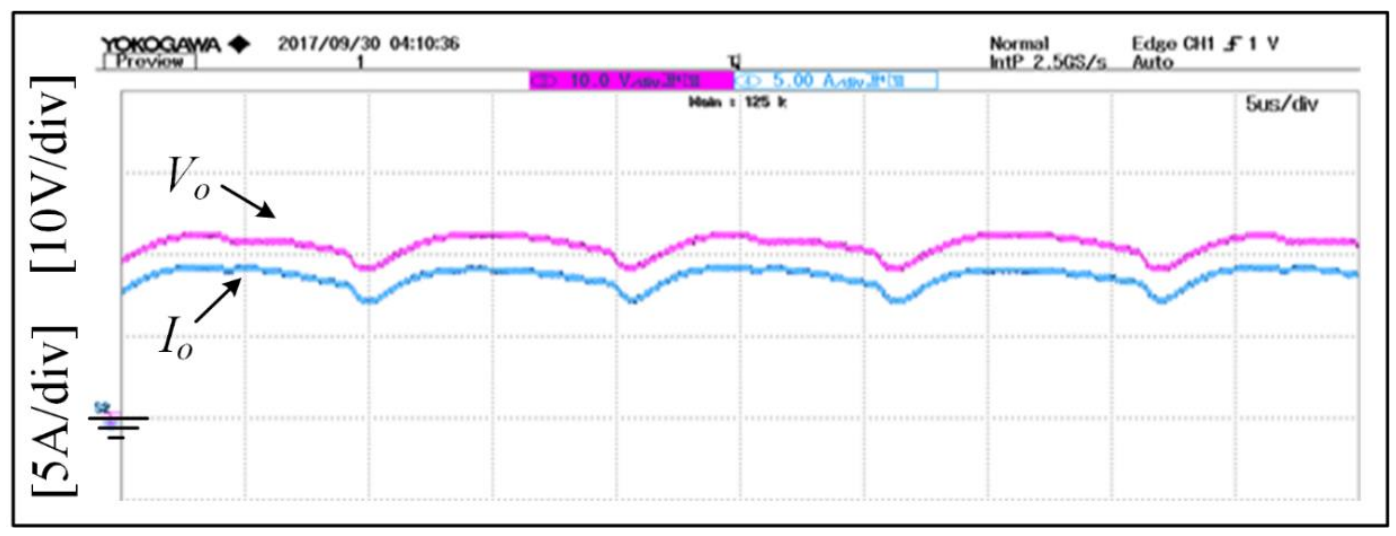

Figure 4.18. Experimental results of steady state waveforms of load current and voltage

\subsection{Efficiency Analysis and Comparison with Diode Rectifier}

An important parameters of a WPT system performance is the overall efficiency, especially for medium and high power level applications as a wireless charger for EVs. In order to increase the efficiency some optimizations under some circumstances could be done such as, compensation parameter optimization, optimizable circuit structure and operating frequency selection. Moreover, based on the type of electrical vehicle considered to be the main application of WPT system, the equivalent resistance of the load could be varied from 2 to 560, depending on the charging profile. The various equivalent load for WPT systems affect the overall efficiency dramatically. Furthermore, another important parameter influencing the efficiency is the tolerance of components [49].

In WPT applications, the distance between wireless pads and load changes frequently. A dynamic WPT is an effective solution to solve short millage and long charging time of EVs. Moreover, multiple charging keeps the battery in a high state of charge, operates more efficiently, and extends battery's life. Power control (fast charging, slow charging or no charging) and efficiency maximization are preferred to be done by an ASPR at secondary side for ground facilities of dynamic charging. According to the main application which is lowvoltage light-load EVs battery charging, MOSFETs have noticeable less conduction losses than diodes, which is another motivation to use ASPR to improve efficiency. 


\subsubsection{Conduction Losses of A Power MOSFET}

Conduction losses of power MOSFETs can be calculated by using a MOSFETapproximation with the drain-source on-state resistance $\mathrm{R}_{\mathrm{DS}(\mathrm{on})}$, as:

$$
U_{D S}\left(i_{D}\right)=R_{D S(\text { on })}\left(i_{D}\right) \cdot i_{D}
$$

Where $U_{D S}$, is the drain-source voltage and $i_{D}$, represents the drain current. The value of $\mathrm{R}_{\mathrm{DS}(\mathrm{on})}$, for a particular MOSFET can be fined in the data-sheet diagrams.

The value of the MOSFET conduction losses at a specific moment can be calculated by:

$$
p_{\text {con }}(t)=U_{D S}(t) \cdot i_{D}(t)=R_{D S(o n)} \cdot i_{D}^{2}(t)
$$

By integration the power loss over one switching cycle of the MOSFETs the average value of the MOSFET conduction losses is derived by:

$$
P_{\text {con }}=\frac{1}{T_{s}} \int_{0}^{T_{s}} p_{\text {con }}(t) d t=\frac{1}{T_{s}} \int_{0}^{T_{S}} R_{D S(o n)} \cdot i_{D}^{2}(t) d t=R_{D S(o n)} \cdot I_{D, r m s}^{2}
$$

Where $I_{D, r m s}$ is the rms value of the MOSFET on-state current [49].

\subsubsection{Switching Losses of a Power MOSFET}

Figure 4.19 shows the ideal switching process of a power MOSFET where, $\mathrm{u}_{\mathrm{GS}}$ and $\mathrm{i}_{\mathrm{G}}$, are the gate voltage and current, respectively. The drain-source voltage is shown as $u_{D S}$, and $i_{D}$ represents the current going through the drain without considering the reverse recovery of the free-wheeling diode. Finally, the area marked with the oval presents the reverse recovery effects on the switching losses and, the power losses in both turning on and off cycle of the MOSFET is shown as $\mathrm{P}_{\text {on }}$ and $\mathrm{P}_{\text {off }}$, respectively. 


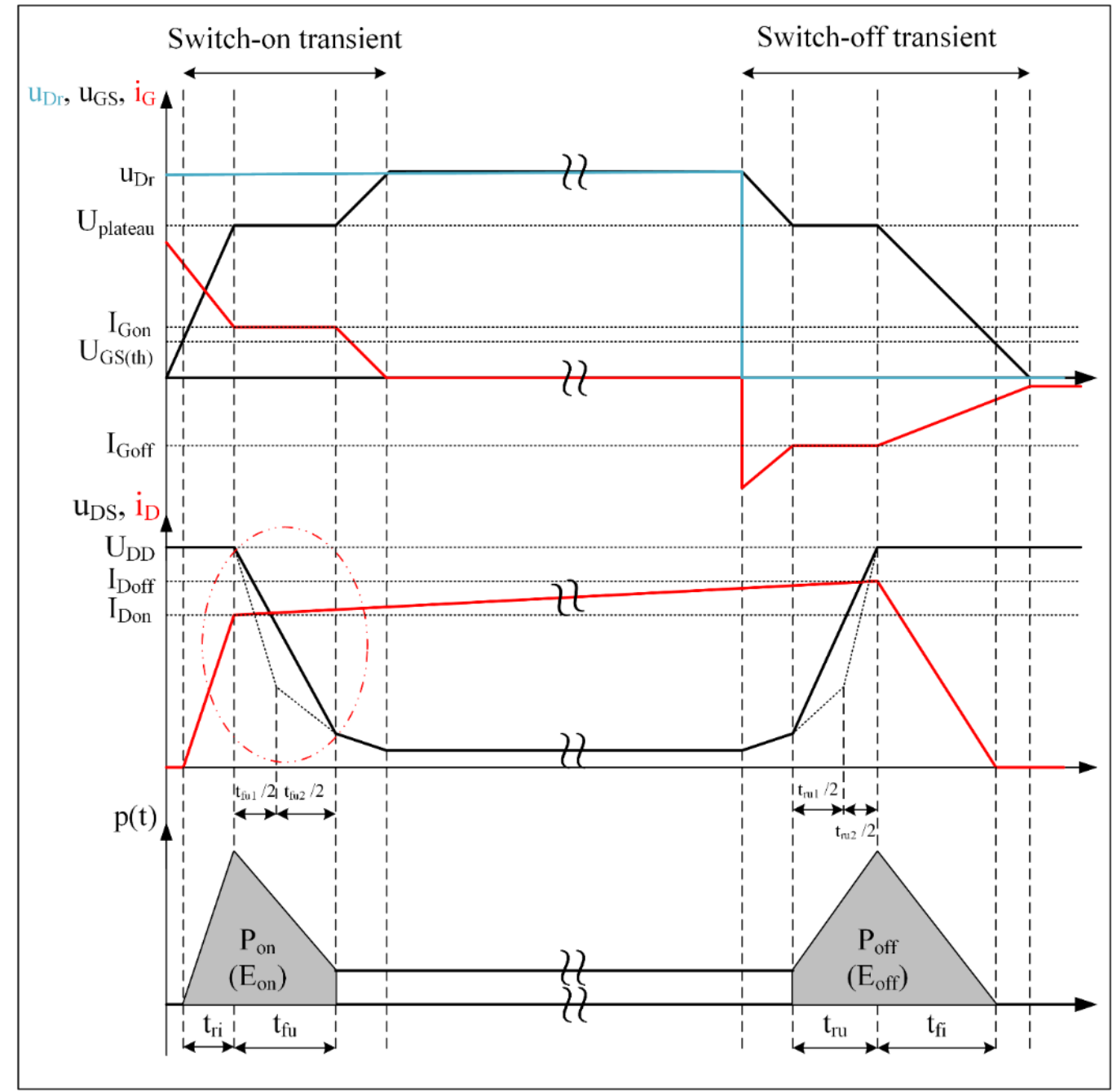

Figure 4.19. Switch-on and switch-off transients of a power MOSFET

\section{Switch-on transient}

As the gate voltage increases from zero to the threshold voltage, $\mathrm{U}_{\mathrm{GS}(\mathrm{th})}$, the MOSFET does not conduct. As the gate voltage reaches to $\mathrm{U}_{\mathrm{GS}(\mathrm{th})}$, the drain current increases and take over the load current. The drain current, $\mathrm{i}_{\mathrm{D}}$, rises from 0 to $\mathrm{I}_{\mathrm{Don}}$ during the current rise time, $\mathrm{t}_{\mathrm{ri}}$, which can be read from data-sheet. Additionally, the free-wheeling diode keeps conducting and the drain-source voltage, $\mathrm{u}_{\mathrm{Ds}}$, remains at $\mathrm{U}_{\mathrm{DD}}$.

As the minority carriers stored in the diode are removed, the diode is switched off. Furthermore, since the reverse-recovery current has to be absorbed by the circuit, some additional power losses are introduced. In order to calculate this power loss, information such as reverserecovery charge and its duration are informed in the MOSFET data sheet as $\mathrm{Q}_{\mathrm{rr}}$ and $\mathrm{t}_{\mathrm{rr}}$, respectively. 
After the diode has been switched off, the drain-source voltage, $u_{D S}$, is reduced to its on-state value:

$$
u_{D S}=R_{D S_{o n}} \cdot I_{o n}
$$

At this point, the gate-source voltage, $\mathrm{u}_{\mathrm{GS}}$, is fixed at $\mathrm{U}_{\text {plateau }}$ which is caused by the Miller effect. The non-linearity of the gate-drain capacitance, $\mathrm{C}_{\mathrm{GD}}$, affects the voltage fall-time, $\mathrm{t}_{\mathrm{fu}}$, with a reasonable accuracy. Hence, In order to calculate the voltage fall-time, $t_{f u}$, the effect of $\mathrm{C}_{\mathrm{GD}}$, should be considered. Furthermore, the value of $\mathrm{C}_{\mathrm{GD}}$ can be read as function of $\mathrm{V}_{\mathrm{DS}}$ through the datasheet of the MOSFET. The gate-drain capacitance effect is shown in Figure 4.19 with an oval where, a two-point approximation is used. If the drain-source voltage, uDS, is in the range of $\left[\frac{U_{D D}}{2}, U_{D D}\right]$, then the gate-drain capacitance is assumed to be:

$$
C_{G D 1}=C_{G D}\left(U_{D D}\right)
$$

And if $\mathrm{u}_{\mathrm{DS}}$ is in the range of $\left[0, \frac{U_{D D}}{2}\right]$, then the gate-drain capacitance takes the value of:

$$
C_{G D 2}=C_{G D}\left(R_{D S_{o n}} \cdot I_{o n}\right)
$$

Figure 4.20 shows typical capacitances of a power MOSFET from the datasheet.

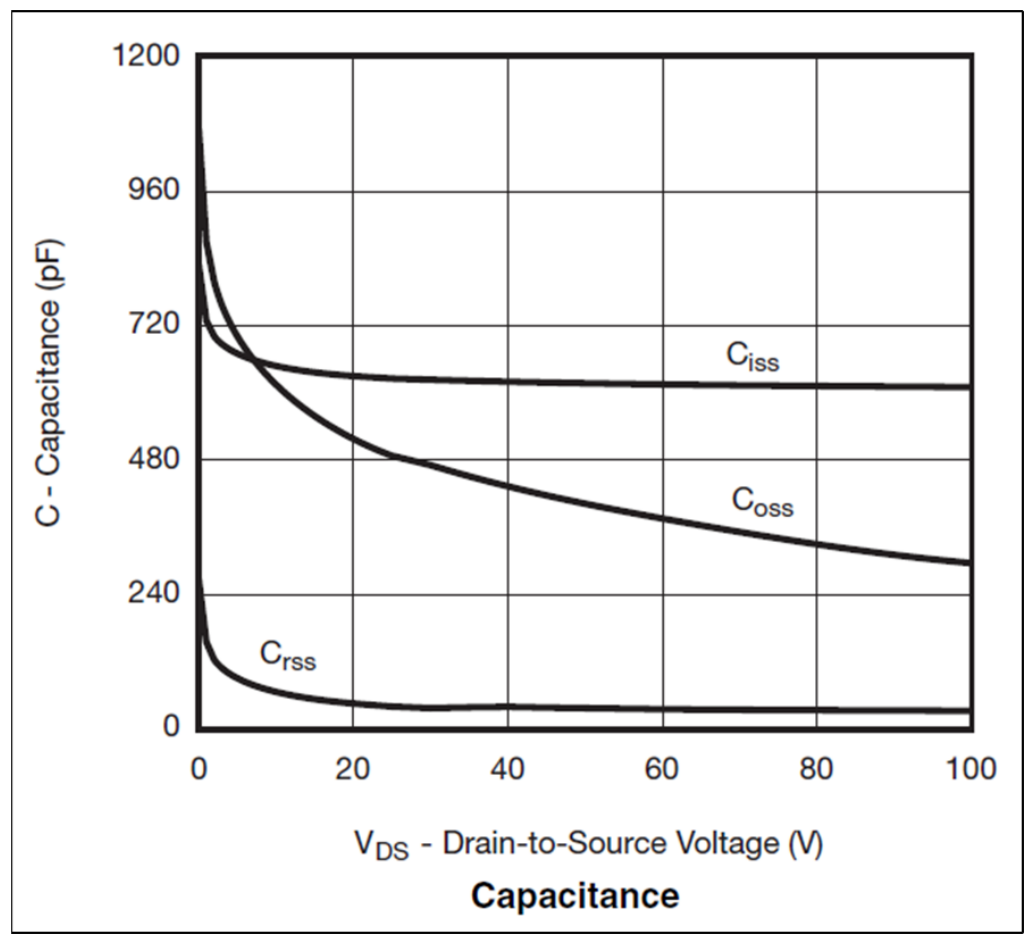

Figure 4.20. Typical capacitances of a power MOSFET

The gate current during $\mathrm{t}_{\mathrm{fu}}$, can be calculated as:

$$
I_{\text {Gon }}=\frac{U_{D r}-U_{\text {plateau }}}{R_{G}}
$$


Where $\mathrm{R}_{\mathrm{G}}$ is the gate resistance. Moreover, the voltage fall-time can be derived by using the gate current given in equation (4.16) and the capacitances $\mathrm{C}_{\mathrm{GD} 1}$ and $\mathrm{C}_{\mathrm{GD} 2}$, mentioned in equations (4.14) and (4.15) as:

$$
t_{f u}=\frac{t_{f u 1}+t_{f u 2}}{2}
$$

Where

$$
\begin{aligned}
& t_{f u 1}=\left(U_{D D}-R_{D S_{o n}} \cdot I_{D_{o n}}\right) \cdot \frac{C_{G D 1}}{I_{G o n}}=\left(U_{D D}-R_{D S_{o n}} \cdot I_{D_{o n}}\right) \cdot R_{G} \cdot \frac{C_{G D 1}}{U_{D r}-U_{\text {plateau }}} \\
& t_{f u 2}=\left(U_{D D}-R_{D S_{o n}} \cdot I_{D_{o n}}\right) \cdot \frac{C_{G D 2}}{I_{G o n}}=\left(U_{D D}-R_{D S_{o n}} \cdot I_{D_{o n}}\right) \cdot R_{G} \cdot \frac{C_{G D 2}}{U_{D r}-U_{\text {plateau }}}
\end{aligned}
$$

\section{Switch-off transient}

The same process for switch-on transient, repeats for switch-off transient but in a reverse order although, there are two noticeable differences. The first difference is that there is no reverse recovery the switching-off transient of a MOSFET. Furthermore, the gate current, $I_{G o f f}$, and the voltage rise-time can be calculated by going through the same process, explained in previous section as:

$$
\begin{gathered}
I_{\text {Goff }}=-\frac{U_{(\text {plateau })}}{R_{G}} \\
t_{r u}=\frac{t_{r u 1}+t_{r u 2}}{2}
\end{gathered}
$$

Where

$$
\begin{aligned}
& t_{r u 1}=\left(U_{D D}-R_{D S_{o n}} \cdot I_{D_{o n}}\right) \cdot \frac{C_{G D 1}}{I_{G o f f}}=\left(U_{D D}-R_{D S_{o n}} \cdot I_{D_{o n}}\right) \cdot R_{G} \cdot \frac{C_{G D 1}}{U_{\text {plateau }}} \\
& t_{r u 2}=\left(U_{D D}-R_{D S_{o n}} \cdot I_{D_{o n}}\right) \cdot \frac{C_{G D 2}}{I_{G o f f}}=\left(U_{D D}-R_{D S_{o n}} \cdot I_{D_{o n}}\right) \cdot R_{G} \cdot \frac{C_{G D 2}}{U_{\text {plateau }}}
\end{aligned}
$$

\section{Switching power losses}

The maximum turn-on energy losses, $\mathrm{E}_{\mathrm{onM}}$, in power a MOSFET, can be calculated by the summation of switch-on energy without considering the reverse recovery process, $\mathrm{E}_{\text {onMi, }}$, and the switch-on energy caused by the reverse-recovery of the free-wheeling diode, $\mathrm{E}_{\text {onMrr: }}$ :

$$
\begin{gathered}
E_{\text {onM }}=\int_{0}^{t_{r i}+t_{f u}} U_{D S}(t) \cdot i_{D}(t) d t=E_{\text {onMi }}+E_{\text {onMrr }}=U_{D D} \cdot I_{D_{o n}} \cdot \frac{t_{r i}+t_{f u}}{2} \\
\quad+Q_{r r} \cdot U_{D D}
\end{gathered}
$$

Where $\mathrm{Q}_{\mathrm{rr}}$ is the body diode reverse recovery charge. The peak value of the reverse recovery current is derived by: 


$$
I_{F r_{p}}=\frac{2 Q_{r r}}{t_{r r}}
$$

Where $t_{\text {rr }}$ represents the body diode reverse recovery time. The reverse recovery energy, $E_{o n D}$, provides most of the turn-on energy in diode:

$$
E_{\text {onD }}=\int_{0}^{t_{r i}+t_{f u}} U_{D}(t) \cdot i_{F}(t) d t \approx E_{\text {onDrr }}=\frac{1}{4} \cdot Q_{r r} \cdot U_{D r r}
$$

Where $\mathrm{U}_{\text {Drr }}$ is the reverse recovery voltage across the diode. For the worst case scenario $U_{\text {Drr }}$ is approximately equal to $\mathrm{U}_{\mathrm{DD}}$. Assuming the switch-off losses in the diode is negligible, the switch-off energy losses in the MOSFET can be calculated as:

$$
E_{o f f M}=\int_{0}^{t_{r u}+t_{f i}} U_{D S}(t) \cdot i_{D}(t) d t=U_{D D} \cdot I_{D o f f} \cdot \frac{t_{r u}+t_{f i}}{2}
$$

Finally, the switch-off power losses of the MOSFET can be calculated by multiplying switching energy by the switching frequency:

$$
\begin{aligned}
& P_{s W M}=\left(E_{\text {onM }}+E_{\text {off }}\right) \cdot f_{S} \\
& P_{S W D}=\left(E_{\text {onD }}+E_{\text {offD }}\right) \cdot f_{S} \approx E_{\text {onD }} \cdot f_{S}
\end{aligned}
$$

Where $\mathrm{P}_{\mathrm{swM}}$ and $\mathrm{P}_{\mathrm{swD}}$ are the power losses in MOSFET and diode, respectively [49].

\subsubsection{Diode Losses}

Figure 4.21 presents the diode characteristic curve where the forward current, $\mathrm{I}_{\mathrm{f}}$, and voltage, $\mathrm{V}_{\mathrm{f}}$, are modeled by a straight line introduced by the threshold voltage point, $\mathrm{V}_{\mathrm{Th}}$, and the dynamic resistance, $\mathrm{R}_{\mathrm{D}}$.

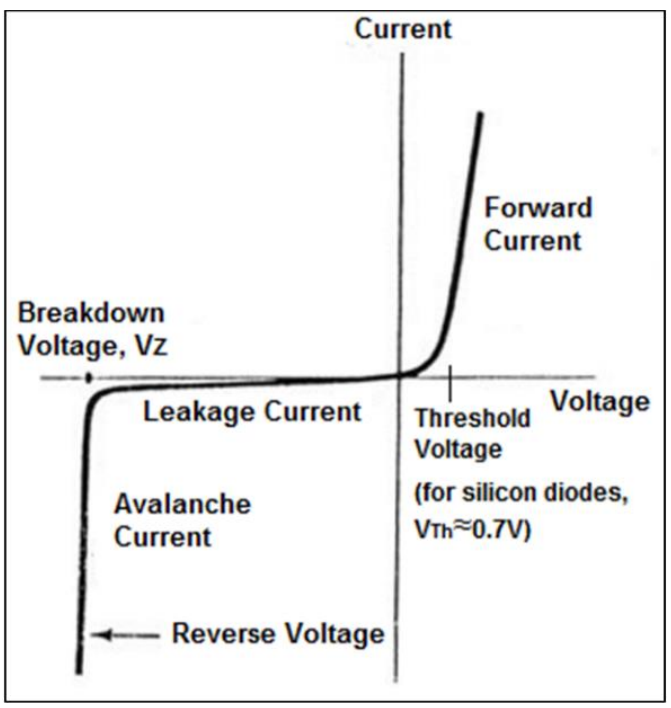

Figure 4.21. Diode characteristic curve 
The forward voltage of a diode, $\mathrm{V}_{\mathrm{f}}$, is derived by:

$$
V_{f}(t)=V_{T h}+R_{D} \cdot I_{f}(t)
$$

Hence the power losses of a diode can be expressed by:

$$
\begin{aligned}
P_{\text {cond }}=\frac{1}{T} \int_{0}^{T} V_{f}(t) . I_{f}(t) d t & \\
& =V_{T h} \cdot \frac{1}{T} \int_{0}^{T} I_{f}(t) d t+R_{D} \cdot \frac{1}{T} \int_{0}^{T} I_{f}^{2}(t) d t=V_{T h} \cdot I_{f(a v)}+R_{D} \cdot I_{f(r m s)}^{2}
\end{aligned}
$$

Where $\mathrm{I}_{\mathrm{f}(\mathrm{av})}$ is the average value of forward current and $\mathrm{I}_{\mathrm{f}(\mathrm{rms})}$ is the rms value of the forward current flowing through the diode [49].

\subsubsection{Comparison of Diode and MOSFET Conduction Losses}

Equations (4.32) and (4.33) show MOSFETs and Diodes conduction losses respectively.

$$
\begin{aligned}
& P_{\text {con }}=R_{D S(o n)} \cdot I_{Q S w(R M S)}^{2} \\
& P_{\text {con }}=V_{t o} I_{f(a v)}+r_{d} I_{f(R M S)}^{2}
\end{aligned}
$$

where, $R_{D s(o n)}$ is the drain-source on-state resistance, $I_{Q s w(R M S)}$ is the drain current and $I_{f}$ is the forward current of diode. According to above equations conduction losses are proportional to the square of passing current. Hence with increase in current, the conduction losses increase rapidly. On the other hand MOSFETs have less forward resistance than diodes, in general, which leads to the significantly higher efficiency for ASPR compared to passive rectifiers. By using a Single phase active rectifier instead of a passive rectifier the efficiency of converter is improved to $4.5 \%$. Table 4.1 compares conduction losses between a single MOSFET and a single diode at the same rated voltage and current.

Table 4.1. Comparison of Diode and MOSFET conducting losses

\begin{tabular}{|c|c|c|}
\hline Component & Diode & MOSFET \\
\hline Part Number & VB30100S-E3 & SiS892DN \\
\hline Manufacturer & Vishay Semiconductor & Vishay Siliconix \\
\hline Rating & $100 \mathrm{~V}, 30 \mathrm{~A}, \mathrm{Vf}=0.69 @ 30 \mathrm{~A}$ & $100 \mathrm{~V}, 30 \mathrm{~A}, \mathrm{Rdson}=0.029 \Omega$ \\
\hline $\begin{array}{c}\text { Conduction } \\
\text { losses }\end{array}$ & $46 \mathrm{~W}$ & $17 \mathrm{~W}$ \\
\hline
\end{tabular}

The diode and MOSFET selected in Table 4.1 are the same components used for the experimental. It is clear that by using the selected MOSFET over the diode with same rating, 
the losses is reduced by $29 \mathrm{~W}$. As explained in section 4.2 during each cycle, one leg of inverter conducts which contains two power MOSFETS. Hence for each cycle the power losses in the rectification process is reduced to $58 \mathrm{~W}$, approximately. Furthermore, as mentioned in 4.3 , the power rating of the proposed converter is $1.25 \mathrm{~kW}$ therefore, reducing the power losses by $58 \mathrm{~W}$ leads to $4.5 \%$ improvement in overall efficiency of the wireless power transfer system.

\subsubsection{Overall Efficiency Analysis}

The overall efficiency of an inductive power transfer system is affected by many parameters. The losses considered in the following analysis are selected based on the components specifications-according to their datasheets, which are listed in Table 4.2.

Table 4. 2 Table of the Converter Losses

\begin{tabular}{|c|c|c|}
\hline Components & Losses Type & Specifications \\
\hline Inverter Inductors, $\mathrm{L}_{\mathrm{d} 1}$ and $\mathrm{L}_{\mathrm{d} 2}$ & Resistive losses & $\mathrm{R}_{\mathrm{Ld} 1}=0.16 \Omega$ \\
\hline \multirow{2}{*}{ Inverter MOSFETs, $\mathrm{S}_{1}$ and $\mathrm{S}_{2}$} & Conduction Losses & $@ \mathrm{~V}_{\mathrm{GS}}=18 \mathrm{~V}, \mathrm{I}_{\mathrm{D}}=5 \mathrm{~A}, \mathrm{~T}_{\mathrm{j}}=25^{\circ} \mathrm{C}, \mathrm{R}_{\mathrm{DS}}(\mathrm{on})=0.16 \Omega$ \\
\cline { 2 - 3 } & Switching Losses & $\begin{array}{c}\mathrm{V}_{\mathrm{DD}}=600 \mathrm{~V}, \mathrm{I}_{\mathrm{D}}=5 \mathrm{~A}, \mathrm{~V}_{\mathrm{Gs}}=18 \mathrm{~V} / 0 \mathrm{~V}, \mathrm{R}_{\mathrm{G}}=0 \Omega, \\
\mathrm{L}=750 \mu \mathrm{H}, \mathrm{E}_{\mathrm{on}}=62 \mu \mathrm{j}, \mathrm{E}_{\mathrm{off}}=12 \mu \mathrm{j}\end{array}$ \\
\hline Inverter Diodes, $\mathrm{D}_{1}$ and $\mathrm{D}_{2}$ & Conduction Losses & $@ \mathrm{I}_{\mathrm{F}(\mathrm{AV})}=20 \mathrm{~A}, \mathrm{~V}_{\mathrm{RRM}}=1200 \mathrm{~V}, \mathrm{~V}_{\mathrm{F}}=1.35 \mathrm{~V}$ \\
\hline IPT coils, $\mathrm{L}_{1}$ and $\mathrm{L}_{2}$ & Resistive Losses & $\mathrm{R}_{\mathrm{L} 1}=0.072 \Omega, \mathrm{R}_{\mathrm{L} 2}=0.024 \Omega$ \\
\hline Rectifier MOSFETs & Conduction Losses & $100 \mathrm{~V}, 30 \mathrm{~A}, \mathrm{Rdson}=0.029 \Omega$ \\
\hline Rectifier Diodes & Conduction Losses & $100 \mathrm{~V}, 30 \mathrm{~A}, \mathrm{Vf}=0.69 @ 30 \mathrm{~A}$ \\
\hline
\end{tabular}

Starting from the input side of the converter the first power losses can be observed are the resistive power losses through the DC link inductors, $\mathrm{L}_{\mathrm{d} 1}$ and $\mathrm{L}_{\mathrm{d} 2}$ which are calculated as:

$$
P_{L d 1}=R_{L d 1} \cdot I_{L d 1}^{2}=1.85 \mathrm{~W}
$$

Where $R_{L d l}$ represents the resistance of the inductor according to its datasheet and $I_{L d l}$ is the current going through the inductor. As the next step, the conduction losses of the inverter MOSFETs and diodes are taken into account. By using the values for drain to source resistance regarding its datasheet the conduction losses of inverter MOSFETs are derived by:

$$
P_{\text {con-inv }}=R_{D S(\text { on })} \cdot I_{D, r m s}^{2}=3.69 \mathrm{~W}
$$

Based on the inverter diodes datasheet the conduction losses of inverter diodes can be calculated using equation (4.36):

$$
P_{\text {con }} \text { diode }=1.07 . I_{F(a v)}+0.059 . I_{F(r m s)}^{2}=4.96 \mathrm{~W}
$$


Power losses in parallel capacitor $\mathrm{C}_{\mathrm{P}}$, series capacitor $\mathrm{C}_{\mathrm{s}}$, and receiver capacitor are neglected. The resistive power losses in transmitter and receiver coils are calculated as $15 \mathrm{~W}$ and $20 \mathrm{~W}$ with respect to Litz wires datasheet and Table (4.2).

On the secondary side the main power losses are caused by rectifier MOSFETs or diodes which are calculated in Table 4.1. Since during each cycle two MOSFETs or two diodes are conducting, the conduction power losses of the active rectifier and the passive rectifier are calculated as $34 \mathrm{~W}$ and $92 \mathrm{~W}$ respectively. Hence, the total power loss of the wireless power transfer system using an active single phase rectifier can be calculated as $79.5 \mathrm{~W}$ while, the similar converter using passive rectification show $137.5 \mathrm{~W}$ power loss. As a result, the overall efficiency of the converter using active rectifier and the converter with passive rectification are $93.3 \%$ and $88.5 \%$ respectively.

Table 4.3 compares the WPT topology using a passive rectifier with the similar converter using an active single phase rectifier from efficiency standpoint.

Table 4.3. Efficiency comparison of converters

\begin{tabular}{|c|c|c|c|c|}
\hline $\begin{array}{l}\text { Converter } \\
\text { Topology }\end{array}$ & Parts & $\begin{array}{c}\text { Power losses } \\
\text { (W) }\end{array}$ & $\begin{array}{c}\text { Total power losses } \\
\text { (W) }\end{array}$ & $\begin{array}{c}\text { Efficiency } \\
(\%)\end{array}$ \\
\hline \multirow{5}{*}{$\begin{array}{l}\text { WPT with passive } \\
\text { rectification }\end{array}$} & Inverter inductors & 1.85 & \multirow{5}{*}{137.5} & \multirow{5}{*}{88.5} \\
\hline & Inverter MOSFETs & 3.69 & & \\
\hline & Inverter diodes & 4.96 & & \\
\hline & IPT coils & 35 & & \\
\hline & Rectifier diodes & 92 & & \\
\hline \multirow{5}{*}{ WPT with an ASPR } & Inverter inductors & 1.85 & \multirow{5}{*}{79.5} & \multirow{5}{*}{93.3} \\
\hline & Inverter MOSFETs & 3.69 & & \\
\hline & Inverter diodes & 4.96 & & \\
\hline & IPT coils & 35 & & \\
\hline & Rectifier MOSFETs & 34 & & \\
\hline
\end{tabular}

\subsubsection{Other Common Power Losses of an IPT System}

The overall efficiency of an inductive power transfer system is affected by some other losses such as, losses across the resonant capacitors, and etc. An ideal model of capacitor stores and releases electrical energy without dissipating any. But in reality all capacitors more or less have some imperfections such as the equivalent series resistance, $\mathrm{R}_{\mathrm{ESR}}$, which adds a real part to the impedance: 
$Z_{C}=\frac{1}{j \omega C}+R_{E S R}$

The losses in a wireless power transfer coils are provided by the losses due to the resistance of winding wires for both primary and secondary coils and the core losses of the ferrite plates used for coupling of wireless pads. Losses in the ferrite materials can be easily estimated by using their datasheets. Also, the simulation of the flux density distribution can be done by "Maxwell" software.

\subsection{Concluding remarks}

In this chapter, a new inductive power transfer topology using half bridge current-fed inverter and active single phase rectifier is proposed for low-voltage light-load electrical vehicles battery charging applications. MOSFETs have noticeable less conduction losses than diodes in low voltage high current applications. The conduction losses of MOSFETs and diodes are briefly discussed and compared to each other in section 4.5 .

Implementing synchronous rectification technique, the proposed system shows more than

$4 \%$ efficiency improvement compare with existing converters. Generally, wireless power system have little lower efficiency than wired systems. This work will compensate this demerit of wireless system significantly. Steady operation and performance of the converter is verified using simulation results performed in Matlab Simulink. Furthermore, a scale down labprototype was built to confirm the simulation results and mathematical analysis. 


\section{Chapter 5}

\section{CONCLUSION and FUTURE WORK}

\subsection{Contribution and Conclusion}

A new inductive power transfer topology using half bridge current-fed inverter and active single phase rectifier is proposed for low-voltage light-load electrical vehicles battery recharging applications. The key motivation of using a full-bridge active rectifier is that MOSFETs have considerably less conduction losses than diodes in low voltage battery vehicles. The proposed converter has been analyzed in detail and simulated.

A scale down lab prototype was built to verify the simulation results and validate the mathematical analysis of the proposed converter using an active single phase rectifier and compare the results with the same converter, using a diode rectifier. The experimental results and conduction losses in MOSFETs and diode are also discussed and compared. Implementing synchronous rectification technique, the proposed system shows more than $4 \%$ efficiency improvement compare with existing converters with diode rectifier. Generally, wireless power transfer systems have lower efficiency than wired systems.

The fundamental theories of WPT systems such as wireless pads design and compensation networks are presented in chapter 3. Further, the steady state analysis and AC circuit analysis of WPT converter with both diode and active rectification process are also presented in this thesis.

\subsection{Future Work}

Controlling the power flow and efficiency maximization of electrical vehicles are preferred to be done on the receiver side. Moreover, tracking the maximum efficiency of the WPT converter under varied load situations and detuning conditions by using the advantages of controlling the operation modes of the an active rectifier, can be investigated.

The modification to proposed topology of WPT converter for bidirectional modes of operation; grid to vehicle and vehicle to grid, and the effects of this modification on smart grids and nano-grids can be further investigated as a future work. 
The experimental set-up, used in this research work leveraged an open loop control system hence, a closed loop control should be designed and implemented to control the power flow from the receiver side (vehicle side) in order to get fast charging slow charging or no charging at all.

Finally, the proposed topology is suitable for dynamic charging applications and the power control can be done from the receiver side by the vehicle user. The grounding system can be further simplified and is under the control of commercial office. 


\section{BIBILIOGRAPHY}

[1] https://www.statista.com/statistics/281134/number-of-vehicles-in-use-worldwide/

[2] Il-Oun Lee, Jun-Young Lee, "A High-Power DC-DC Converter Topology for Battery Charging Applications", Energies, vol. 10, pp. 871, 2017, ISSN 1996-1073.

[3] S. Li and C. C. Mi, "Wireless Power Transfer for Electric Vehicle Applications," in IEEE Journal of Emerging and Selected Topics in Power Electronics, vol. 3, no. 1, pp. 4-17, March 2015.

[4] I. Subotic, N. Bodo, E. Levi and M. Jones, "Onboard Integrated Battery Charger for EVs Using an Asymmetrical Nine-Phase Machine," in IEEE Transactions on Industrial Electronics, vol. 62, no. 5, pp. 32853295, May 2015.

[5] Bi, Zicheng \& Song, Lingjun \& De Kleine, Robert \& Mi, Chunting Chris \& Keoleian, Gregory A., 2015. "Plug-in vs. wireless charging: Life cycle energy and greenhouse gas emissions for an electric bus system," Applied Energy, Elsevier, vol. 146(C), pages 11-19.

[6] M. Pinuela, D. C. Yates, S. Lucyszyn and P. D. Mitcheson, "Maximizing DC-to-Load Efficiency for Inductive Power Transfer," in IEEE Transactions on Power Electronics, vol. 28, no. 5, pp. 2437-2447, May 2013. [7] R. Mai, Y. Liu, Y. Li, P. Yue, G. Cao and Z. He, "An Active- Rectifier-Based Maximum Efficiency Tracking Method Using an Additional Measurement Coil for Wireless Power Transfer," in IEEE Transactions on Power Electronics, vol. 33, no. 1, pp. 716- 728, Jan. 2018.

[8] K. Colak, E. Asa, M. Bojarski, D. Czarkowski and O. C. Onar, "A Novel Phase-Shift Control of Semibridgeless Active Rectifier for Wireless Power Transfer," in IEEE Transactions on Power Electronics, vol. 30, no. 11, pp. 6288-6297, Nov. 2015.

[9] S. A. Teston, C. M. O. Stein, J. P. da Costa, E. G. Carati, R. Cardoso and G. W. Denardin, "Comparison of diode full-bridge rectifier and voltage-doubling diode rectifier in the output stage of active-clamping currentfed half-bridge isolated DC-DC converter," 2015 IEEE 24th International Symposium on Industrial Electronics (ISIE), Buzios, 2015, pp. 251-256.

[10] S. Samanta and A. K. Rathore, "A new inductive wireless power transfer topology using current-fed half bridge CLC transmitter LC receiver configuration," 2016 IEEE Energy Conversion Congress and Exposition (ECCE), Milwaukee, WI, 2016, pp. 1 - 8.

[11] M. Yilmaz and P. T. Krein, "Review of Battery Charger Topologies, Charging Power Levels, and Infrastructure for Plug- In Electric and Hybrid Vehicles," in IEEE Transactions on Power Electronics, vol. 28, no. 5, pp. 2151-2169, May 2013.

[12] Shuo Wang and D. Dorrell, "Review of wireless charging coupler for electric vehicles," IECON 2013 39th Annual Conference of the IEEE Industrial Electronics Society, Vienna, 2013, pp. 7274-7279.

[13] Y. H. Chao, J. J. Shieh, C. T. Pan, W. C. Shen and M. P. Chen, "A Primary-Side Control Strategy for Series-Parallel Loosely Coupled Inductive Power Transfer Systems," 2007 2nd IEEE Conference on Industrial Electronics and Applications, Harbin, 2007, pp. 2322-2327.

[14] Kurs, Andre, Aristeidis Karalis, Robert Moffatt, John D. Joannopoulos, Peter Fisher, and Marin Soljačić. "Wireless power transfer via strongly coupled magnetic resonances." science 317, no. 5834 (2007): 83-86. 
[15] T. Imura, H. Okabe, T. Uchida and Y. Hori, "Study on open and short end helical antennas with capacitor in series of wireless power transfer using magnetic resonant couplings," 2009 35th Annual Conference of IEEE Industrial Electronics, Porto, 2009, pp. 3848-3853.

[16] T. Mizuno, S. Yachi, A. Kamiya and D. Yamamoto, "Improvement in Efficiency of Wireless Power Transfer of Magnetic Resonant Coupling Using Magnetoplated Wire," in IEEE Transactions on Magnetics, vol. 47, no. 10, pp. 4445-4448, Oct. 2011.

[17] W. Li High efficiency wireless power transmission at low frequency using permanent magnetic coupling Master of Applied Science Thesis University of British Columbia Vancouver Canada 2007 p. 152.

[18] L. Whitehead Systems and methods for dipole enhanced inductive power transfer patent application PCT/CA2010/000252 2010.

[19] G. A. Covic J. T. Boys M. Budhia and C.-Y. Huang "Electric vehicles-Personal transportation for the future " Proc. World Battery Hybrid Fuel Cell Elect. Veh. Symp. Exhibi. Shenzhen China 2010

[20] N. P. Suh "Design of On-Line Electric Vehicle" CIRP Design Conference 2010.

[21] M. Budhia G. A. Covic and J. T. Boys "Design and Optimization of Circular Magnetic Structures for Lumped Inductive Power Transfer Systems " IEEE Transactions on Power Electronics Vol. 26 pp. 3096-3108 2011.

[22] G. A. Covic and J. T. Boys "Inductive Power Transfer " Proc. of the IEEE Early Access Articles 2013.

[23] 18. J. M. Miller C. P. White O. C. Onar and P. M. Ryan "Grid side regulation of wireless power charging of plug-in electric vehicles " IEEE Energy Conversion Congress and Exposition (ECCE) 2012 pp. 261-268. [24] M. Budhia G. Covic and J. Boys "A new IPT magnetic coupler for electric vehicle charging systems " 36th Annual IEEE Industrial Electronics Society conf. (IECON) 2010 pp. 2487-2492.

[25] M. Budhia G. A. Covic J. T. Boys and H. Chang-Yu "Development and evaluation of single sided flux couplers for contactless electric vehicle charging " IEEE Energy Conversion Congress and Exposition (ECCE) 2011 pp. 614-621.

[26] S. Jaegue S. Boyune L. Seokhwan S. Seungyong K. Yangsu J. Guho and J. Seongjeub "Contactless power transfer systems for On-Line Electric Vehicle (OLEV) " IEEE International Electric Vehicle Conference (IEVC) 2012 pp. 1-4.

[27] C. Liu, C. Jiang and C. Qiu, "Overview of coil designs for wireless charging of electric vehicle," 2017 IEEE PELS Workshop on Emerging Technologies: Wireless Power Transfer (WoW), Chongqing, 2017, pp. 1-6.

[28] Z. Zhang K.T. Chau Chunhua Liu C. Qiu T.W. Ching "A positioning-tolerant wireless charging system for roadway-powered electric vehicles" <em>Journal of Apply Physics</em> vol. 117 pp. 17-520 2015.

[29] Z. Zhang K. T. Chau "Homogeneous wireless power transfer for move-and-charge" <em>IEEE Transactions on Power Electronics</em> vol. 30 no. 11 pp. 6213-6220 Nov 2015. 
[30] A. Zaheer H. Hao G. A. Covic D. Kacprzak "Investigation of multiple decoupled coil primary pad topologies in lumped ipt systems for interoperable electric vehicle charging" <em>IEEE Transactions on Power Electronics.</em> vol. 30 no. 4 pp. 1937-1955 2015.

[31] J. T. Boys G. A. Covic "The inductive power transfer story at the university of auckland" <em>IEEE Circuits and Systems Magazine</em> vol. 15 no. 2 pp. 6-27 May 2015.

[32] M. Budhia J. T. Boys G. A. Covic C.-Y. Huang "Development of a single-sided flux magnetic coupler for electric vehicle ipt charging systems" <em>IEEE Transactions on Industrial Electronics</em> vol. 60 no. 1 pp. 318-328 Dec 2013.

[33] S. A. Teston, C. M. O. Stein, J. P. da Costa, E. G. Carati, R. Cardoso and G. W. Denardin, "Comparison of diode full-bridge rectifier and voltage-doubling diode rectifier in the output stage of active-clamping currentfed half-bridge isolated DC-DC converter," 2015 IEEE 24th International Symposium on Industrial Electronics (ISIE), Buzios, 2015, pp. 251-256.

[34] P. J. Wolfs "A current-sourced dc-dc converter derived via the duality principle from the half-bridge converter" <em>IEEE Transactions on Industrial Electronics</em> vol. 40 no. 1 pp. 139-144 February 1993.

[35] S. Samanta, A. K. Rathore and S. K. Sahoo, "Concept study and feasibility analysis of current-fed power electronics for wireless power transfer system," 2016 IEEE International Conference on Power Electronics, Drives and Energy Systems (PEDES), Trivandrum, 2016, pp. 1-6.

[36] Monteiro, Vítor Duarte Fernandes, J. G. Pinto, J. C. Fernandes, and João L. Afonso. "Experimental comparison of single-phase active rectifiers for EV battery chargers." In VEHITS International Conference on Vehicle Technology and Intelligent Transport Systems, Porto Portugal, Abr. 2017., pp. 419-425. 2017.

[37] E. Asa, K. Colak and D. Czarkowski, "Analysis of a CLL Resonant Converter With Semi-Bridgeless Active Rectifier and Hybrid Control," in IEEE Transactions on Industrial Electronics, vol. 62, no. 11, pp. 68776886, Nov. 2015.

[38] Z. Qin, Y. Shen, P. C. Loh, H. Wang and F. Blaabjerg, "A Dual Active Bridge Converter with an Extended High-Efficiency Range by DC Blocking Capacitor Voltage Control," in IEEE Transactions on Power Electronics, vol. PP, no. 99, pp. 1-1.

[39] S. Mansouri and E. Afjei, "Performance improvement on dual active bridge converter using CLLC resonant network with separated capacitor and inductor," 2017 Iranian Conference on Electrical Engineering (ICEE), Tehran, 2017, pp. 1032-1036.

[40] V. M. Iyer, S. Gulur and S. Bhattacharya, "Optimal design methodology for dual active bridge converter under wide voltage variation," 2017 IEEE Transportation Electrification Conference and Expo (ITEC), Chicago, IL, 2017, pp. 413-420.

[41] D. S. y. Rosas, D. Frey, J. L. Schanen and J. P. Ferrieux, "Close loop control to bidirectional isolated single stage DAB with resonant circuit DC/AC converter to connection of batteries to the single phase grid," 2017 IEEE Applied Power Electronics Conference and Exposition (APEC), Tampa, FL, 2017, pp. 1333-1340. 
[42] J. Michalík, J. Molnár and Z. Peroutka, "Active suppression of current harmonics on single-phase current-source active rectifier AC side: Proposed approches and their evaluation," IECON 2012 - 38th Annual Conference on IEEE Industrial Electronics Society, Montreal, QC, 2012, pp. 3768-3773

[43] F. Yazdani, S. Haghbin, M. Zolghadri and T. Thiringer, "Accurate analysis of a single-phase dual active bridge converter for ZVS and deadband conditions," 2017 IEEE International Conference on Environment and Electrical Engineering and 2017 IEEE Industrial and Commercial Power Systems Europe (EEEIC / I\&CPS Europe), Milan, 2017, pp. 1-6.

[44] Ying Cui, R. Hou, P. Malysz and A. Emadi, "Improved combined modulation strategy for dual active bridge converter in electrified vehicles," 2017 IEEE Transportation Electrification Conference and Expo (ITEC), Chicago, IL, 2017, pp. 101-107.

[45] M. Moghaddami and A. Sarwat, "Single-Phase Soft-Switched AC-AC Matrix Converter with Power Controller for Bidirectional Inductive Power Transfer Systems," in IEEE Transactions on Industry Applications.

[46] H. L. Li, A. P. Hu and G. A. Covic, "A Direct AC-AC Converter for Inductive Power-Transfer Systems," in IEEE Transactions on Power Electronics, vol. 27, no. 2, pp. 661-668, Feb. 2012.

[47] M. Moghaddami, A. Anzalchi and A. I. Sarwat, "Single-Stage Three-Phase AC-AC Matrix Converter for Inductive Power Transfer Systems," in IEEE Transactions on Industrial Electronics, vol. 63, no. 10, pp. 66136622, Oct. 2016.

[48] S. Y. R. Hui, W. Zhong and C. K. Lee, "A Critical Review of Recent Progress in Mid-Range Wireless Power Transfer," in IEEE Transactions on Power Electronics, vol. 29, no. 9, pp. 4500-4511, Sept. 2014.

[49] Sotiriou, Sotirios. "Analysis of Operation and System Losses of an Inductive Power Transfer System for Wireless Charging of Electric Vehicles." (2014).

[50] http://www.tesla-institute.com/!app/sim/fscic.php

[51] H. Jiang, P. Brazis, M. Tabaddor and J. Bablo, "Safety considerations of wireless charger for electric vehicles - A review paper," 2012 IEEE Symposium on Product Compliance Engineering Proceedings, Portland, OR, 2012, pp. 1-6.

[52] M. Moghaddami, A. Anzalchi, A. Moghadasi and A. Sarwat, "Pareto optimization of circular power pads for contactless electric vehicle battery charger," 2016 IEEE Industry Applications Society Annual Meeting, Portland, OR, 2016, pp. 1-6 